Audible Images: um sistema para síntese de imagens controladas por áudio

Mariana Zaparolli Martins

DISSERTAÇÃO APRESENTADA

$\mathrm{AO}$

INSTITUTO DE MATEMÁTICA E ESTATÍSTICA

DA

UNIVERSIDADE DE SÃO PAULO

PARA

OBTENÇÃO DO TÍTULO

$\mathrm{DE}$

MESTRE EM CIÊNCIAS

Área de Concentração: Ciência da Computação

Orientador: Marcelo Gomes de Queiroz

São Paulo, janeiro de 2008 


\title{
Audible Images: um sistema para síntese de imagens controladas por áudio
}

\author{
Este exemplar corresponde à redação \\ final da dissertação devidamente corrigida \\ e defendida por Mariana Zaparolli Martins \\ e aprovada pela Comissão Julgadora.
}

Banca Examinadora:

- Prof. Dr. Marcelo Gomes de Queiroz (orientador) - IME-USP

- Prof. Dr. Fábio Kon - IME-USP

- Prof. Dr. Fernando Iazzetta - ECA-USP 


\section{Agradecimentos}

Em primeiro lugar agradeço imensamente aos meus pais (Valdir e Lud) e aos meus irmãos (Ieda e João Luiz) pelo aprendizado que me proporcionaram e continuam proporcionando nesta vida, pela confiança que sempre depositaram em mim e pelo incondicional apoio dado em todos os momentos. Amo vocês.

Agradeço muito as demais pessoas da minha família (tia Iramaia e família, Dilza e família, tia Idinha e família, tio Joãozinho e família, Dirléa e família, Zeco e família, vó Dea, vô Luiz, vó Jandira e vô João) por todo auxílio dado em todos os momentos da minha vida, especialmente a este período em que passei a viver em São Paulo. Em especial agradeço a tia Iramaia, tio Renato, Vítor e Thiago por terem me recebido com tanto carinho no seu lar.

Deixo meus agradecimentos aos amigos paulistanos, que me incentivaram, apoiaram e preencheram este período de alegrias. Aos amigos que me receberam inicialmente com muita atenção, Cláudio Sá, Marina, Adriana, Caio, Luiz Gustavo, Flávio, Bia Rey e Daniela, meu muito obrigada e eterno carinho. Aos amigos Imeanos, companheiros de todas as horas, pessoas que preencheram de felicidade e conquistas esta nova etapa da minha vida, meu eterno agradecimento. Não posso deixar de citar alguns deles por tudo que fizeram e ainda fazem por mim: Dea, Paty, Drê, Vivian, Bia, Vânia, Monique, Somália, Aninha, Fabi, Carlos Batata, Naty, Daniel, Jun, Lois, Luciana, Suzi e por fim, com atenção especial, agradeço a Grazi, Marcinha, Luciene e Ise, amigas que compartilharam ou compartilham o dia a dia comigo e tornaram o ap51 o meu novo lar.

Agradeço também aos amigos que mesmo de longe acompanharam este período, apoiando, acreditando e enviando sempre muito carinho, estes compõem a mais tempo parte fundamental na minha vida. Alguns deles são: Patrícia, Raquel, Maurano, Luizinho, Daniel, Velloso, Clayton, De Bem, Rogério, Gonças, Alex, Ralfh, Nedilo, Vandi, Giovana, Lelê, Roberta, Mônica, Camila, Joseane, Vika, demais amigos da EC6, Sílvia Botelho, Natália, Ingrid, Cristina, Mônica, Guilherme e família.

Por fim deixo um grande agradecimento ao meu orientador, prof. Marcelo Queiroz, por toda paciência, compreensão, apoio, incentivo e ajuda que me deu. Aprendi muito com ele neste período e este trabalho é resultado de uma grande parceria.

A todos vocês eu dedico esta vitória, pois vocês foram fundamentais para que eu pudesse concluir mais esta etapa da minha vida. 


\section{Resumo}

Neste trabalho é apresentada a biblioteca AIM, uma biblioteca de objetos Pd que combina ferramentas de análise de áudio e síntese de imagens para a geração de acompanhamentos visuais para uma entrada musical. O usuário estabelece conexões que determinam como os parâmetros musicais afetam a síntese de objetos gráficos, e controla estas conexões em tempo-real durante a performance. A biblioteca combina um protocolo de comunicação para intercâmbio de parâmetros musicais e visuais com uma interface fácil de usar, tornando-a acessível a usuários sem experiência em programação de computadores. Suas áreas possíveis de aplicação incluem a musicalização infantil e a indústria de entretenimento.

Palavras-Chave: multimídia, visualização musical, instrumentos visuais, performance interativa. 


\begin{abstract}
This thesis describes the AIM library, a Pd object library which combines audio analysis and image synthesis tools for generating visual accompaniments to musical input data. The user establishes connections that determine how musical parameters affect the synthesis of graphical objects, and controls these connections in real-time during performance. The library combines a straightforward communication protocol for exchanging musical and visual parameters with an easy-to-use interface that makes it accessible for users with no computer programming experience. Its potential applications areas include children's musical education and the entertainment industry.
\end{abstract}

Keywords: multimedia, music visualization, visual instruments, interactive performance. 


\section{Sumário}

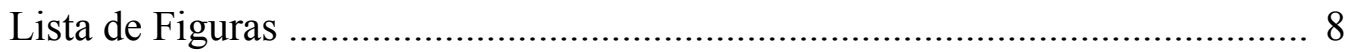

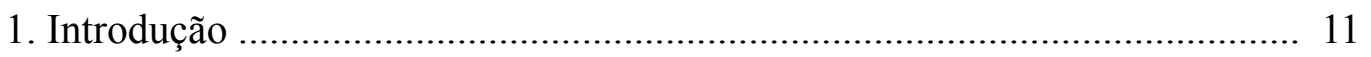

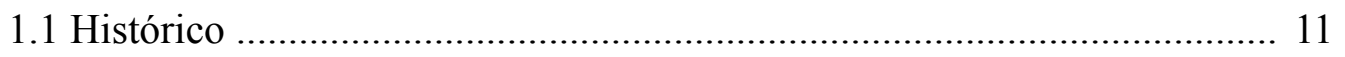

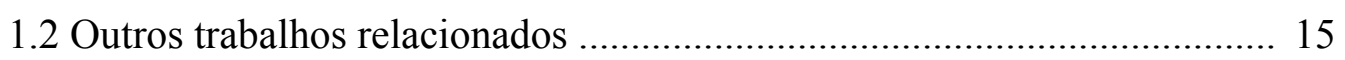

1.3 Motivação: Sistemas Interativos e Cypher ……………………………..... 21

1.4 Objetivos do Trabalho ........................................................................ 22

2. Sons e Imagens: Conceitos Fundamentais ……………………………….... 25

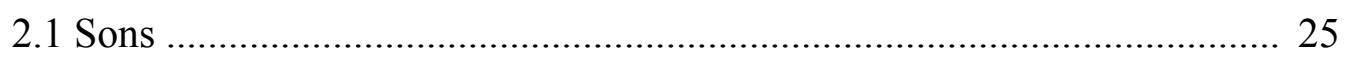

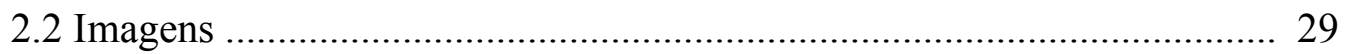

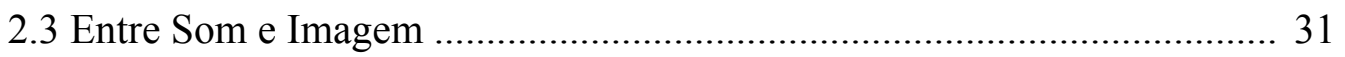

3. Implementação da Biblioteca AIM .............................................................. 33

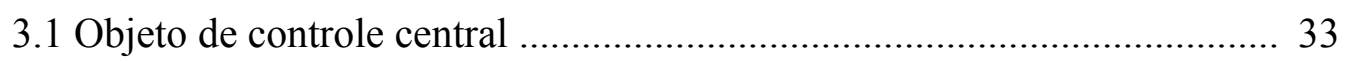

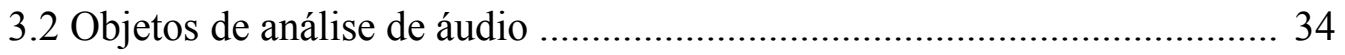

3.3 Objetos de síntese de imagens .............................................................. 39

3.4 Objetos de síntese e processamento de sinais de controle .......................... 45

3.5 Objetos para criação de interfaces ………………………………........ 49

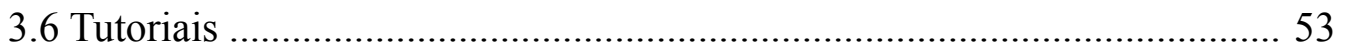

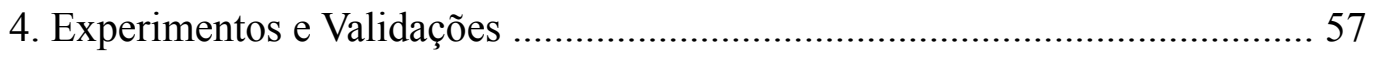

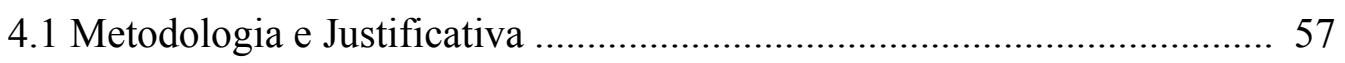

4.2 Aplicação dos Testes ........................................................................... 57

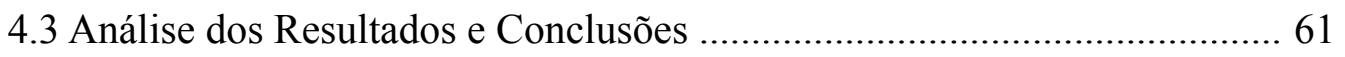

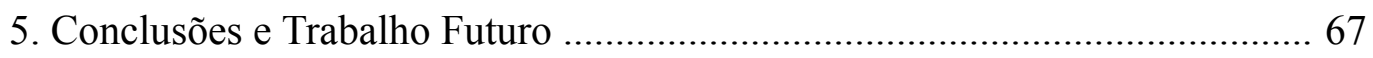

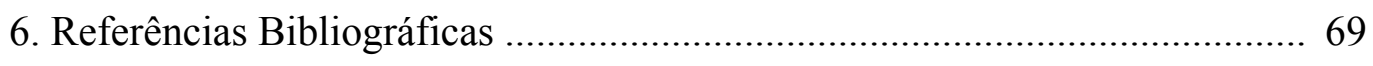

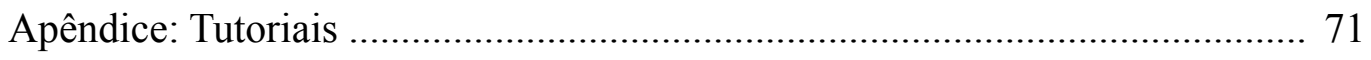




\section{Lista de Figuras}

Figura 1: Instrumento semelhante ao cravo ocular de Louis-Bertrand Castel ... 12

Figura 2: Pyrophone de Frederick Kastner ..................................................... 12

Figura 3: Colour-Organ de Alexander Rimington ......................................... 13

Figura 4: Relações entre cores e notas musicais estabelecidas por artistas e

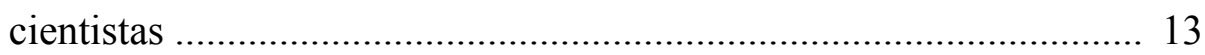

Figura 5: Cartaz do filme Chromophonie (1939) de Charles Blanc-Gatti ......... 14

Figura 6: Código de relação entre altura musical e cor criado por Roy De

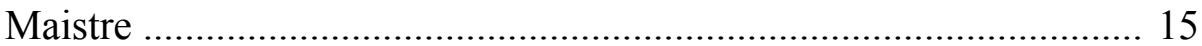

Figura 7: Rhythmic Composition in Yellow Green Minor (1919) de Roy De

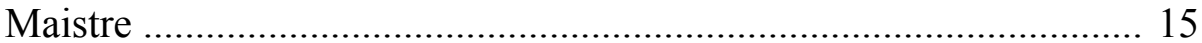

Figura 8: Exemplo de um patch do Isadora com sua respectiva saída ............... 16

Figura 9: Cena captada pelo sistema $M v M$ e respectiva saída ........................... 16

Figura 10: Projeto Conducting a Virtual Orchestra ......................................... 17

Figura 11: Programa construído na ferramenta EyesWeb e três momentos da

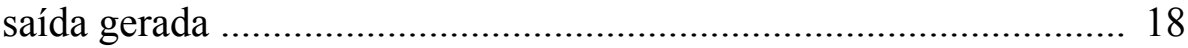

Figura 12: Outro programa construído na ferramenta EyesWeb........................ 18

Figura 13: Tela do PixelToy e um conjunto de saídas geradas pela ferramenta 19

Figura 14: Saídas das ferramentas SoundJam (esquerda) e AVS (direita) ......... 19

Figura 15: Imagens do cenário e do tenor virtual do projeto Aria .................... 20

Figura 16: Exemplos de saídas construídas no Bliss Paint ............................... 20

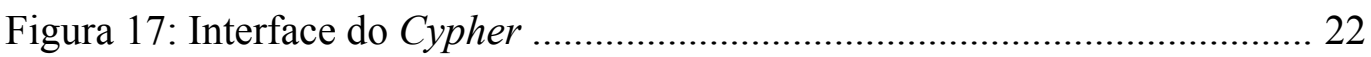

Figura 18: Exemplo de um sinal digital amostrado e quantizado ...................... 25

Figura 19: Medidas de amplitude de um sinal sonoro ...................................... 26

Figura 20: Envoltória gerada pelo sinal da palavra "frio" ................................ 26

Figura 21: (a) Exemplo de onda gerada por uma flauta (nota $\mathrm{Si}_{4}-247 \mathrm{~Hz}$ ) com seu respectivo espectro e (b) exemplo de onda gerada por um clarinete (nota $\mathrm{Bb}_{3}-233 \mathrm{~Hz}$ ) com seu respectivo espectro ........ 28

Figura 22: Diagrama da análise, processamento e síntese de imagens ............. 29

Figura 23: O objeto aim.control ................................................................... 33

Figura 24: Exemplo de um programa em Pd utilizando a biblioteca AIM ........ 35

Figura 25: Implementação do objeto aim.amplitude ......................................... 35

Figura 26: Patch do objeto aim.timedensity ................................................... 37

Figura 27: Primeira parte do patch do objeto aim.timedensity .......................... 38

Figura 28: Segunda parte do patch do objeto aim.timedensity .......................... 38

Figura 29: O objeto aim.register .................................................................... 39

Figura 30: Primeira parte do patch do objeto aim.square ................................ 39

Figura 31: Segunda parte do patch do objeto aim.square ............................... 40 
Figura 32: Patch do objeto aim.bezierseagull

Figura 33: Subpatches checkonoff e tripleRndColor do objeto aim.bezierseagull

Figura 34: Subpatch forme2 do objeto aim.bezierseagull 42

Figura 35: Subpatches tripleRnd e 1stseagull do objeto aim.bezierseagull ....... 43

Figura 36: Subpatch rightarm do objeto aim.doll ........................................... 44

Figura 37: Exemplos de saída dos objetos aim.planets e aim.runningdolls ....... 45

Figura 38: Exemplo de um patch com o objeto aim.bezierseagulls e a saída respectiva 45

Figura 39: Sinais gerados pelos objetos aim.sine, aim.cosine e aim.phasor ...... 46

Figura 40: Tipos de sinais aleatórios que podem ser gerados pelo objeto

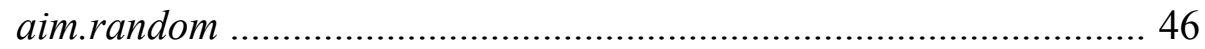

Figura 41: Implementação do objeto aim.rotation ........................................... 47

Figura 42: Patch do objeto aim.mirror ........................................................... 48

Figura 43: Chaveamento de conexões entre objetos AIM através do objeto

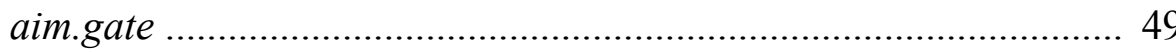

Figura 44: Interface oferecida pelo objeto aim.interface 4 ............................. 49

Figura 45: Exemplo de patch completo utilizando uma interface da biblioteca AIM …...................................................................... 50

Figura 46: Exemplo de patch com interface e os objetos das conexões

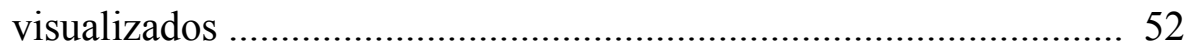

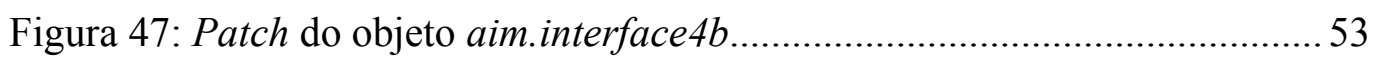

Figura 48: Patch do objeto aim.tutorial01 e uma saída gerada ......................... 54

Figura 49: Patch do objeto aim.tutorial03 e saídas correspondentes ................ 55

Figura 50: Patch do objeto aim.tutorial07 e saídas correspondentes ................ 56

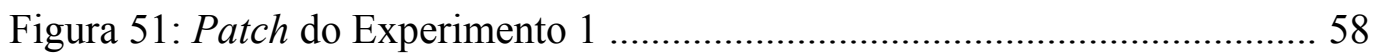

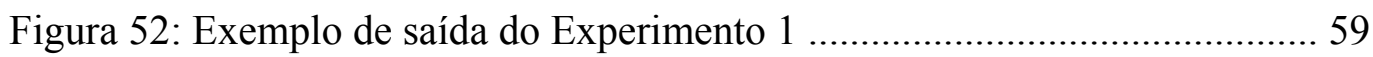

Figura 53: Texto do Experimento 2 e patch correspondente ............................. 60

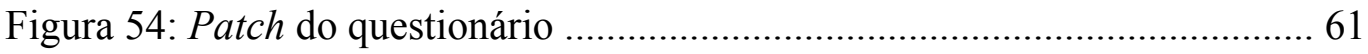

Figura 55: Respostas coletadas pelos experimentos ......................................... 62

Figura 56: Facilidade de utilização da interface .............................................. 62

Figura 57: Clareza das associações entre as características musicais e a saída

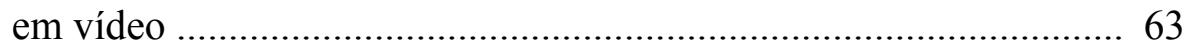

Figura 58: Clareza das instruções no tutorial do Experimento 2 ....................... 64

Figura 59: Avaliação da duração do segundo experimento ............................... 65

Figura 60: Facilidade de utilização da biblioteca na construção de patches ..... 65

Figura 61: Interesse dos usuários na proposta do trabalho ................................ 66

Figura 62: Momentos de performances de VJs ............................................. 67 


\section{Introdução}

As possíveis formas de relacionamento entre sons e imagens são assuntos que fascinam a humanidade desde longa data. As artes cênicas (teatro, ópera, dança e circo) incluem diretamente elementos sonoros (trilha sonora, música incidental, sonoplastia). As artes visuais (pintura, desenho, escultura, arquitetura, cinema, entre muitas outras) podem incluí-los diretamente (desenho animado, cinema) ou indiretamente, através de associações e correspondências sutis entre dados sonoros e dados visuais [Maur 1999]. A música já se utilizou várias vezes de associações entre sons, luzes, cores e formas [Casnok 2003].

Este trabalho visa a construção de um sistema computacional (AIM - Audible IMages) que permita a definição de associações entre parâmetros musicais e visuais a fim de permitir a geração automática de animações em vídeo a partir de entradas sonoras, que servem de acompanhamento visual à entrada musical. As associações entre parâmetros musicais e visuais podem ser controladas e modificadas em tempo-real, através de interfaces, que se comportam como instrumentos visuais [Collopy 1999].

Neste capítulo será apresentado um panorama histórico de trabalhos que buscaram associar informações visuais com informações sonoras; em seguida serão apresentados brevemente alguns sistemas computacionais que serviram de motivação para o desenvolvimento da biblioteca AIM e por fim serão detalhados os objetivos do sistema desenvolvido e a estrutura da dissertação.

\subsection{Histórico}

O interesse em relacionar de alguma maneira imagem e som está longe de ser algo recente. Em um plano físico-teórico, vários cientistas estudaram o relacionamento entre altura musical e cor, apoiando-se em considerações filosóficas, físicas ou estéticas. Entre eles está Isaac Newton, que em seu tratado Opticks de 1704 propôs um mapeamento entre as cores do arco-íris e os graus da escala diatônica em ré (dórica). Newton foi um precursor do estabelecimento de relações entre a cor e o som, tendo detectado similaridades físicas entre as 7 cores na decomposição da luz com referência direta às 7 notas da escala diatônica, concluindo que cada cor corresponderia a uma nota [Salles 2002]. Hermann von Helmholtz (On the Sensations of Tone, 1863) estabelece um mapeamento diferente considerando a teoria de Young-Helmholtz acerca da tripartição da visão humana em componentes de luz vermelha, verde e violeta.

Em um plano mais abstrato, a influência de idéias plásticas em obras musicais ou de idéias musicais na obra de artistas plásticos também permeia a história da arte. Desde artistas com uma base sólida em música e pintura, como Paul Klee e Arnold Schoenberg, a outros mais focados em uma destas atividades, como Wassily Kandinsky, Piet Mondrian e Alexander Scriabin, os exemplos de empréstimo entre as duas áreas são abundantes [Maur 1999, Ruschioni 1999].

$O$ interesse na relação entre som e imagem freqüentemente se desloca do plano teórico/abstrato para a aplicação em performances que envolvem os dois aspectos simultaneamente. Alguns exemplos clássicos podem ser citados, como o cravo ocular de Louis-Bertrand Castel (1725), instrumento pioneiro inspirado nas teorias óticas de Newton, que possibilitava ao intérprete "tocar cores" [Collopy 2007]. A saída deste instrumento era um quadrado com janelas de vidro colorido, cada uma delas ligadas por engrenagens a uma tecla de um órgão comum; ao se tocar determinada tecla, a cor correspondente era revelada no quadrado de janelas. A Figura 1 mostra um instrumento semelhante construído em 1993 na França [Paquette 2001]. 


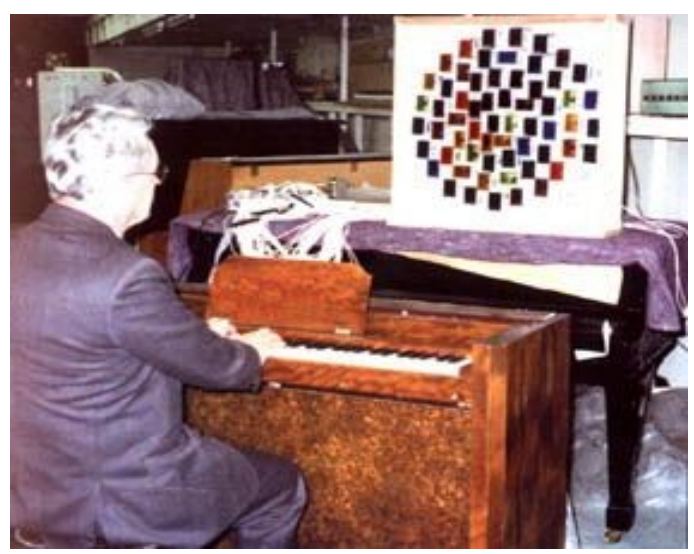

Figura 1: Instrumento semelhante ao cravo ocular de Louis-Bertrand Castel

Outro exemplo semelhante é o Pyrophone construído por Frederick Kastner (1870), formado por treze tubos compridos de cristal conectados a um órgão; ao se acionar uma tecla do órgão uma corrente elétrica causava a explosão de gás colorido em um determinado tubo. A Figura 2 abaixo mostra uma gravura do Pyrophone [Peacock 1988].

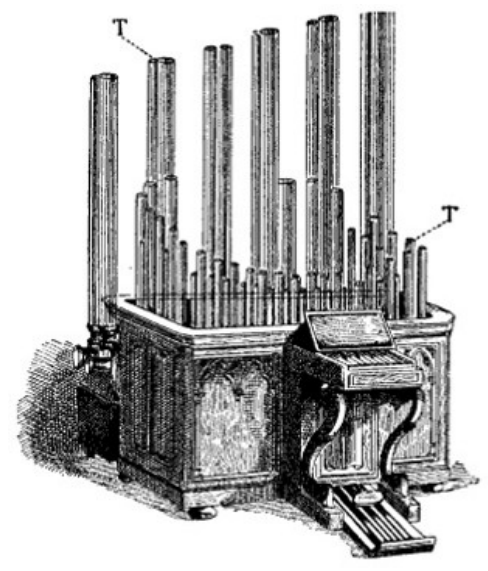

Figura 2: Pyrophone de Frederick Kastner

Alexander Rimington constrói em 1893 o Colour-Organ (Figura 3), um órgão conectado eletronicamente a quatorze orifícios em um quadro de madeira, e que não produzia nenhum som. Um complexo mecanismo controlava a relação da nota tocada no órgão e a cor - e intensidade - da luz que surgia nos orifícios. O termo colour-organ torna-se, a partir daí, genérico para esse tipo de instrumento. Entre os compositores que sugeriram em suas obras a utilização de instrumentos como o órgão de cores, considera-se Alexander Scriabin (1972-1915) o mais incisivo. Sua obra Prometeu - Poema do Fogo (1910), para piano, orquestra, voz e órgão de cores é a mais expressiva de seus anseios sinestésicos ${ }^{1}$ [Caznok 2003].

1 Vale notar que a palavra "sinestesia" admite dois significados correntes: o primeiro, como figura de linguagem, se refere à associação deliberada entre dois ou mais planos sensoriais diferentes; o segundo, como neuropatologia, se refere à evocação automática de um sentido em um indivíduo a partir de um estímulo de um sentido diverso. Neste trabalho qualquer referência à palavra "sinestesia" se refere à figura de linguagem com este nome. 


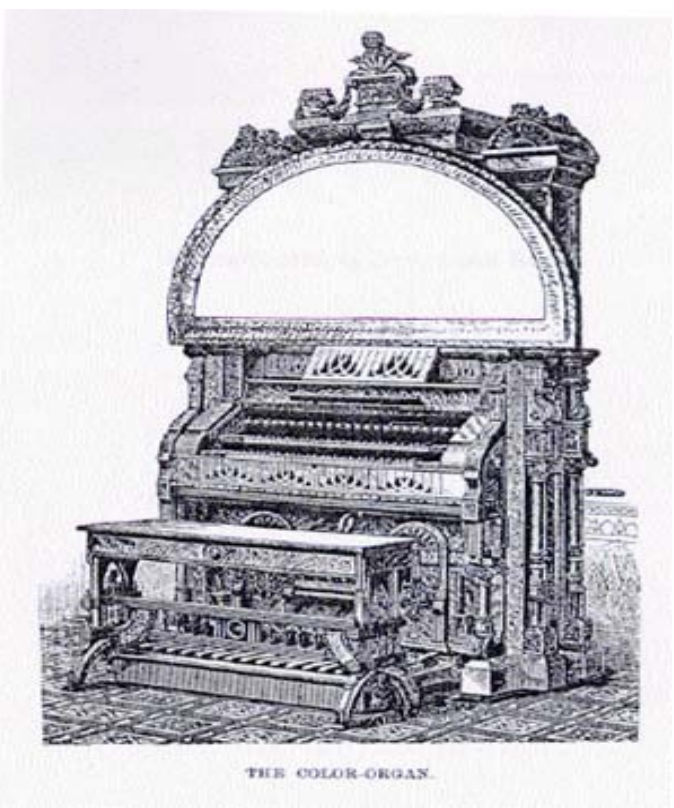

Figura 3: Colour-Organ de Alexander Rimington

Um resumo das associações criadas por diversos artistas e cientistas com o objetivo de estabelecer relações entre as cores e as notas musicais é mostrado na Figura $4^{2}$ abaixo.

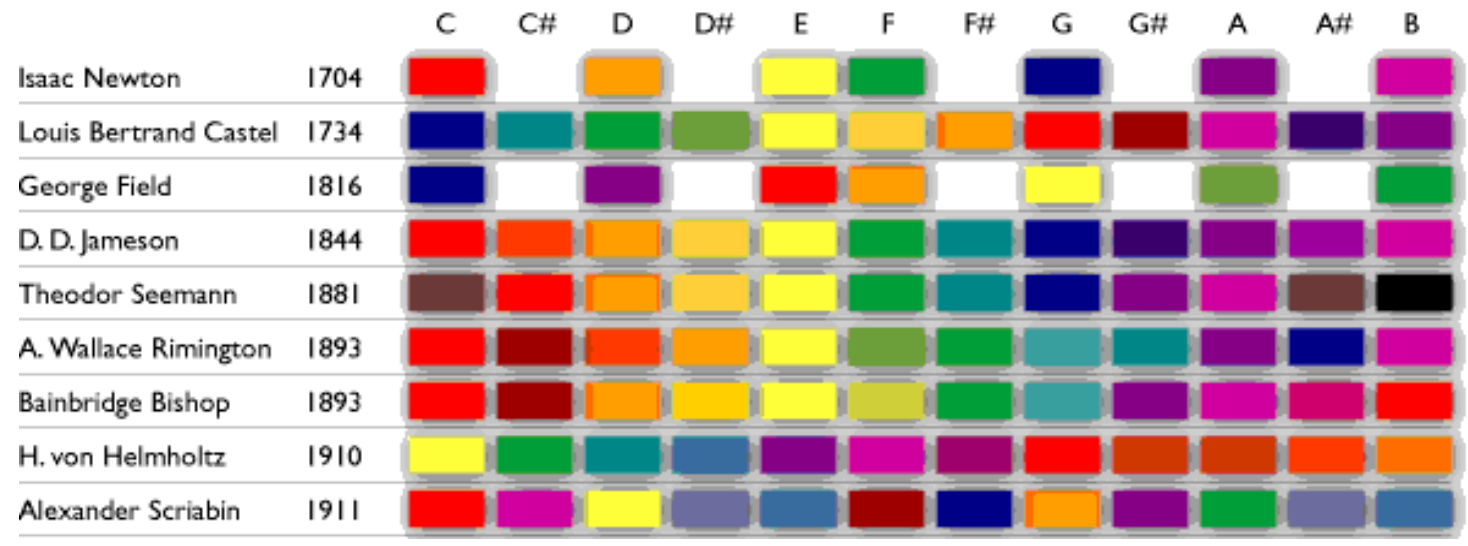

Figura 4: Relações entre cores e notas musicais estabelecidas por artistas e cientistas

No século XX outros compositores trouxeram para suas obras musicais a idéia do uso de cores. Arnold Schoenberg (1874-1951), por exemplo, imaginou o uso da projeção de cores em seu drama com música Die glückliche Hand (A mão afortunada) em 1913. Olivier Messiaen (19081992), por sua vez, acrescentou indicações de cores específicas em algumas obras (por exemplo, nas partituras de Couleurs de la Cité Céleste e Des canyons aux étoiles...), a fim de guiar a interpretação/execução.

Um compositor que também merece ser considerado é o brasileiro Jorge Antunes (1942-), que publicou um pequeno livro intitulado $A$ correspondência entre sons e cores (1982). Antunes levanta a hipótese de que os nervos sensitivos óptico e auditivo, por sua proximidade de localização, seriam excitados mutuamente, provocando a sensação do cruzamento sensorial (sinestesia no sentido neuropatológico). Ele estabeleceu uma relação entre fenômenos vibratórios acústicos e as radiações das cores baseando-se em cálculos matemáticos e físicos, e apresenta em

2 http://rhythmiclight.com/archives/ideas/colorscales.html 
seu livro uma tabela de correspondências cromofônicas, a partir da qual ele desenvolveu uma técnica de composição a que dá o nome de Música cromofônica. Algumas obras de Jorge Antunes são: Cromorfonética (1969), Catástrofe ultravioleta (1974) e Elegia violeta para monsenhor Romero (1980).

No lado das artes plásticas, o pintor Wassily Kandinsky (1866-1944) já havia escrito em 1910 seu livro Do Espiritual na Arte, onde expõe sua própria teoria de sinestesia através de uma série de associações entre cores, emoções e movimentos. Várias de suas obras possuem referências sonoras; entre elas pode-se destacar Der Gelbe Klang ( $O$ som amarelo, publicado no Der Blaue Reiter Almanach, 1912), uma composição cênica abstrata onde o artista combina cores e luzes, sons e movimento, através de instruções detalhadas de cenário, figurino, coreografia e sonoplastia.

Seguindo a linha de Kandinsky e outros precursores, surgiram artistas como Charles BlancGatti, Henri Valensi, Gustave Bourgogne e Vito Stracquadaini que fundaram em 1932 em Paris o grupo de artistas musicalistas. O objetivo do grupo não era traduzir plasticamente nenhum dos atributos da linguagem musical, mas revelar os ecos psíquicos da música no domínio visual [Caznok 2003].

Dentro do próprio grupo, cada integrante desenvolveu uma linha pessoal bastante diferenciada. Bourgogne criou uma doutrina denominada bleuisme, na qual arte e ciência estariam em harmonia com a natureza, baseada em uma crença de que as ondas vibratórias seriam predominantemente azuis. O suíço Blanc-Gatti criou um método matemático de concordância entre as vibrações das cores e dos sons: as cores quentes (vermelho e laranja) corresponderiam às sonoridades graves, enquanto as cores frias (azuis e violeta) teriam sua correspondência nos sons agudos. Sua idéia de construir uma "Orquestra Cromofônica", em 1933, teve como objetivo a criação de um espaço no qual os efeitos luminosos se movimentassem em um perfeito sincronismo com as movimentações sonoras. Em 1939 Gatti lança o filme Chromophonie onde explora no cinema suas idéias sinestésicas (Figura 5). De certa forma, Blanc-Gatti retoma as idéias de Castel (1688 1757) e de Scriabin (1872-1915), com a tecnologia oferecida pelo século XX.

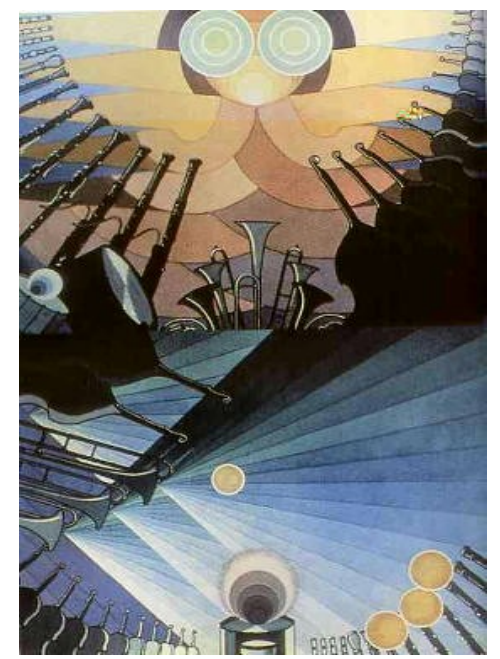

Figura 5: Cartaz do filme Chromophonie (1939) de Charles Blanc-Gatti

Um outro artista plástico que coloca nas suas obras relações sinestésicas é o australiano Roy De Maistre (1894-1968). De Maistre criou sua própria escala de relação entre música e cor utilizando as mesmas oito cores descritas por Newton, ROYGBIV (red, orange, yellow, green, blue, indigo e violet), porém dividindo o espectro em 11 seções para estabelecer seu código próprio. A Figura $6^{3}$ ilustra a relação montada por De Maistre.

3 http://home.vicnet.net.au/ colmusic/maistre.htm 


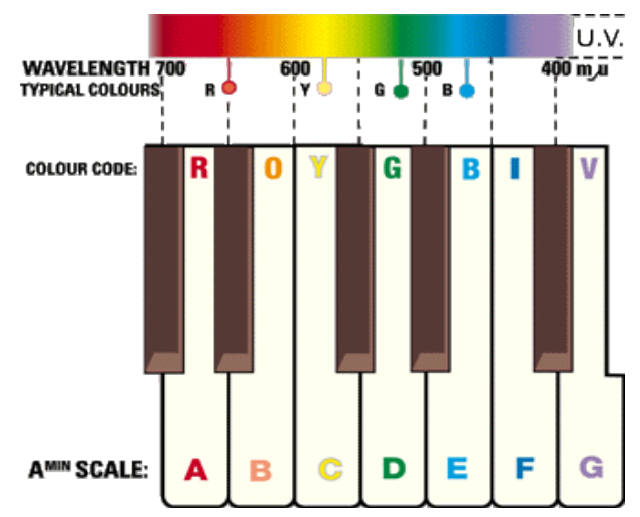

Figura 6: Código de relação entre altura musical e cor criado por Roy De Maistre

Roy De Maistre investigava os conceitos da harmonia das cores, pois para ele cores em uma pintura eram como notas musicais que compõem uma sinfonia. Suas obras foram expostas em diversas galerias pelo mundo, podendo ser citadas: Arrested Movement from a Trio (1934) e Colour Composition Derived from three Bars of Music in the key of Green (1935). A Figura 7 exibe uma outra obra deste mesmo artista.

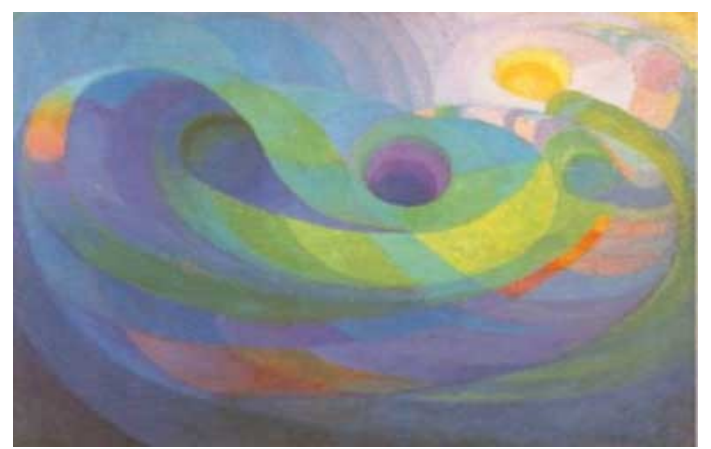

Figura 7: Rhythmic Composition in Yellow Green Minor (1919) de Roy De Maistre

Quaisquer que fossem suas motivações, fossem elas físicas, psicológicas ou estéticas, as obras destes artistas ilustram a vontade humana de combinar elementos visuais e musicais através de associações diversas. As seções a seguir apresentam diversas soluções tecnológicas e interativas para lidar com tais associações, e que relacionam-se de algum modo com o presente trabalho.

\subsection{Outros trabalhos relacionados}

Mais recentemente, o surgimento de novas tecnologias, como o padrão MIDI, o aumento do poder de processamento dos computadores pessoais e a facilidade de circulação de informação multimídia em banda-larga fizeram com que muitos sistemas computacionais para associação de áudio e vídeo fossem desenvolvidos [Rowe 2001].

Um destes sistemas é o Isadora ${ }^{4}$, desenvolvido por Mark Coniglio para a companhia de dança Troika Ranch [Coniglio]. Esta é uma ferramenta interativa usada em apresentações de dança, teatro, instalações interativas e na produção de vídeos para casas noturnas, que oferece controles interativos para manipulação de informações de áudio, vídeo e MIDI em tempo-real. Este sistema oferece suporte ao protocolo OpenSound Control [Wright 2003] que permite troca de informações com outros sistemas, como o Pd. A Figura 8 mostra um programa desenvolvido no Isadora com a

4 http://www.troikatronix.com/isadora.html 
saída respectiva e exibe dois objetos da ferramenta mais detalhadamente.
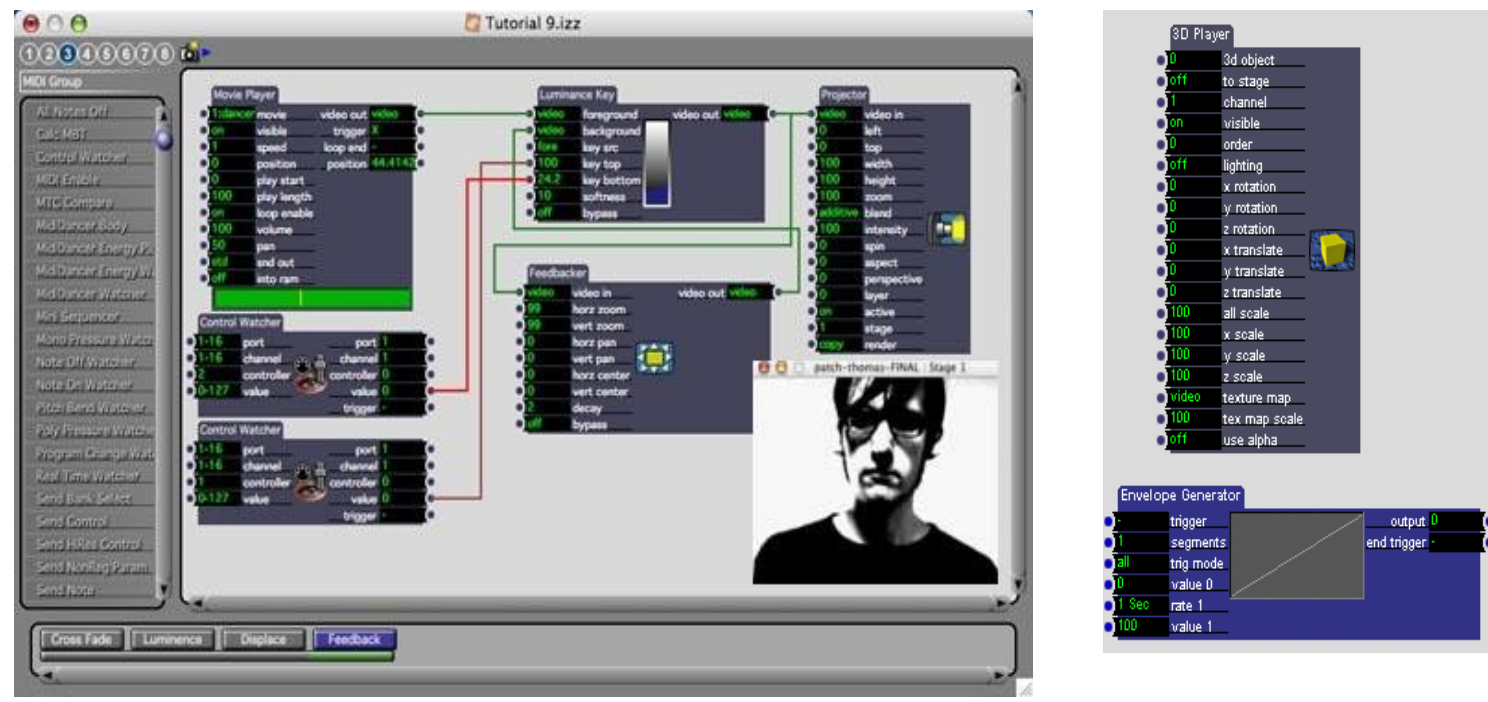

Figura 8: Exemplo de um patch do Isadora com sua respectiva saída

Buscando uma relação mais estreita entre os movimentos de dançarinos em um palco e os efeitos sonoros que acompanham esses movimentos, um grupo de pesquisadores desenvolveu um ambiente áudio-visual interativo para performances de dança, teatro e instalações artísticas $[\mathrm{Ng}$ 2000]. Dois sistemas são utilizados: o MvM (Music via Motion), que através de uma câmera de vídeo reconhece as atividades dos dançarinos, digitaliza essas atividades e com um mapeador de movimentos e um detector de cores gera respostas musicais; e o CoIN (The Coat of Invisible Notes) que oferece recursos para a construção de vestimentas, música e dança no ambiente interativo simulado pelo $M v M$. A Figura 9 mostra uma cena captada pela câmera de vídeo e a respectiva resposta dada pelo sistema $M v M$; a resposta do mapeador de movimentos é exibida na área mais à esquerda da tela de saída e as cores detectadas na região mais à direita.

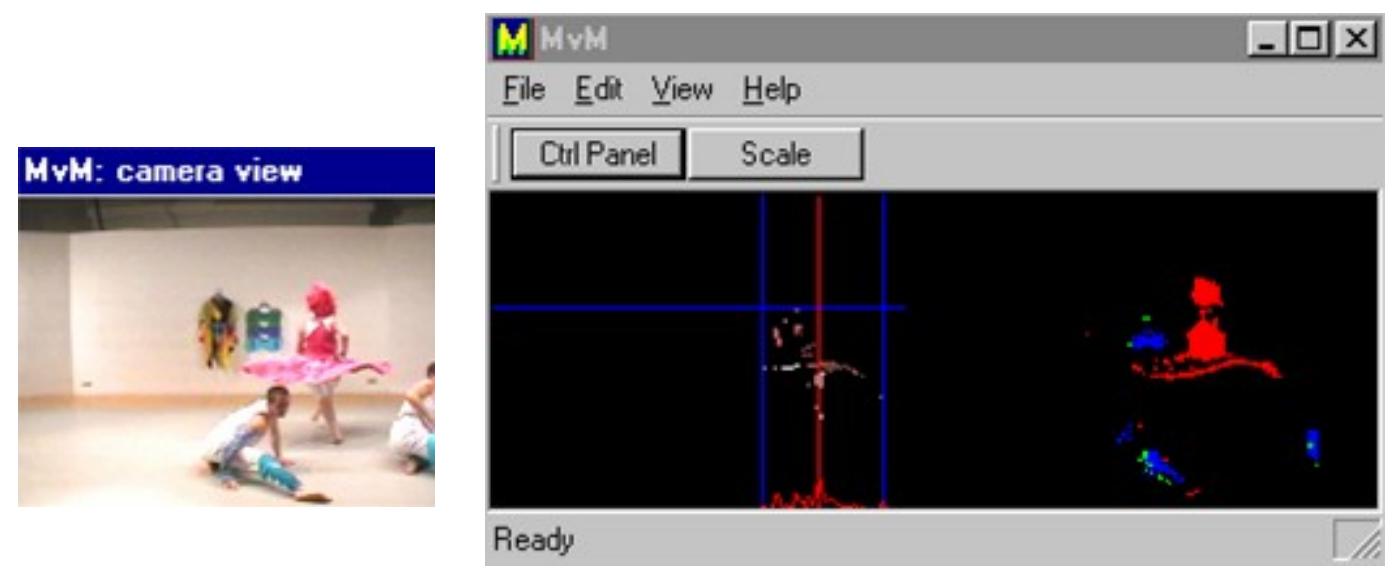

Figura 9: Cena captada pelo sistema $M v M$ e respectiva saída

A possibilidade dos movimentos construírem o som que os acompanha faz com que a dança e a música se complementem na performance, garantindo a sincronia dos movimentos do dançarino com a parte musical e encorajando a platéia a perceber, no contexto artístico, essa relação. Ainda no campo da interatividade entre música, imagens e dança podem ser mencionados os trabalhos [Nagashima 1998] e [Iazzetta 2003]. 
No âmbito de realidade virtual também encontram-se exemplos de interação entre som e imagem, como no projeto Soundscape da Universidade McGill no Canadá [Charlebois 2005]. Neste projeto é estabelecida uma forma de coerência áudio-visual ao se associar propriedades acústicas dos objetos representados em uma cena 3D a técnicas de acústica geométrica, de tal maneira que os sons recriados correspondam à realidade acústica do ambiente.

O projeto Egosound da Universidade de Paris [Sedes 2003] fornece um ambiente virtual interativo para espacialização sonora, onde a movimentação dos sons é determinada pela movimentação de esferas controladas pelo usuário no espaço virtual.

Schertenleib apresenta o projeto Conducting a Virtual Orchestra [Schertenleib 2004], que é um ambiente áudio-visual onde o usuário atua como regente de uma orquestra virtual. Aqui a simulação áudio-visual responde a sensores de movimento conectados ao usuário, que pode controlar a dinâmica, a agógica e inclusive a posição dos músicos. A resposta visual e auditiva é rica em detalhes, como por exemplo a correta representação da posição dos dedos do flautista virtual durante sua execução. A Figura 10 mostra os detalhes de um personagem do sistema e um usuário testando a ferramenta.

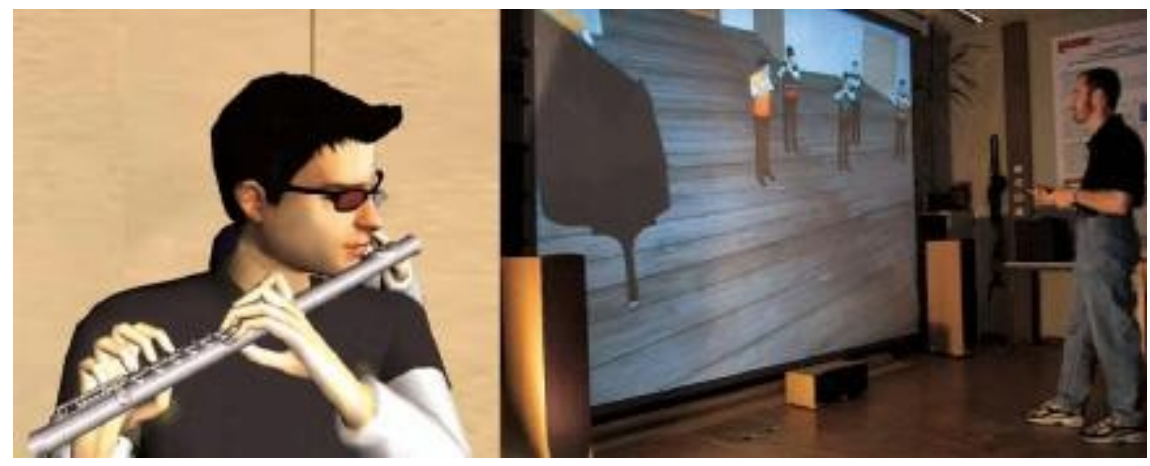

Figura 10: Projeto Conducting a Virtual Orchestra

Ainda no âmbito de interação homem-máquina envolvendo computação gráfica e musical, pode ser mencionado o trabalho de Tarabella, que se dedica à construção de sensores remotos de movimento (isto é, sem fios ou transmissores eletrônicos), utilizando apenas feixes infra-vermelhos e análise de imagens de vídeo em tempo-real [Tarabella 1997].

Outro sistema que possui suas aplicações focadas na captura de imagens com uma câmera de vídeo conectada ao computador é o Eyes $W e b^{5}$, desenvolvido pelo Laboratório de Informática Musical da Universidade de Gênova, Itália. Este sistema busca a exploração e o desenvolvimento de modelos de interação entre gestos e linguagens visuais com a linguagem musical. O EyesWeb permite a criação de aplicações multimídia com análise de áudio e síntese de vídeo em tempo-real a partir de uma interface gráfica programada com blocos que são interligados. A Figura 11 abaixo exibe um programa disponível nos tutoriais da ferramenta EyesWeb e a saída respectiva.

5 http://www.eyesweb.org 


\section{Bounding rect height volume modulation}
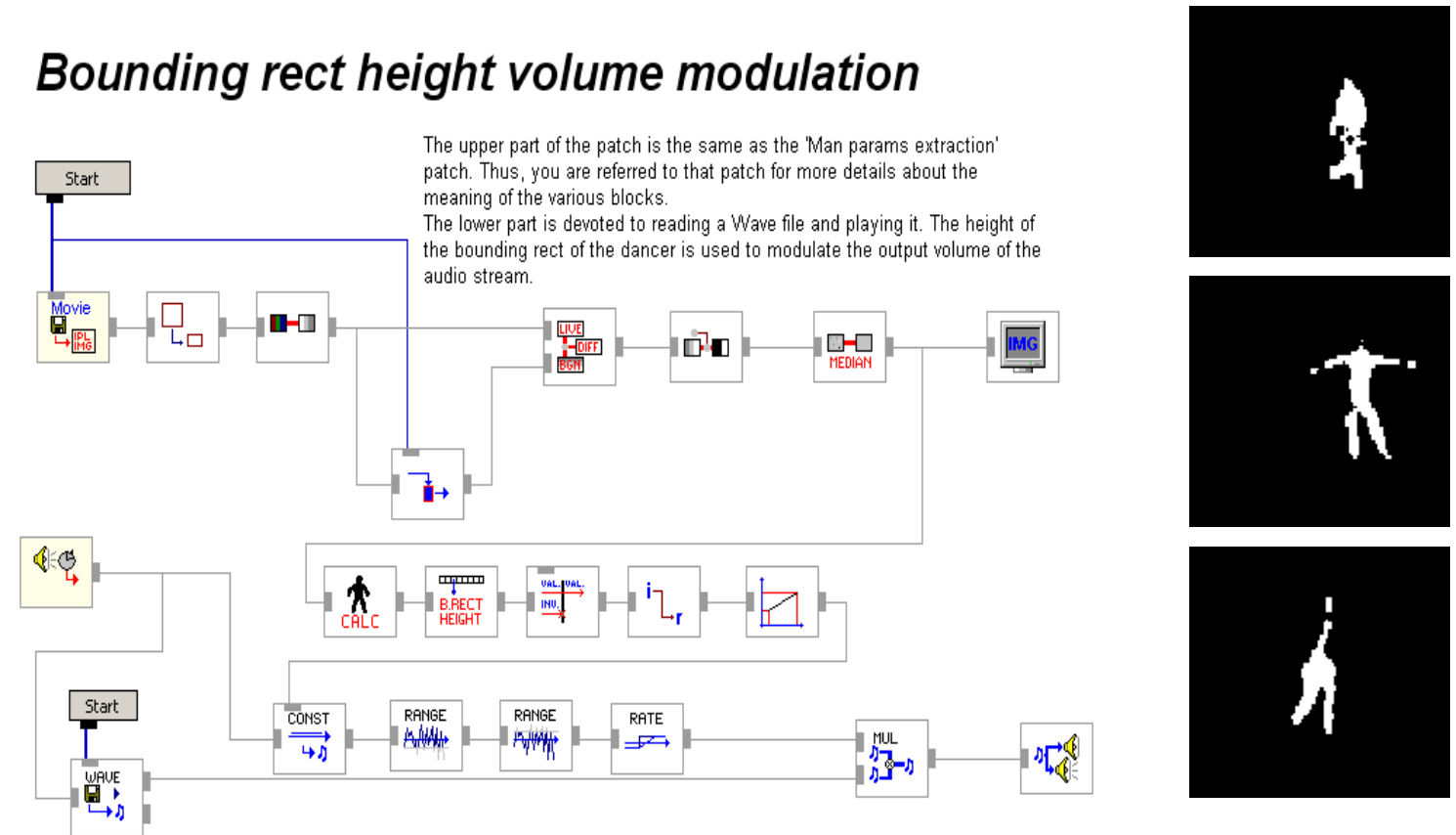

Figura 11: Programa construído na ferramenta EyesWeb e três momentos da saída gerada

O EyesWeb permite o mapeamento de gestos em diferentes níveis e possui um ambiente integrado para processamento de vídeo, sinais musicais e informações MIDI. O sistema permite ainda a adição de novos módulos (desenvolvidos em $\mathrm{C} / \mathrm{C}++$ ), a criação de novos tipos de dados e a comunicação com módulos de outros sistemas. A Figura 12 mostra um outro exemplo de programa montado na ferramenta e a respectiva saída.

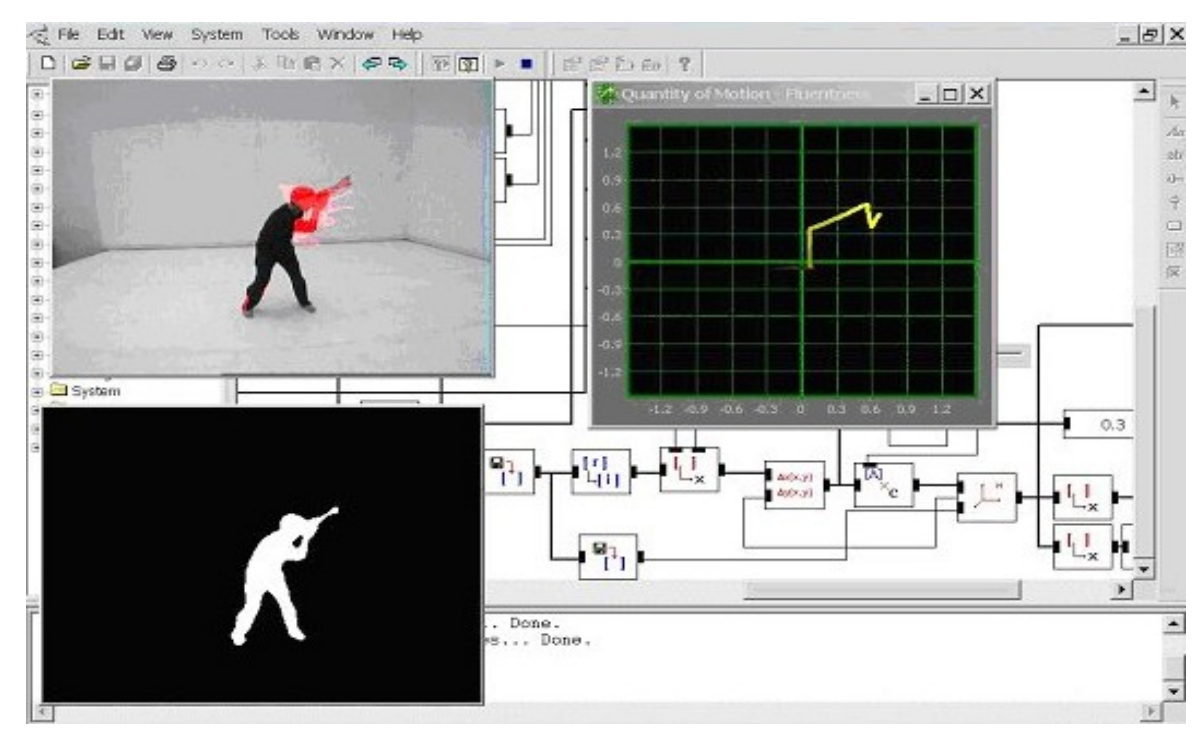

Figura 12: Outro programa construído na ferramenta EyesWeb

Uma ferramenta interativa com o propósito específico de gerar imagens a partir de uma entrada de áudio (portanto mais próxima da proposta deste trabalho) é o PixelToy ${ }^{6}$, desenvolvido por Leon McNeill. Este sistema oferece alguns padrões de animação abstratos que podem ser modificados através do uso de filtros de processamento de imagens (Figura 13), e permite que a saída seja exportada no formato de vídeo QuickTime.

6 http://www.lairware.com/pixeltoy 

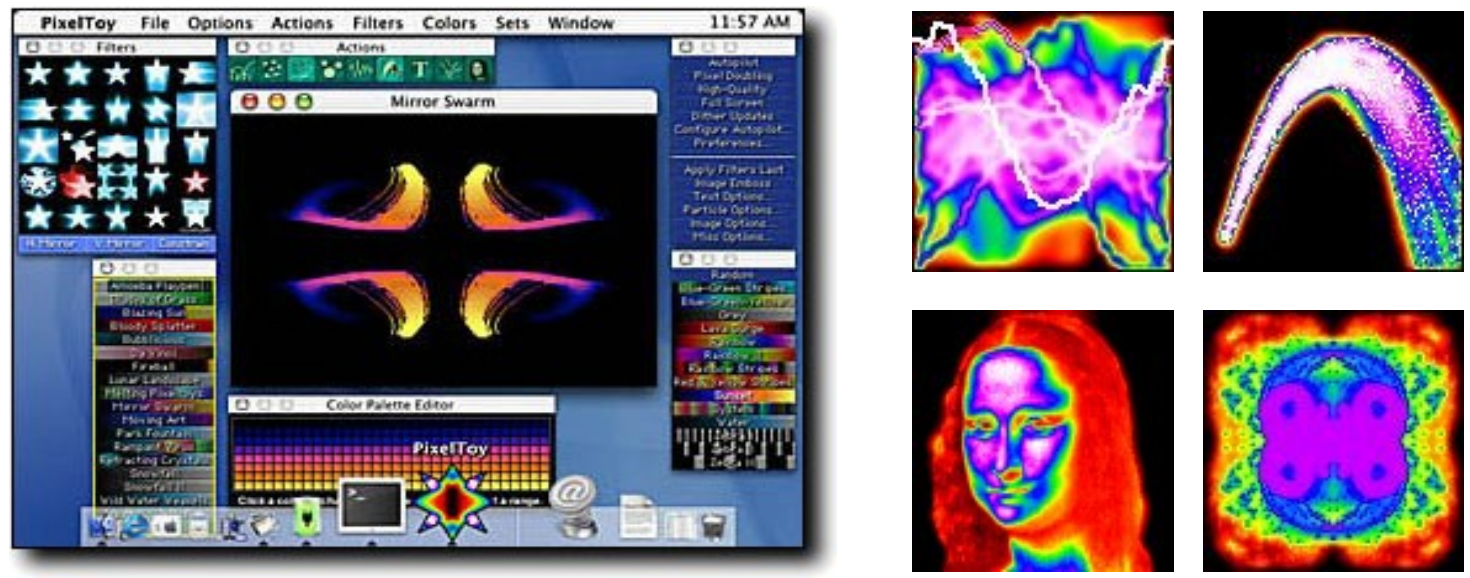

Figura 13: Tela do PixelToy e um conjunto de saídas geradas pela ferramenta

Outros programas desenvolvidos com a mesma finalidade, e que estão normalmente integrados a algum media player são o Advanced Visualization Studio (AVS), o G-Force e o Milkdrop. Os media players para computadores pessoais foram difundidos nos anos 90 com aplicações como Winamp, Audion e SoundJam, e hoje existem em grande quantidade, provendo saídas visualmente atraentes. Duas saídas de ferramentas distintas são exibidas na Figura 14 abaixo. Os efeitos gerados por este tipo de ferramenta vão desde técnicas simples, como simular a saída de um osciloscópio exibindo um sinal sonoro simples em função do tempo, até técnicas mais complexas que misturam diversos processamentos para gerar uma saída mais elaborada.
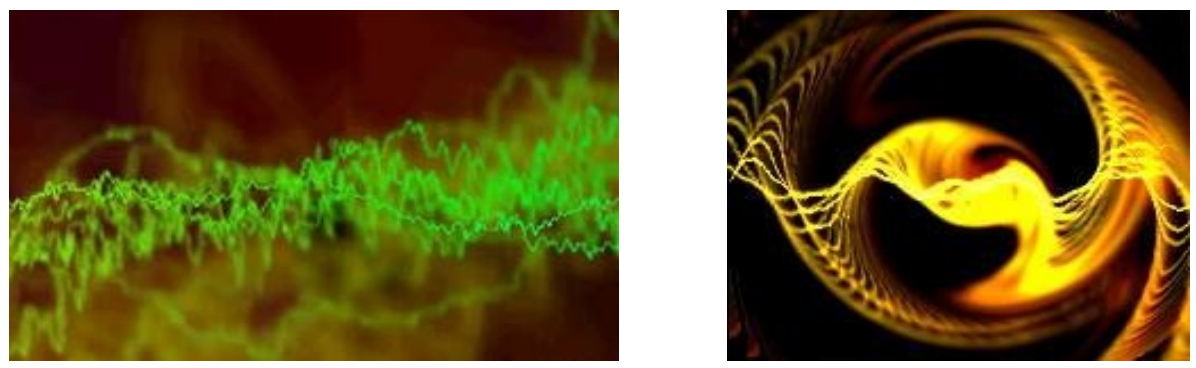

Figura 14: Saídas das ferramentas SoundJam (esquerda) e AVS (direita)

Ruschioni apresenta formas de associar informações visuais e sonoras a partir de um canal de comunicação que permite acoplar ferramentas computacionais para síntese de imagens e síntese sonora [Ruschioni 1999]. São descritos alguns experimentos com trocas de mensagens entre os sistemas Csound e Softimage utilizando channel drivers, onde parâmetros das imagens geradas pelo Softimage foram manipulados por sinais gerados pelo Csound e vice-versa.

Buscando estabelecer estas relações em um ambiente de realidade virtual, o trabalho apresenta experimentos utilizando a ferramenta visual Improv, que é baseada na linguagem $K P L$, em conjunto com as ferramentas de síntese sonora Csound e Max. Utilizando estes recursos é desenvolvido o projeto Aria, onde o usuário é um regente que controla um tenor virtual (Figura 15), personagem este que reagirá de acordo com a regência recebida. O projeto prevê um ambiente computacional distribuído, a utilização de sensores de movimento, além de modelagens gráficas e sonoras para tratar a animação facial e a síntese de voz do tenor. 

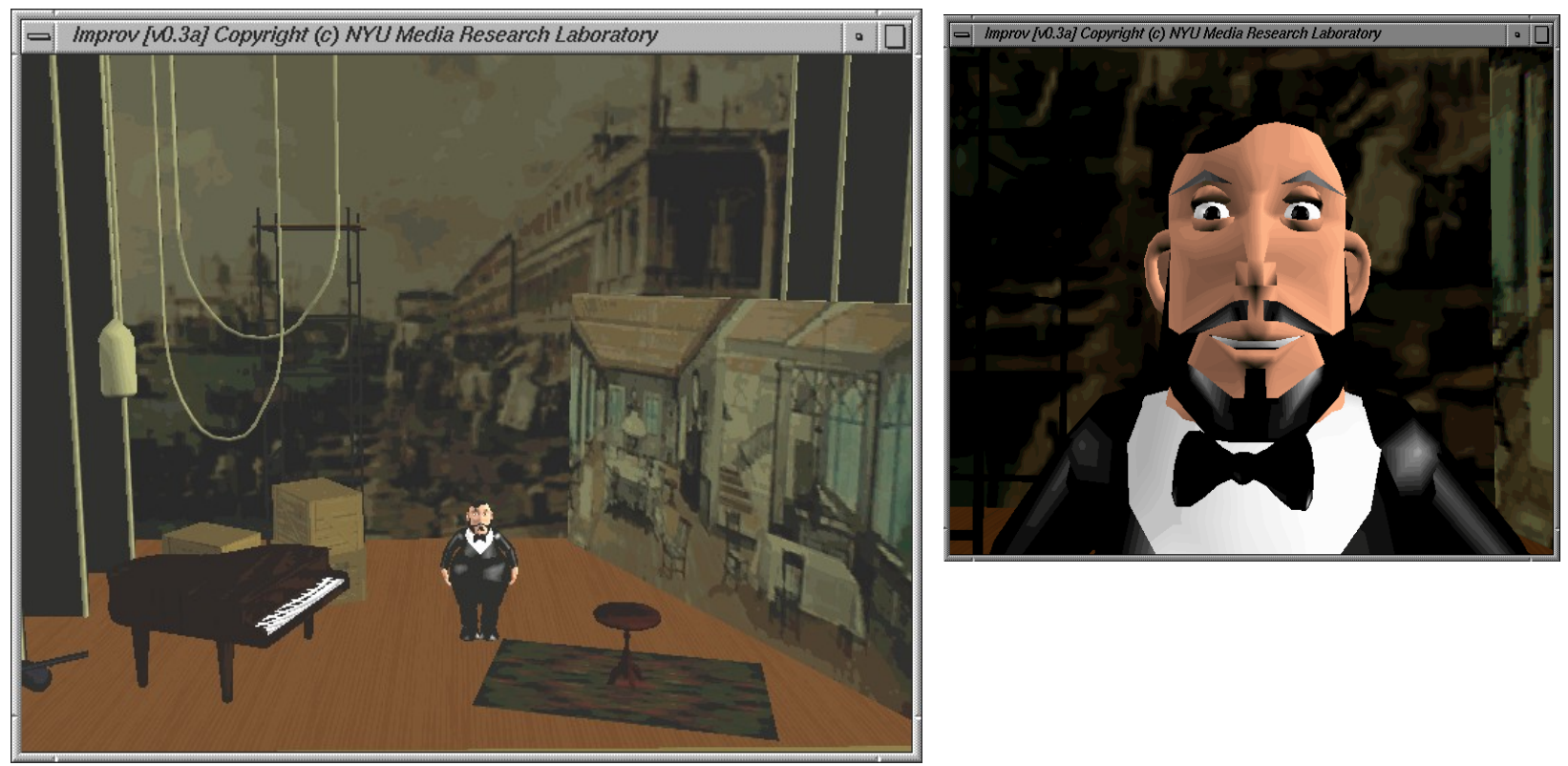

Figura 15: Imagens do cenário e do tenor virtual do projeto Aria

Algumas ferramentas foram desenvolvidas buscando generalizar a manipulação de informações multimídia, e dessa forma expandir as opções de utilização dessas informações em diversos contextos. Em particular, sistemas voltados à geração de imagens (também chamados instrumentos visuais) são ferramentas de síntese de imagem em tempo-real que obedecem a controles interativos, como Imager, Bomb, MusiKalscope, Virtual Choreographer, Bindhu e Bliss Paint [Collopy 1999, Jacquemin 2004]. Estas ferramentas normalmente são construídas sobre alguma plataforma de programação multimídia em tempo-real, como MAX, Pd ou Sonnet. A Figura 16 mostra algumas saídas construídas no Bliss Paint, que é uma ferramenta utilizada para construção de animações e vídeos.
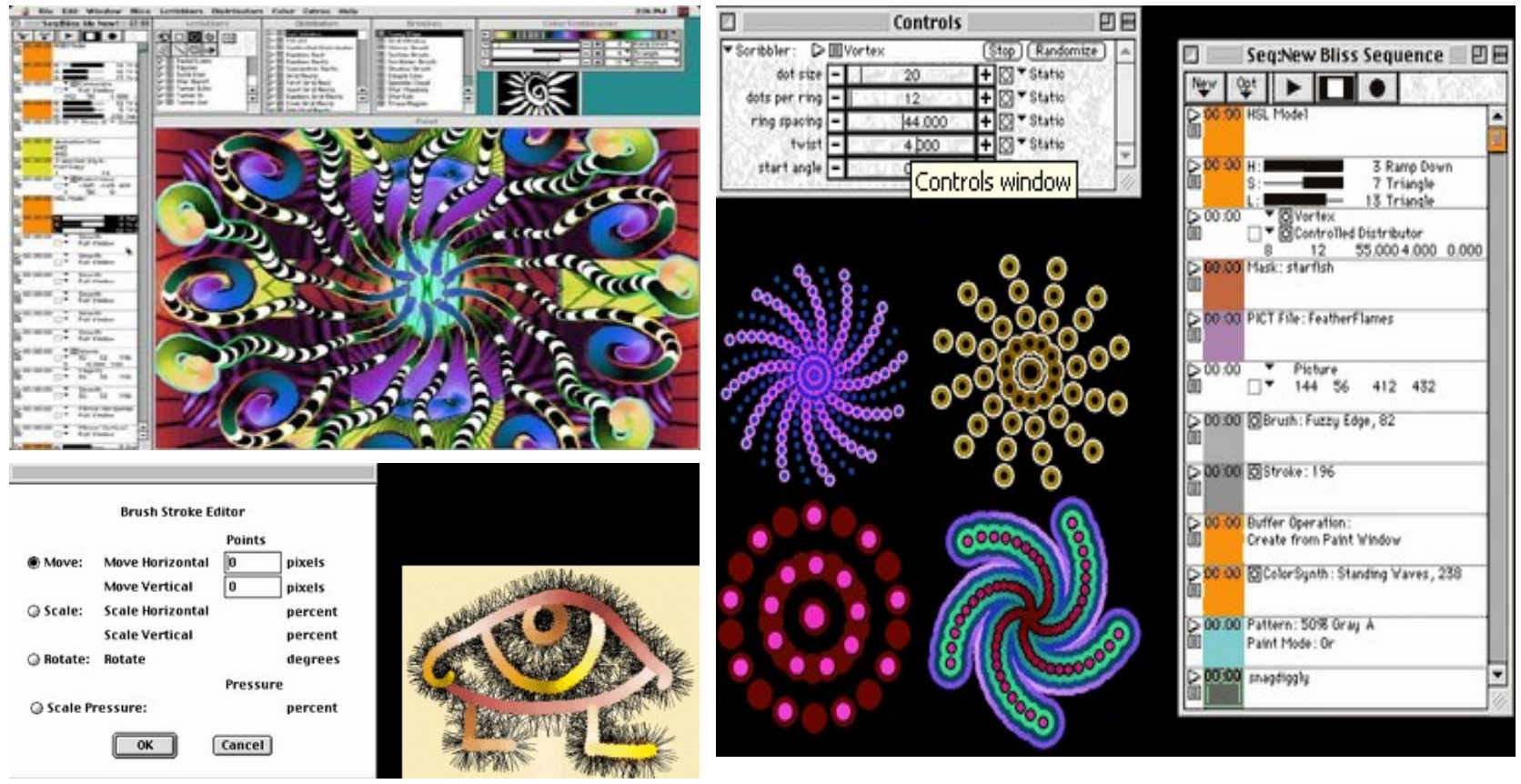

Figura 16: Exemplos de saídas construídas no Bliss Paint 
Um outro instrumento visual é o GEM [Danks 1997], que é uma biblioteca escrita originalmente por Mark Danks que utiliza os conceitos do OpenGL e fornece objetos Pd para síntese de imagens a partir da descrição de uma cena 3D. Trata-se de uma biblioteca sofisticada para manipulação de objetos gráficos e projeção de texturas (tanto estáticas quanto de vídeo) sobre objetos geométricos. Esta ferramenta será utilizada neste trabalho, sendo abordada em mais detalhes no Capítulo 3.

\subsection{Motivação: Sistemas Interativos e Cypher}

Os sistemas chamados de Interativos são aqueles em que ocorre uma interação direta entre a ferramenta e o usuário. São exemplos clássicos de sistemas de computação musical interativos os chamados score followers, que implementam técnicas para sincronizar uma performance de um músico humano com uma representação simbólica (partitura) armazenada no computador, visando uma adaptação temporal à performance humana. Em uma visão geral, o acompanhamento de uma performance humana em tempo-real requer a solução de três subproblemas: a detecção daquilo que o solista está tocando, a correlação da entrada detectada com a partitura armazenada e a produção do acompanhamento (cuja partitura também está armazenada). Alguns trabalhos relacionados ao problema do acompanhamento musical em tempo-real são encontrados em [Dannenberg 1984, Dannenberg e Mukaino 1988, Buxton, Dannenberg e Vercoe 1986, Puckette e Lippe 1992, Orio, Lemouton e Schwartz 2003, Schwartz, Orio e Schnell 2004, Winkler 1999].

Outro modo de explorar a interatividade musical homem-máquina, abordando um aspecto diferente dos score followers, são os chamados Sistemas Dirigidos por Performance [Rowe 2004]. Nestes o computador reage à informação musical presente na entrada de acordo com regras de contexto, sem nenhum tipo de partitura armazenada. Um destes sistemas é o Cypher, escrito por Robert Rowe [Rowe 2004]. O Cypher é uma ferramenta para a composição e performance musicais composto por dois componentes principais: um ouvinte (listener) e um executante (player).

O componente ouvinte é responsável por analisar performances musicais representadas em seqüências de dados MIDI, que podem vir de um músico humano, de outro programa de computador ou do próprio Cypher. Este módulo é responsável por analisar e classificar cada evento musical recebido de acordo com algumas características, tais como: densidade, velocidade, volume, registro, duração e harmonia. Existem dois níveis de análise: o mais baixo descreve os eventos isolados (notas individuais ou acordes), enquanto o mais alto descreve a forma como esses eventos variam no tempo.

O componente executante é a seção de composição, que utiliza algoritmos de síntese para produzir a resposta musical. A saída do sistema é gerada dependendo das associações estabelecidas pelo usuário entre as características detectadas na entrada e a ação que deve ser executada pelo Cypher sobre o trecho musical analisado. O usuário possui à sua disposição alguns métodos de resposta, como por exemplo tocar seqüências pré-armazenadas, inicializar algoritmos de síntese ou composição algorítmica, ou ainda a aplicação de transformações nos eventos detectados. Essas transformações são normalmente operações pequenas e simples, como uma aceleração, inversão, atraso ou transposição do fragmento da entrada. Porém, apesar de qualquer operação simples produzir uma única mudança na entrada, combinações de várias delas resultam em efeitos mais complexos.

O Cypher possui uma interface gráfica que permite que as conexões entre os módulos das características musicais (provenientes do componente de análise) e das transformações (elementos de síntese) sejam feitas interativamente (Figura 17). Séries específicas de operações são executadas em cada evento da entrada de acordo com as conexões feitas pelo usuário: o estabelecimento de uma conexão indica que sempre que determinada característica musical for encontrada no evento da entrada, a transformação na qual ela está conectada será aplicada ao evento e o resultado da 
operação enviado aos sintetizadores que irão gerar a saída sonora.

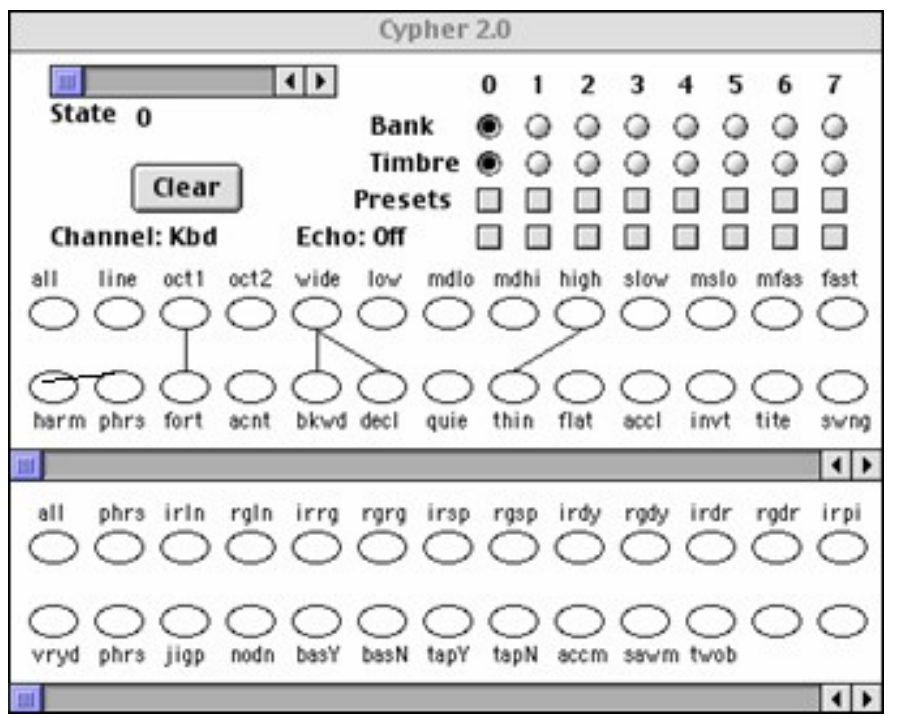

Figura 17: Interface do Cypher

No Cypher são geradas informações musicais em resposta a uma entrada musical. A resposta é gerada a partir de associações entre características detectadas na entrada musical e transformações a serem aplicadas ao trecho detectado, estabelecidas em tempo-real pelo usuário. A interface oferece um meio fácil de estabelecer e modificar tais associações em tempo-real, definindo a reação do sistema à entrada.

Esta decomposição do sistema em componentes de análise da entrada, componentes de síntese da resposta e interface através de conexões diretas serviu de motivação para o desenvolvimento do trabalho descrito nesta dissertação, cujos objetivos são detalhados a seguir.

\subsection{Objetivos do Trabalho}

Como visto anteriormente, a busca por associar imagens e sons é um desafio antigo, e diversos músicos e artistas plásticos criaram suas próprias associações em suas obras. Estas associações podem ser definidas de modos muito diferentes, e mesmo a associação entre os mesmos parâmetros, por exemplo entre cor e altura musical, dará ensejo a relações completamente diversas nas mãos de pessoas diferentes. Todos os casos analisados no início deste capítulo procuravam de alguma forma estabelecer relações diretas entre o mundo visual e o sonoro, mas em todos os casos a forma específica da associação envolvia algum componente subjetivo e estético.

Atualmente existem muitos recursos computacionais que oferecem facilidades para a realização e experimentação de associações sinestésicas deste tipo através do computador, e a possibilidade de manipular estas associações de forma interativa e observar o resultado em temporeal torna o tema atrativo para o desenvolvimento de ferramentas que facilitem este tipo de experimentação.

A biblioteca GEM citada anteriormente possui muitos recursos para a geração de imagens 3D em tempo-real. A integração do GEM com o Pd favorece sua utilização em conjunto com ferramentas de processamento de áudio, e o estabelecimento de conexões diversas entre elementos de áudio e de síntese de imagens de acordo com o gosto do usuário. Tanto o GEM como outros instrumentos visuais obtém sua generalidade e flexibilidade às custas de uma maior complexidade na especificação de objetos, o que dificulta o seu uso por pessoas inexperientes em linguagens de 
programação.

Com o objetivo de tornar a experimentação com elementos áudio-visuais acessível a usuários sem experiência em programação, foi desenvolvida uma biblioteca para o Pd que permite de forma direta a conexão de objetos sonoros com objetos visuais, viabilizando a geração de acompanhamentos visuais a uma música dada com um mínimo de esforço do usuário. Esta biblioteca contém objetos de análise para a extração de características musicais da entrada de áudio (um arquivo, um instrumento ou um microfone), um conjunto de objetos auxiliares para síntese e processamento de sinais, bem como um conjunto de objetos de síntese de imagens usando GEM, e pode ser utilizada de forma independente na construção de programas no $\mathrm{Pd}$ (patches) ou de forma interativa através de interfaces.

O sistema desenvolvido possui semelhanças e diferenças importantes em relação aos softwares discutidos na Seção 1.2, mais especificamente em relação ao PixelToy, ao sistema descrito por Ruschioni [Ruschioni 1999] e aos instrumentos visuais como GEM e Bliss Paint. Todos estes softwares são geradores de imagens, e assim como o PixelToy e o sistema de Ruschioni, a biblioteca AIM se destina a gerar imagens a partir de uma entrada musical. As diferenças principais estão associadas a uma escala que expressa simultaneamente dois fatores inter-dependentes: facilidade de uso e expressividade [Jácome 2007].

Num dos extremos da escala, o software PixelToy oferece um número limitado de padrões de animação e filtros de efeitos que podem ser facilmente combinados para criar saídas relativamente sofisticadas; apesar disso, o usuário não tem poder para acrescentar padrões novos (em particular porque o código do software é fechado). No outro extremo, os instrumentos visuais são bastante genéricos, flexíveis e extensíveis, sendo regidos por controles abstratos, não necessariamente obtidos por processamentos de áudio; no entanto, tratam-se de verdadeiras linguagens de programação, que demandam bastante tempo e esforço do usuário a fim de habilitarlhe a expressar idéias e associações áudio-visuais. A biblioteca AIM pretende posicionar-se no meio-termo desta escala, possibilitando a programação e extensão da ferramenta por parte do usuário, sem abrir mão de uma especificação intuitiva do sistema que traga consigo uma facilidade de uso por parte de usuários sem experiência em programação.

A estrutura da dissertação será descrita a seguir:

No Capítulo 2 serão apresentados alguns conceitos fundamentais a respeito de sons e imagens, englobando alguns aspectos do som em seu formato digital e extração de características musicais através do processamento de imagens, bem como conceitos básicos em relação à síntese de imagens no computador. No mesmo capítulo serão abordadas as questões relativas à conversão de informações extraídas do áudio em informações de controle de parâmetros visuais, permitindo o estabelecimento de conexões diretas entre eles.

A implementação da biblioteca AIM é apresentada no Capítulo 3. Inicialmente serão discutidas as ferramentas utilizadas na implementação da ferramenta proposta e em seguida são apresentados os objetos desenvolvidos, que se dividem em objeto de controle central, objetos de análise de áudio, objetos de síntese de imagens, objetos de síntese e processamento de sinais de controle, objetos para a criação de interfaces e tutoriais.

O Capítulo 4 descreve os experimentos desenvolvidos para a avaliação da biblioteca, feitos com voluntários. São discutidas a metodologia e a forma de aplicação dos testes, bem como é apresentada uma análise dos resultados obtidos e algumas conclusões.

As conclusões gerais do trabalho são apresentadas no Capítulo 5, juntamente com as perspectivas de trabalho futuro.

Um apêndice traz os tutoriais que fazem parte da biblioteca, e que servem como introdução ao uso dos objetos e interfaces. 


\section{Sons e Imagens: Conceitos Fundamentais}

Neste capítulo serão abordadas algumas propriedades elementares de sons e imagens, que merecem destaque por fornecer características passíveis de associação entre estes dois domínios, bem como a fundamentação conceitual para a definição e construção de tais associações. Esta discussão fornece a contrapartida teórica para a implementação do sistema computacional desenvolvido, que será descrito no próximo capítulo.

\subsection{Sons}

Os sons que ouvimos são flutuações na pressão do ar - pequenas variações da pressão atmosférica normal - causadas por objetos em vibração. O contínuo aumento e diminuição da pressão cria a chamada onda sonora, que se propaga a partir da fonte e é recebida pelos nossos ouvidos, que convertem esta variação de pressão em sinais elétricos transmitidos ao cérebro.

O registro do som é feito através de dispositivos que convertem as variações de pressão do ar em uma representação análoga chamada de sinal sonoro (analógico), que pode ser armazenado em diversos formatos (cilindros de cera, discos de vinil, fitas magnéticas). Para se manipular o som através de um computador é necessário que o sinal sonoro analógico seja convertido em uma seqüência de dígitos binários ( 0 e 1$)$, compondo assim uma representação do som chamada de sinal digital, que nada mais é do que uma lista de números representando valores discretos no tempo e na amplitude. O sinal sonoro analógico é transformado em sinal digital através de três processos [Sakane 1997] :

- amostragem: discretização do sinal analógico original no tempo;

- quantização: discretização da amplitude do sinal amostrado; e

- codificação: atribuição de códigos às amplitudes do sinal quantizado.

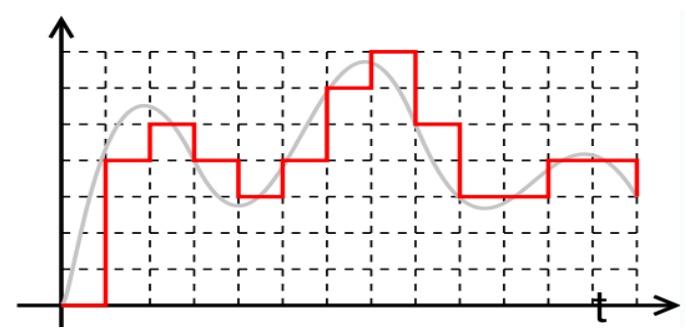

Figura 18: Exemplo de um sinal digital amostrado e quantizado

O som pode ser representado não apenas através da sua forma de onda (sinal sonoro) mas também pelo espectro associado a esta forma de onda, que revela outras propriedades do som. Uma forma de onda particular pode ser transformada no seu espectro correspondente e vice-versa, sem perda de informação. De maneira simplificada, as representações da forma de onda revelam aspectos temporais do fenômeno sonoro, como o pulso e o ritmo, enquanto representações do espectro revelam aspectos de freqüência, como melodia e harmonia. No entanto, várias técnicas de análise de sinais de áudio combinam as informações temporais e espectrais para detectar de forma mais precisa tais parâmetros musicais.

Um fragmento musical possui uma série de informações musicalmente relevantes, como por exemplo notas, acordes, timbres, ataques, ritmo e pulso, entre tantas outras. O processamento digital de sinais fornece ferramentas de análise que permitem extrair tais informações, bem como ferramentas de manipulação destes sinais, a fim de imprimir certas características musicais ou 
sonoras ao sinal. De uma maneira simplificada pode-se classificar estas informações com relação a quatro parâmetros fundamentais: intensidade, duração, altura e timbre.

A intensidade do som está relacionada à amplitude da onda sonora, definindo uma escala de valores que vai do silêncio até o som mais forte que se possa conceber, suportar, executar ou representar. Em uma partitura esta escala costuma ir do pppp (molto pianíssimo) ao ffff (molto fortíssimo) e define a dinâmica musical de um trecho; em se tratando de áudio digital o limite é dado pela representação. A relação entre a percepção subjetiva da intensidade e o dado objetivo da amplitude segue leis muito diversas, dependendo da familiaridade do ouvinte com o som, da existência de dados visuais simultâneos, entre outros.

A Figura 19 abaixo ilustra algumas medidas relacionadas à amplitude de uma onda, entre elas o pico de amplitude, a amplitude média e a amplitude RMS (root-mean-square). No caso digital, a amplitude RMS corresponde à norma Euclideana do vetor de amostras: dado um conjunto de $n$ amostras $\left\{\mathrm{x}_{1}, \mathrm{x}_{2}, . ., \mathrm{x}_{\mathrm{n}}\right\}$, a amplitude é dada pela equação:

$$
x_{r m s}=\sqrt{\frac{1}{n} \sum_{i=1}^{n} x_{i}^{2}}=\sqrt{\frac{x_{1}^{2}+x_{2}^{2}+\cdots+x_{n}^{2}}{n}}
$$

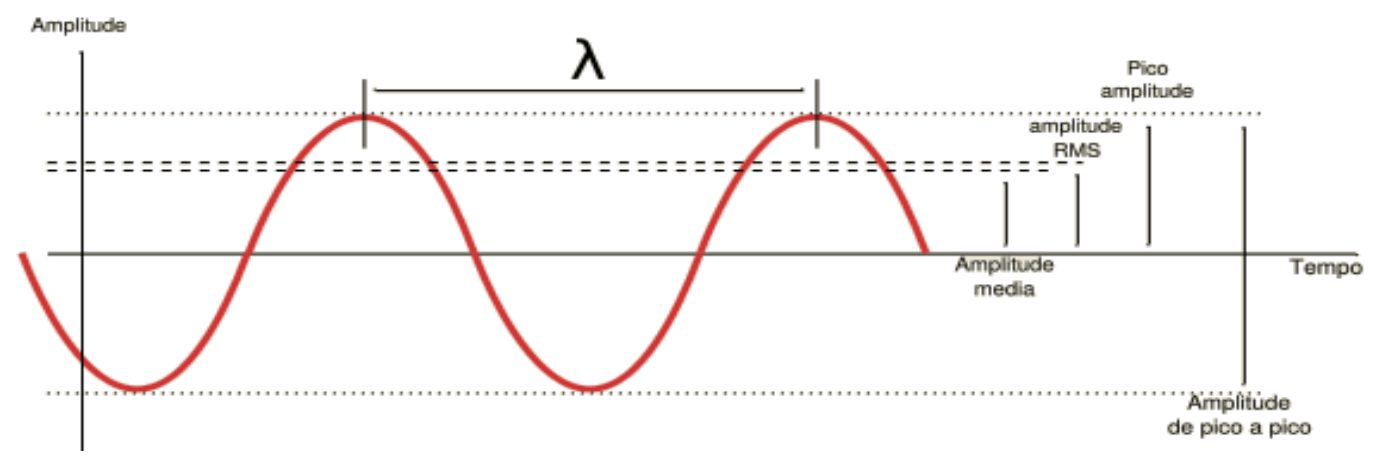

Figura 19: Medidas de amplitude de um sinal sonoro

A partir do acompanhamento da envoltória dinâmica (variação da amplitude ao longo do tempo) de um sinal sonoro podem ser identificadas várias características musicais, tais como ataques, figuras rítmicas (padrões rítmicos), observar mudanças de andamento (acelerandos e ritardandos), obter estimativas do pulso da peça, dinâmica média em um trecho musical, etc.

A Figura 20 mostra um exemplo de uma gravação de voz da palavra "frio", e da construção da envoltória dinâmica do sinal, onde a parte negativa do sinal (abaixo do eixo horizontal) foi retirada e utilizou-se os picos de amplitude para construção da envoltória [Tafner 1996].
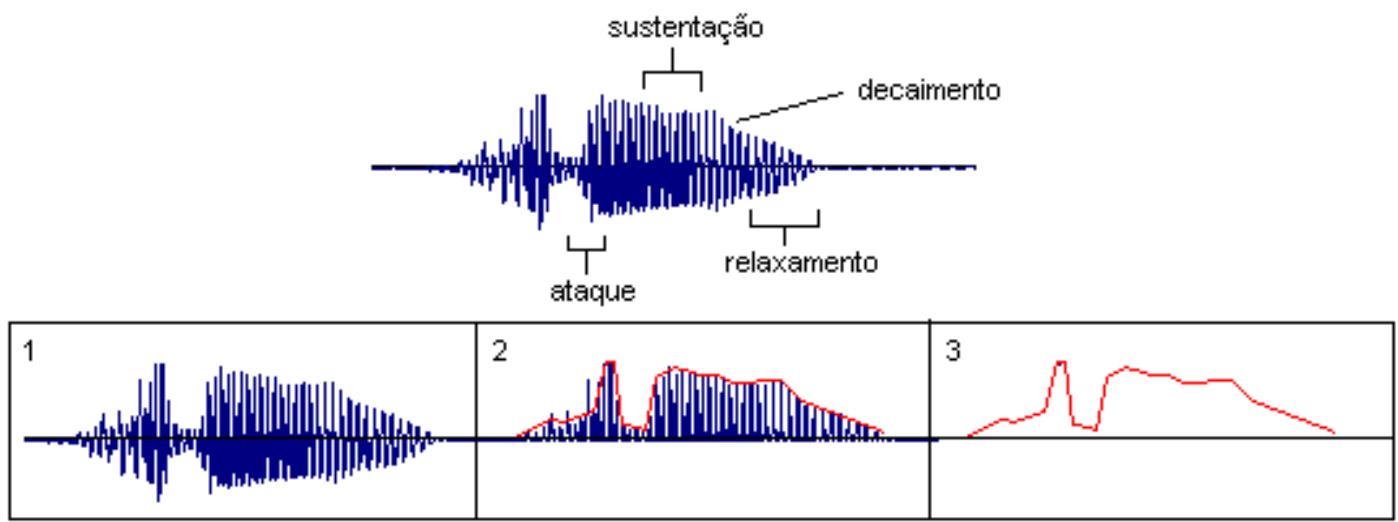

Figura 20: Envoltória gerada pelo sinal da palavra "frio" 
Ao examinar a envoltória dinâmica de um evento isolado (por exemplo uma nota de um instrumento musical) podem ser identificadas quatro partes:

- (A)taque: porção inicial em que a amplitude do som cresce;

- (D)ecaimento: quando a amplitude do som começa a diminuir;

- (S)ustentação: prolongamento do som sem grandes variações de amplitude; e

- (R)epouso (ou Relaxamento): quando o som diminui até o silêncio.

Nem todos os eventos possuem exatamente o mesmo perfil dinâmico: as siglas ADSR, ASR, AD ou AR identificam perfis dinâmicos distintos a partir das partes acima consideradas.

A determinação da duração de um evento sonoro corresponde a identificar o instante inicial e o instante final associados àquele evento. Os métodos para identificar durações dependem fundamentalmente de informações a priori sobre os eventos; por exemplo, se os mesmos possuírem ataques percussivos, é possível determinar os instantes iniciais a partir da envoltória dinâmica; se os eventos possuírem altura musical definida, com freqüência de oscilação relativamente estável, é possível determinar os instantes inicial e final a partir da análise espectral.

Um dos métodos utilizados para a detecção de ataques [Puckette, Apel, Zicarelli 1998] consiste em segmentar o sinal, obtendo para cada segmento estimativas de picos de freqüência e amplitudes correspondentes, e inferir os ataques a partir do rastreamento destes picos ao longo do tempo. Esta técnica utiliza fortemente análise espectral, fazendo manipulações sobre o segmento do sinal no tempo e sobre seu espectro de maneira relacionada à técnica de phase vocoder, sendo que os detalhes específicos podem ser encontrados em [Puckette, Brown 1998].

Assim como a técnica de detecção de ataques acima mencionada, diversos outros métodos de análise dependem da representação espectral do sinal sonoro. O espectro de um sinal representa uma maneira de decompor este sinal em componentes mais simples, geralmente funções senoidais de diversas freqüências diferentes. Estas componentes, também chamadas de parciais (ou harmônicos, conforme o contexto), além de participar de uma decomposição matemática abstrata, representam fenômenos sonoros concretos, participando da qualidade sonora do sinal como um todo, e podendo ser percebidas individualmente por ouvidos treinados. Este espectro fornece assim uma espécie de mapa das componentes freqüenciais que formam um som, a partir de uma descrição que envolve freqüências, amplitudes e fases de cada parcial.

Matematicamente, o espectro é definido a partir da teoria de Jean Baptiste Joseph Fourier (1768-1830), que mostrou como decompor um sinal no domínio do tempo em uma soma de funções ortogonais, especificamente em uma família de senos e cossenos de diferentes freqüências. Quando o sinal é perfeitamente periódico, esta soma é discreta (um somatório), também chamada de série de Fourier, e as freqüências dos parciais são múltiplos inteiros de uma freqüência fundamental, sendo os parciais chamados de harmônicos do som. Caso contrário, a soma é incontável, sendo expressa por uma integral, chamada de Transformada de Fourier, cuja teoria mais geral engloba o caso periódico [Fornari 2003].

No caso de sinais digitais utiliza-se o conceito da Transformada Discreta de Fourier (DFT Discrete Fourier Transform), bem como um algoritmo particular e eficiente de calcular a Transformada de Fourier, chamado de Transformada Rápida de Fourier (FFT - Fast Fourier Transform). A Figura 21 abaixo mostra exemplos de gráficos gerados a partir de dois instrumentos musicais específicos. Os gráficos representam, para cada instrumento, um trecho da forma de onda (amplitude em função do tempo) e o espectro resultante da aplicação da FFT no sinal original [Wuensche 2005]. 


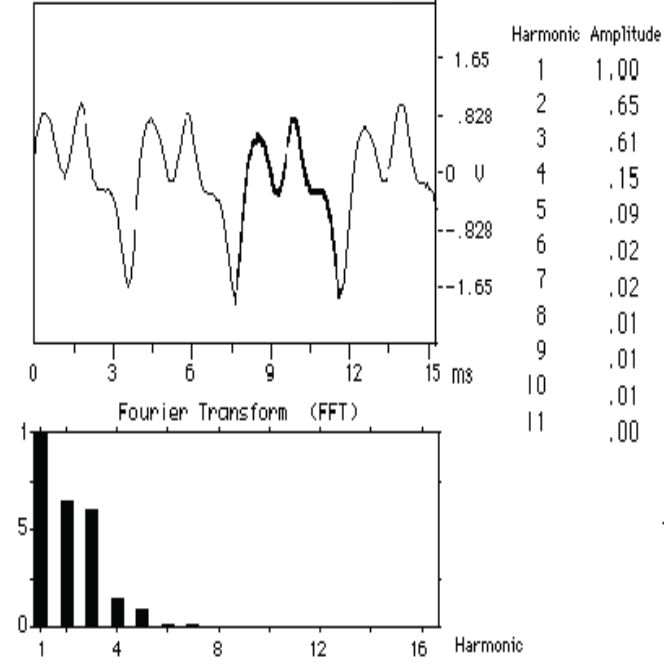

(a) flauta

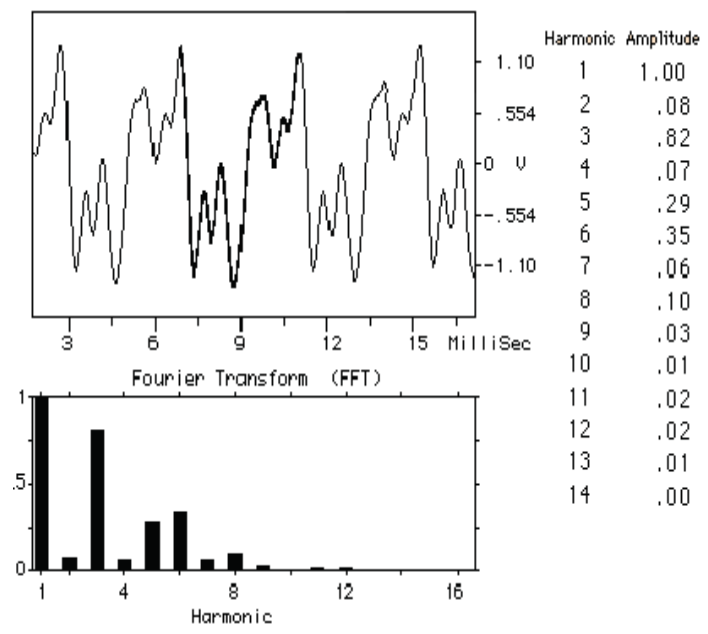

(b) clarinete

Figura 21: (a) Exemplo de onda gerada por uma flauta (nota $\mathrm{Si}_{4}-247 \mathrm{~Hz}$ ) com seu respectivo espectro e (b) exemplo de onda gerada por um clarinete (nota $\left.\mathrm{Bb}_{3}-233 \mathrm{~Hz}\right) \mathrm{com}$ seu respectivo espectro

A partir dos espectros sonoros é possível determinar a altura musical de um som, quando esta existir. A altura musical refere-se à impressão subjetiva associada à freqüência dos sons, e está associada a uma escala convencional de valores que vai dos sons graves aos sons agudos. Especialmente em sons gerados por instrumentos melódicos ou pela voz é comum observar uma característica quasi-periódica, sendo nestes casos a altura musical determinada pela freqüência fundamental de vibração do som.

Para estimar a freqüência fundamental pode-se utilizar o método MLE (Maximum Likelihood Estimation) de inferência estatística [Puckette, Apel, Zicarelli 1998], através de uma função positiva $\mathfrak{I}(f)$ onde $f$ é a freqüência. A presença de picos do espectro na freqüência $f$ ou próximo a múltiplos inteiros de $f$ aumenta a função $\mathfrak{I}(f)$ da seguinte forma:

$$
\mathfrak{J}(f)=\sum_{i=0}^{k} a_{i} t_{i} n_{i}
$$

onde $k$ é o número de picos do espectro, $a_{i}$ é um fator dependente da amplitude do $i$-ésimo pico, $t_{i}$ representa o quão próximo o i-ésimo pico está de algum múltiplo inteiro de $f$ e $n_{i}$ varia conforme a proximidade do pico em relação aos primeiros harmônicos de $f$ ou aos harmônicos de ordem mais alta. A técnica permite a obtenção de estimativas de altura monofônicas (quando há apenas uma nota) e também polifônicas (várias notas simultâneas). A estimativa de altura monofônica é dada pela freqüência $f$ que possui o maior valor de $\mathfrak{I}(f)$, enquanto as estimativas de altura polifônicas são dadas por sucessivos valores de $f$ que possuam maior valor de $\mathfrak{I}(f)$ que não sejam nem múltiplos nem submúltiplos das freqüências $f$ anteriores [Puckette 1998].

Sons complexos, incluindo acordes e ruídos, possuem componentes de altura que não estão restritas a uma única série harmônica, sendo o espectro do som a representação usual da distribuição de energia no âmbito das freqüências. A partir da análise do espectro é possível identificar outras características sonoras além da altura, como o espalhamento ou a concentração de energia em diversas bandas de freqüência, ou variações contínuas no espectro, como glissandos.

O timbre, informalmente falando, é a qualidade do som que permite identificar as qualidades intrínsecas que caracterizam um som, possibilitando o reconhecimento do instrumento que o 
produz. Várias propriedades físicas entram na determinação de um timbre, como por exemplo o modo de excitação, distribuição de formantes e modo de ressonância. Várias características que estão relacionadas ao timbre podem ser identificadas a partir do espectro e da envoltória dinâmica, ou mais precisamente da evolução dinâmica do espectro sonoro. Pode-se determinar a partir da evolução do espectro se um timbre é harmônico (possui energia concentrada em uma série harmônica) ou inarmônico, se está associado a uma envoltória do tipo ataque-ressonância, como variam seus parciais, etc.

\subsection{Imagens}

Existe uma similaridade entre o processo de percepção de áudio e vídeo, que se dá basicamente através de três elementos principais: um estímulo externo, um receptor apropriado e um transdutor. $\mathrm{Na}$ percepção dos fenômenos acústicos, a variação de pressão do ar é captada pelo tímpano, transmitida até os nervos auriculares que convertem esta informação, que por sua vez é levada para o córtex cerebral. Na visão, o estímulo é a luz, o receptor é o olho e o transdutor a retina, que converte as mudanças físicas causadas pelo estímulo em fenômenos eletroquímicos no cérebro.

A luz é percebida como um espectro de cores integrado em um período de tempo, e não como formas de onda individuais; em contrapartida, o som é percebido no tempo, e não como um espectro estacionário no domínio da freqüência. Ainda assim, ambos podem ser representados de modo similar pelo ferramental matemático de processamento de sinais, com a diferença que o som é representado por um sinal unidimensional, enquanto a imagem é representada bi- ou tridimensionalmente [Ruschioni 1999].

Etimologicamente, a palavra imagem (do latim imago) significa representação visual de um objeto. Do ponto de vista computacional uma imagem plana pode ser representada por uma matriz onde cada entrada representa um ponto visual através de parâmetros que determinam cor ou luz. Todas as técnicas computacionais destinadas à criação de imagens artificiais a partir de modelos matemáticos e geométricos são chamadas de técnicas de síntese de imagens. A Figura 22 ilustra uma visão geral das operações de síntese, processamento e análise de imagens, estando a análise ligada à obtenção de informações simbólicas ou conceituais, e o processamento à manipulação das imagens geradas.

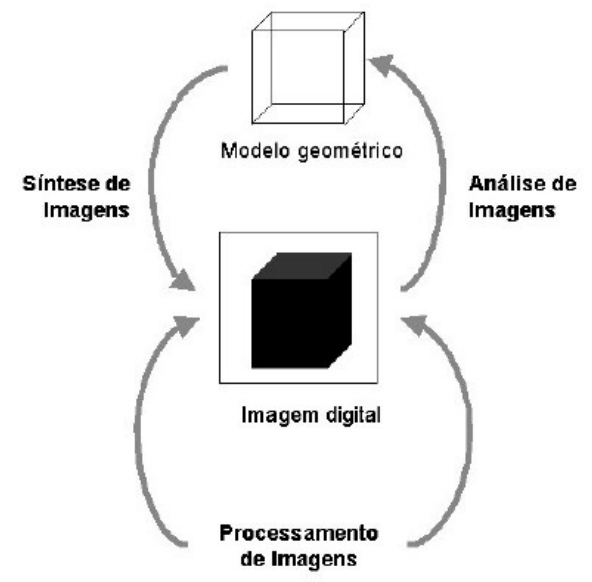

Figura 22: Diagrama da análise, processamento e síntese de imagens

A síntese de imagens por computador pode ser feita de inúmeras maneiras, podendo produzir imagens estáticas ou em movimento (vídeo), com padrões geométricos em 2D ou 3D, caracteres de texto ou imagens mais complexas, como mapas ou paisagens. 
Técnicas de síntese de imagem que produzem gráficos em duas dimensões (2D) podem combinar bitmaps (matrizes de pixels que representam pontos de cor), textos (definidos por uma fonte, cor, posição), modelos geométricos (ou vetoriais, onde são usadas primitivas geométricas, como pontos, linhas, curvas e polígonos, baseadas em equações matemáticas para representar as imagens), entre outros. Estas componentes podem ser modificadas e manipuladas por transformações geométricas bi-dimensionais como a translação, rotação ou mudança de escala. Os modelos de síntese de imagem em 2D trabalham com o conceito de camadas, permitindo o posicionamento relativo de objetos através de sobreposições e transparências. Gráficos em 2D ainda são muito utilizados em jogos de computadores, pois oferecem recursos flexíveis para controle das imagens geradas através de métodos computacionalmente muito eficientes.

Técnicas de síntese de imagens 3D (também chamadas de técnicas de renderização) geram normalmente imagens 2D com características tri-dimensionais, tais como profundidade e perspectiva. As técnicas de Síntese por Simulação possuem um enfoque baseado em conceitos físicos, incorporando modelos tanto de objetos quanto de leis óticas e serão abordadas em mais detalhe. Outras técnicas não se prendem a modelos físicos, mas implementam métodos que têm como único objetivo gerar imagens próximas da realidade, através de transformações (geométricas, de visualização), matriciação, determinação de visibilidade, tonalização (iluminação), emulação de sombras, reflexões, efeitos de transparência e refração, e são chamadas de técnicas de Síntese por Emulação [Santos 1994].

As técnicas de Síntese por Simulação mais utilizadas são: rasterização, ray tracing, ray casting e radiosidade [Watt 2000].

A rasterização faz a conversão de primitivas geométricas em conjuntos de pixels. Estas primitivas dependem do escopo em questão, podendo ser segmentos de retas ou curvas, polígonos, etc. Este modelo utiliza técnicas específicas para a escolha dos pixels que corresponderão à cada primitiva, e por serem estas operações muito freqüentes, cada algoritmo utilizado deve ser o mais eficiente possível para que o desenho das diversas primitivas que compõem a cena seja realizado no menor tempo possível.

Os métodos de ray tracing calculam a imagem da cena pela simulação da forma como os raios de luz percorrem o seu caminho no mundo real. Os raytracers (por exemplo POV-Ray e RADIANCE) são programas de simulação de iluminação que sintetizam imagens a partir de modelos geométricos tridimensionais de espaços físicos.

O método de ray casting é semelhante ao ray tracing: calcula-se a contribuição de cor e intensidade obtida para cada pixel atingido por um raio de luz, utilizando algoritmos mais simples, que necessitam de menos recurso computacional, mas produz conseqüentemente resultados menos precisos.

O método da radiosidade, também conhecido como Iluminação Global, simula as trocas difusas de radiação entre os objetos de uma cena, tendo por objetivo o cálculo da iluminação e do sombreamento em cenas onde predominam superfícies refletoras difusas, sendo que o cálculo deriva das trocas de radiação térmica entre superfícies (transmissão de calor), adaptadas ao domínio visual.

Sintetizadores de vídeo realizam a síntese de imagens em tempo real, podendo fornecer uma grande variedade de resultados com manipulações puramente eletrônicas, sem possuir uma entrada de vídeo tradicional (como uma câmera). Um conceito correlato é o de instrumento visual [Collopy 1999], como analogia ao instrumento musical, que corresponde a um sintetizador de vídeo que responde a controles interativos, podendo ser operado por uma pessoa, um software, etc. Um destes instrumentos visuais é o GEM [Danks 1997], que utiliza a biblioteca para gráficos e modelagem 3D chamada OpenGL (Open Graphics Library). Esta biblioteca fornece um conjunto de comandos que permitem a especificação de objetos geométricos em duas ou três dimensões, além de comandos 
que controlam o modo como estes objetos são renderizados no buffer de imagem. O OpenGL é uma ferramenta portável e que possui uma performance melhor do que a performance típica de um ray tracer [Lima 1999].

Dentro do contexto deste trabalho, que utiliza o GEM para a síntese de imagens, o foco está na construção de uma seqüência de imagens a partir da descrição dos elementos que compõem uma cena tridimensional. Uma cena tridimensional é usualmente descrita através de três tipos de elementos: objetos, fontes de luz e câmeras.

Os objetos que compõem uma cena possuem atributos geométricos (forma, tamanho, posição) e atributos óticos (cor, transparência, espelhamento, textura, etc), podendo desta forma ser descritos por uma escolha apropriada de parâmetros para a representação destes atributos.

A forma do objeto pode ser dada, por exemplo, por uma figura geométrica abstrata ou por uma malha de pontos e linhas, entre outras descrições possíveis. A superfície do objeto pode ser recoberta pela projeção de uma imagem ou vídeo, pode ser espelhada ou possuir uma cor, que pode ser uniforme, ter algum tipo de padrão, textura ou dégradé.

As dimensões com as quais se caracteriza um objeto dependem da forma do objeto: o tamanho de um círculo é dado por seu raio, enquanto o de um paralelepípedo é dado pela altura, largura e profundidade. Se um objeto possui articulações ou é composto por vários objetos menores, então suas dimensões se relacionam ao posicionamento das articulações e ao tamanho das partes.

A posição do objeto em um cenário $3 \mathrm{D}$ pode ser representada pelos valores de suas coordenadas nos eixos $\mathrm{X}, \mathrm{Y}$ e Z. A posição também pode ser representada indiretamente, por exemplo através de operações de translação e rotação, que facilitam a descrição de movimentos do objeto na cena.

Como todos estes parâmetros podem variar dinamicamente, a movimentação e a evolução de um objeto podem ser determinadas pelos parâmetros anteriores, como funções do tempo. Na interação entre dois objetos outras características podem ser consideradas, como por exemplo a elasticidade ou a materialidade destes objetos (se eles podem ou não se sobrepor).

Dois sistemas de cores bastante utilizados na representação computacional de imagens são o RGB (Red, Green, Blue) e o HSV (Hue, Saturation, Value). O sistema RGB representa as cores com base na sua decomposição em componentes de intensidades de vermelho, verde e azul, e pode ser visto como um espaço de representação tridimensional, onde os três eixos correspondem às intensidades citadas. O sistema HSV representa as cores com base no matiz, saturação e brilho, sendo que o matiz define o comprimento de onda dominante na cor, a saturação indica a quantidade de matiz acrescentada à cor e o componente de brilho (ou intensidade) representa a quantidade de luz presente na cor. A iluminação de um objeto é um fator importante relacionado à cor, que permite entre outros a obtenção de efeitos como sombreamento, profundidade e movimentação.

Outros elementos importantes na descrição de uma cena são: a composição do cenário, a iluminação externa, a posição da câmera (ponto de vista de quem observa a cena), a cor do fundo, a quantidade e tipo dos objetos em cena, se os objetos estão sujeitos a alguma lei externa (e.g. gravidade), entre outros.

\subsection{Entre Som e Imagem}

Independentemente da escolha feita em relação a que tipos de objetos gráficos serão sintetizados, ao se controlar imagens a partir de informações retiradas do áudio um problema evidente é a tradução dos parâmetros musicais em parâmetros visuais. De fato, parece ser difícil encontrar qualquer elemento intrínseco que seja comum à música e a uma seqüência de imagens em movimento além do próprio tempo que serve de suporte para os dois acontecimentos. 
Qualquer associação entre altura musical e, digamos, tamanho, posição ou cor de um objeto, será arbitrária, subjetiva. A criação de tais associações, bem como as possíveis justificativas, para elas corresponde a problemas estéticos, que fogem totalmente ao escopo deste trabalho. Trata-se aqui apenas de viabilizar a criação de tais associações, ou melhor, de formalizar o processo de estabelecimento destas associações.

Neste contexto específico, parece natural propor que a tradução entre som e imagem seja intermediada por um universo de representação abstrato, que não seja nem musical nem visual a priori, mas que permita o estabelecimento de conexões diversas entre estes dois universos.

A partir da observação de características elementares do áudio, tais como envelope dinâmico, altura e detecção de início de eventos sonoros, parece natural representar tais características como sinais discretos (funções do tempo) com valores num intervalo arbitrário [0...1], ou alternativamente como disparos (bangs). Essas duas modalidades de representação permitem um mapeamento convencional de parâmetros sonoros que admitam uma ordem linear, tais como freqüência (que varia entre $20 \mathrm{~Hz}$ e $20 \mathrm{KHz}$ ) ou amplitude (para um sinal de áudio de $\mathrm{N}$ bits existem $2^{\mathrm{N}}$ valores distintos), em sinais variando no intervalo [0...1], bem como a representação, através de disparos, de eventos pontuais (inícios de notas ou eventos percussivos).

Por outro lado, tamanho e posição de objetos gráficos, dentro de limites razoáveis determinados pela janela de projeção, também podem ser mapeados neste intervalo [0...1] arbitrário; cores no sistema RGB podem ser representadas por 3 valores entre [0...1]; e disparos podem ser úteis para sinalizar o início de uma seqüência qualquer de movimentos de um objeto, a fim de estabelecer uma trajetória no espaço.

Desta maneira, na implementação que será descrita no próximo capítulo, a comunicação entre objetos de análise de áudio e objetos de síntese de imagens será feita através de sinais discretos de controle que variam no intervalo [0...1] ou através de disparos. Cada valor produzido por um objeto de análise, bem como cada parâmetro de controle de síntese de imagem, devem pertencer a uma destas duas categorias, e qualquer conexão entre saídas [0...1] e entradas [0...1] ou entre saídas bang e entradas bang é permitida, e estabelece uma relação causal entre a entrada de áudio e a síntese de imagens.

Outra questão importante a ser discutida é a relação entre as taxas de amostragem destes sinais de controle. O processamento de áudio é normalmente feito utilizando-se uma taxa de amostragem de $44.100 \mathrm{~Hz}$, que corresponde à qualidade de CD. Já a renderização de imagens em tempo-real é usualmente feita em cerca de 20 fps (quadros por segundo); outros valores comuns para a taxa de amostragem de imagens são 24 fps (cinema) e 30 fps (TV, DVD).

Dessa forma, não existe necessidade de troca de informações entre as camadas de processamento de áudio e de síntese de imagens a uma taxa maior do que aquela utilizada para a síntese de imagens. A utilização da mesma taxa de amostragem na camada de comunicação e na camada de síntese de imagens garante máximo aproveitamento dos recursos do processador e permite a manipulação de um maior número de objetos em cena. 


\section{Implementação da Biblioteca AIM}

A biblioteca AIM foi implementada utilizando-se a ferramenta Pd (Pure Data), que é um sistema para processamento em tempo-real que oferece recursos para manipulação de áudio e MIDI através de um ambiente gráfico para programação. $\mathrm{O}$ Pd foi desenvolvido originalmente por Miller Puckette e inclui o trabalho de muitos desenvolvedores, sendo um software livre distribuído sob uma licença GNU GPL. A ferramenta é multi-plataforma, completamente portável, existindo versões para Windows, IRIX, GNU/Linux, BSD e MacOS. Para este trabalho foi utilizada a versão 0.40.2-extended do Pd que contém algumas bibliotecas extras, incluindo a versão 0.90 da biblioteca GEM (Graphics Environment for Multimedia). Além das bibliotecas disponíveis, o Pd permite o desenvolvimento de objetos externos (externals) em linguagem $\mathrm{C}$, que podem ser utilizados dentro de programas em Pd.

O GEM foi originalmente escrito por Mark Danks para IRIX/Windows e foi adaptado por outros desenvolvedores para Linux e MacOS, sendo mantido atualmente por Iohannes M. Zmoelnig. Esta biblioteca utiliza os conceitos do Open $G L$ e fornece objetos Pd para renderização de cenas em três dimensões, que são visualizadas em uma janela separada.

A facilidade de comunicação entre objetos de manipulação de áudio e MIDI (nativos do Pd ou de suas bibliotecas) e objetos para manipulação de elementos gráficos (objetos GEM) tornou natural o desenvolvimento do sistema como uma biblioteca de objetos Pd para a geração de resultados visuais de forma simples e rápida a partir de entradas musicais, bem como de objetos para geração de interfaces facilmente controláveis em tempo-real (durante uma performance, por exemplo).

Os objetos da biblioteca AIM estão divididos nas seguintes categorias: objetos para análise do áudio de entrada, objetos para síntese de imagens, objetos para síntese e processamento de sinais de controle e objetos para geração de interfaces, além de um objeto de controle central (aim.control), cuja função será detalhada a seguir. Cada objeto AIM possui um cabeçalho contendo sua categoria e resumos, em inglês e português, de sua funcionalidade e forma de utilização.

\subsection{Objeto de controle central}

O objeto de controle central (aim.control) possui várias funções independentes e é responsável por gerenciar certas estruturas e parâmetros gerais do sistema, sendo necessário em todo programa Pd que utilize a biblioteca AIM.

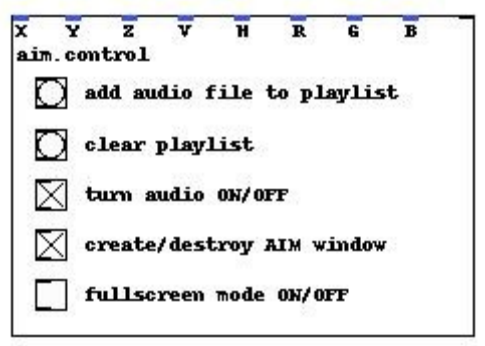

Figura 23: O objeto aim.control

Em relação à entrada de som, o sistema AIM permite o uso de microfone (que é a opção default) ou de arquivos de áudio, que são gerenciados através de uma playlist. A execução da playlist é feita de forma circular, sendo que a entrada volta imediatamente a ser o microfone quando a playlist está vazia. A entrada (inlet) mais à direita do objeto de controle recebe três tipos diferentes de mensagens para manipulação da playlist: 
- nome1, nome2, ..., nomeN: mensagens de texto formadas por nomes de um ou mais arquivos de áudio (separados por vírgulas) inserem estes arquivos no final da playlist;

- bang: abre uma janela de diálogo para a seleção de um arquivo de áudio que será acrescentado ao final da playlist;

- clear: esvazia a playlist.

As duas últimas opções (bang e clear) também podem ser acessadas através da interface gráfica do objeto (vide Figura 23).

Em relação à síntese de imagens, este objeto cria a janela GEM para visualização do resultado gráfico, permitindo também o uso em todo o monitor (modo fullscreen ou tela cheia). Além disso, o objeto possui diversas entradas (compatíveis com sinais de controle [0...1]) para definir a posição da câmera (entradas identificadas por X, Y e Z), a direção da iluminação externa, através dos ângulos de elevação e azimute (entradas identificadas por $\mathrm{V}=$ vertical e $\mathrm{H}=$ horizontal), e a cor do fundo de cena (em padrão RGB, nas entradas assim identificadas). Estes parâmetros podem ser modificados continuamente durante a performance.

Como explicado no final do capítulo anterior, a comunicação entre os objetos da biblioteca AIM pode ser feita de duas formas: ou através de sinais discretos de controle que variam no intervalo [0...1], ou através de disparos. A fim de facilitar a utilização destes objetos, as entradas e saídas que passam sinais discretos [0...1] são identificadas pela cor azul, enquanto as entradas e saídas que passam disparos são identificadas pela cor vermelha. Para garantir a consistência das conexões entre objetos AIM, cada entrada passa por uma verificação de consistência de tipo: se a mensagem recebida não é compatível com o tipo esperado, é gerada uma mensagem de erro na janela principal do Pd. Os objetos auxiliares responsáveis por estas verificações de consistência de tipo são aim._check01 e aim._checkbang.

\subsection{Objetos de análise de áudio}

Os objetos de análise de áudio extraem informações da entrada fornecida para o sistema (arquivos de áudio ou microfone), e não possuem entradas pois compartilham a mesma entrada de áudio gerenciada pelo objeto aim.control. Suas saídas (outlets) podem fornecer sinais de controle [0...1] ou bangs, e são sinalizadas através do código de cores associados a estes dois tipos.

A Figura 24 abaixo é um exemplo de um programa simples em Pd utilizando a biblioteca AIM, e ilustra a utilização de dois objetos de análise de áudio para a geração de sinais de controle para um objeto de síntese de imagem. Ao objeto aim.control está ligada uma mensagem para inicializar a playlist com um arquivo de áudio. As entradas e saídas azuis transmitem sinais de controle [0...1] à taxa de 20 valores por segundo, conforme discussão no final do capítulo anterior. 

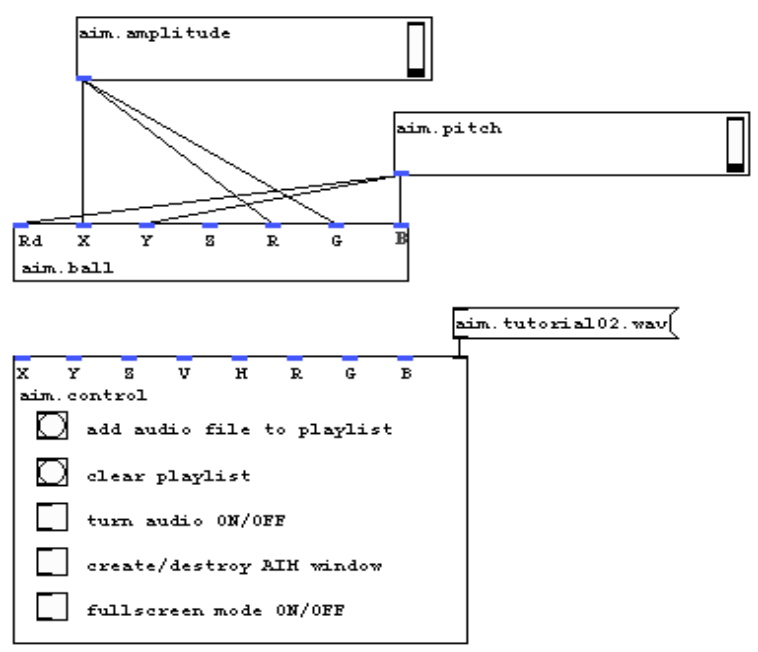

Figura 24: Exemplo de um programa em Pd utilizando a biblioteca AIM

A extração da envoltória de amplitude RMS (root-mean-square) é feita pelo objeto aim.amplitude, e fornece valores instantâneos de amplitude no intervalo [0...1]. Este objeto oferece ainda a possibilidade de suavização dos valores de amplitude em intervalos de tempo definidos pelo usuário, através de um argumento numérico. Assim, por exemplo, ao se criar o objeto “aim.amplitude 10" os valores gerados representarão médias de amplitude RMS dos dez segundos anteriores. Como todos os objetos AIM são patches Pd, eles podem ser abertos e seus detalhes de implementação podem ser visualizados em uma janela separada. Internamente, o objeto aim.amplitude permite a visualização dos valores calculados na forma de um gráfico.

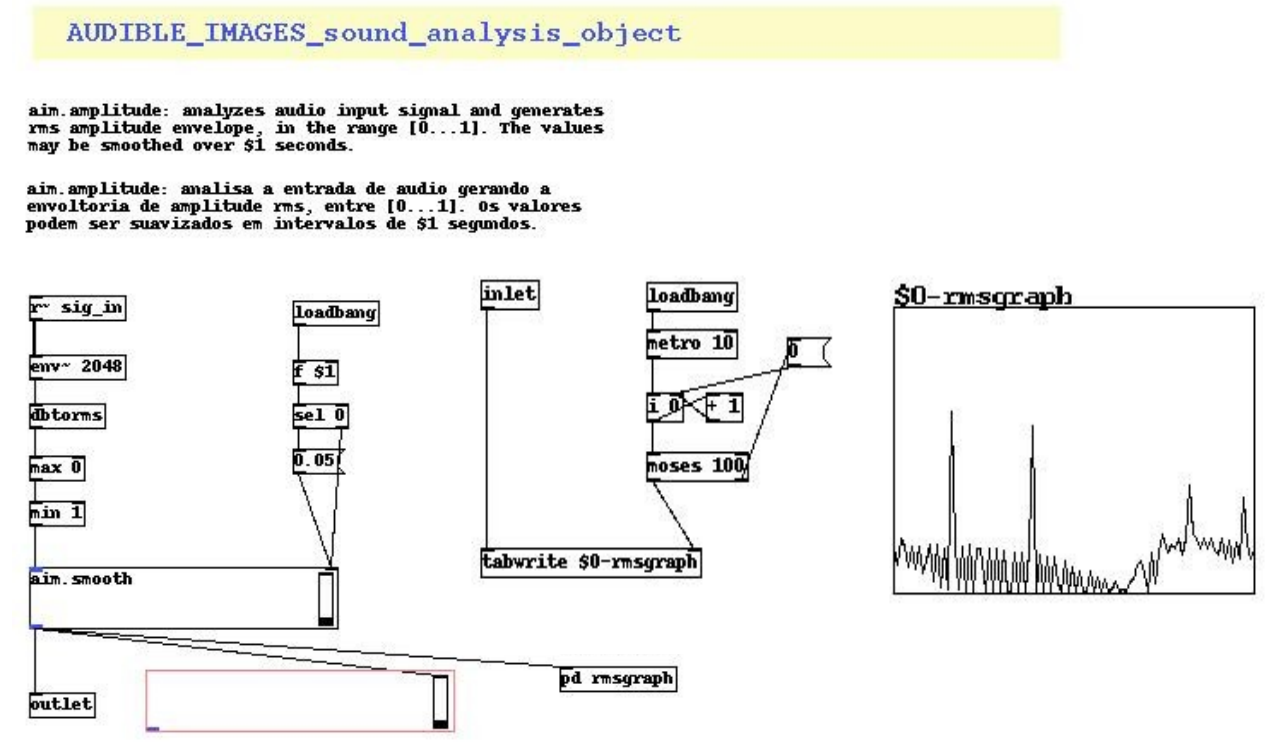

Figura 25: Implementação do objeto aim.amplitude

Observe que o objeto aim.amplitude utiliza um outro objeto da biblioteca AIM, chamado aim.smooth, que será descrito na seção 3.4. O retângulo vermelho abaixo do objeto aim.smooth é um canvas que define a aparência externa do objeto (vide Figura 25), e inclui a coloração azul da saída e um pequeno slider vertical para visualização dos valores da saída. Além disso, o objeto aim.amplitude utiliza o objeto env $\sim$ (nativo do Pd) para o cálculo da amplitude RMS em segmentos 
de 2048 amostras (46,4 milissegundos).

O objeto aim.pitch faz a detecção da altura musical, em uma escala de valores [0...1] que vai de sons graves aos sons agudos, produzindo um sinal de controle que representa a curva melódica do sinal de entrada. Especificamente, foi adotada a faixa de valores MIDI de 46 a 86 (116,5Hz a $1174,7 \mathrm{~Hz})$, em parte por limitações da técnica de análise utilizada e em parte em função dos exemplos de arquivo utilizados nos experimentos. Assim como no objeto aim.amplitude, essas informações também podem ser suavizadas em intervalos de tempo definidos pelo usuário. Seu componente interno principal é o objeto fiddle [Puckette 1998], que faz uma análise espectral do sinal de entrada e produz, entre outros, a estimativa da altura musical e da amplitude do trecho analisado, além de informações complementares como os picos de freqüência correspondentes aos parciais mais proeminentes. Para estimar a freqüência fundamental o fiddle $\sim$ utiliza o método MLE (Maximum Likelihood Estimation) de inferência estatística citado no Capítulo 2.

Para a detecção de início de notas ou eventos percussivos (ataques) na entrada de áudio foi desenvolvido o objeto aim.attack, que gera na saída um disparo (bang) a cada novo evento. $\mathrm{O}$ processamento do sinal de entrada para a detecção de ataques está embutido no objeto fiddle $\sim$, que utiliza em sua análise uma técnica de acompanhamento do envelope dinâmico não apenas do sinal como um todo, como também de cada faixa de freqüência analisada pelo espectro, permitindo a detecção de inícios de notas que não sejam acompanhadas de variações abruptas de dinâmica. A saída do aim.attack é identificada pela cor vermelha, por ser do tipo bang, conforme explicação anterior.

Outros dois objetos de análise de áudio extraem informações relativas a densidades de informação no sinal da entrada. O objeto aim.timedensity faz a análise da densidade temporal de eventos através da contagem do número de ataques por segundo na entrada de áudio, enquanto o objeto aim.spectraldensity mede a concentração ou espalhamento da energia no espectro. A Figura 26 abaixo mostra o objeto aim.timedensity internamente. 


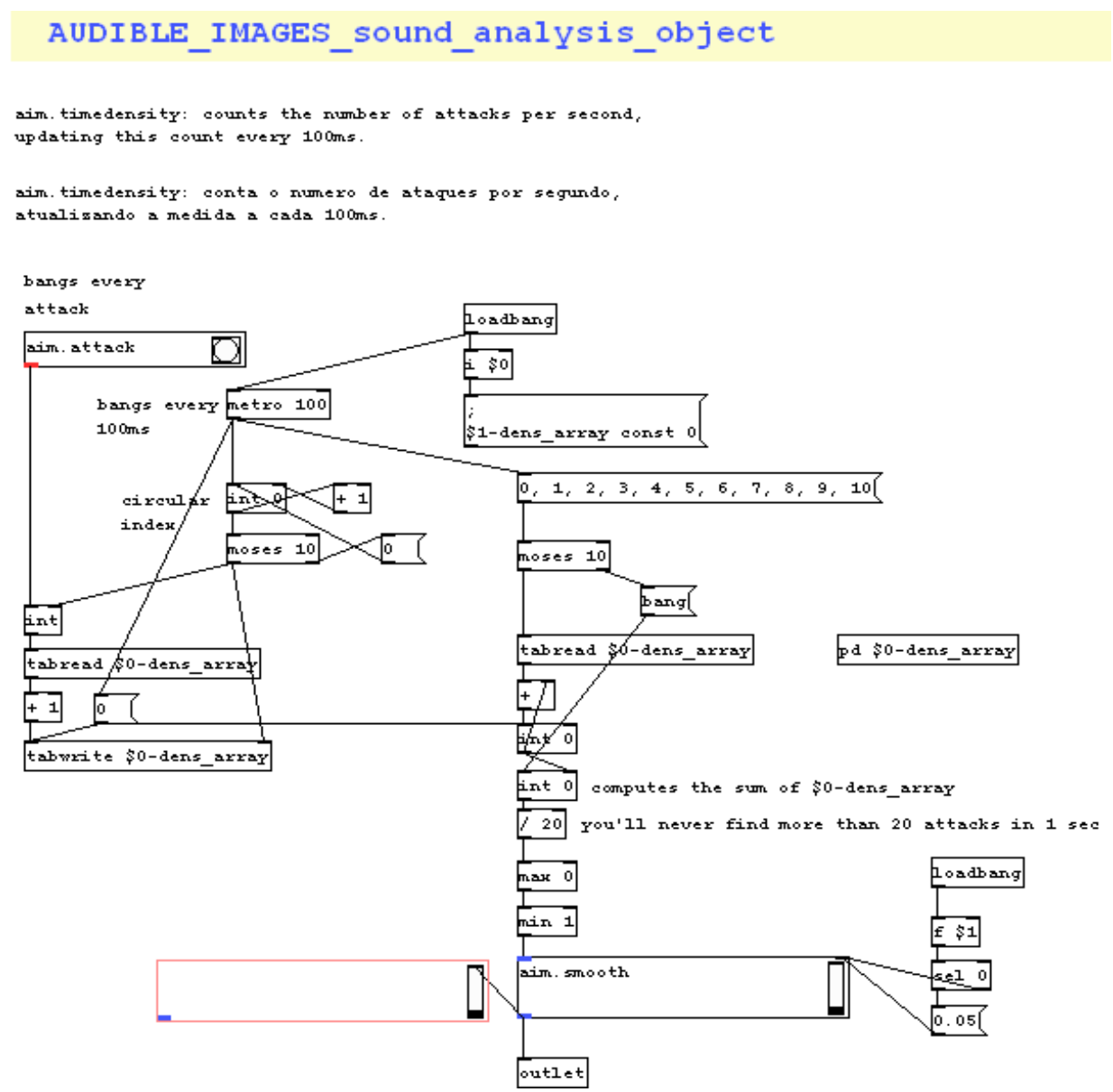

Figura 26: Patch do objeto aim.timedensity

A primeira parte deste patch (Figura 27 abaixo) mostra a utilização do objeto aim.attack para identificar os ataques no trecho de áudio analisado. A contagem de ataques é feita em subjanelas de 100 milissegundos $^{7}$ (controle este realizado pelo objeto metro), sendo os resultados parciais armazenados em um vetor de 10 posições chamado \$0-dens_array, que é percorrido circularmente para que se tenha sempre a informação atualizada do número de ataques no último segundo (10 janelas de $100 \mathrm{~ms})$. O $\$ 0$ - que antecede o nome do vetor é substituído internamente por um valor numérico que identifica univocamente aquela instância do objeto, permitindo a criação e utilização de vários objetos de mesmo nome independentes.

7 Isso garante uma atualização da medida de densidade temporal a uma taxa de 10 valores por segundo; embora esta taxa seja menor do que a utilizada pelos demais objetos AIM, ela é mais do que suficiente para a contagem de eventos temporais isolados. 


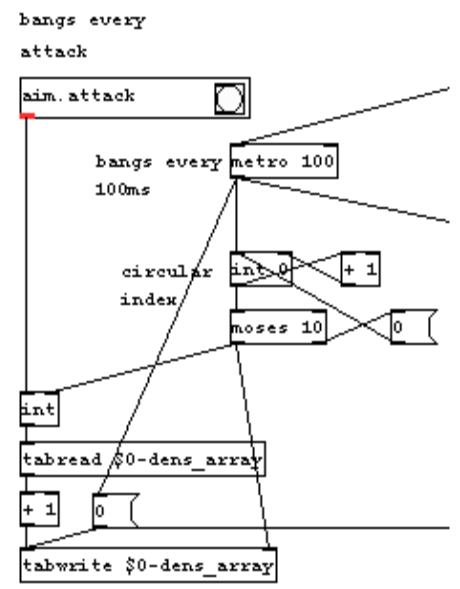

Figura 27: Primeira parte do patch do objeto aim.timedensity

A Figura 28 mostra a segunda parte do patch do objeto aim.timedensity onde os totais das 10 posições do vetor são somados compondo a informação que será mapeada no intervalo [0..1] e repassada à saída do objeto. Como nos objetos anteriores, é possível definir um parâmetro de suavização na criação do objeto, que será utilizado internamente pelo objeto aim.smooth.

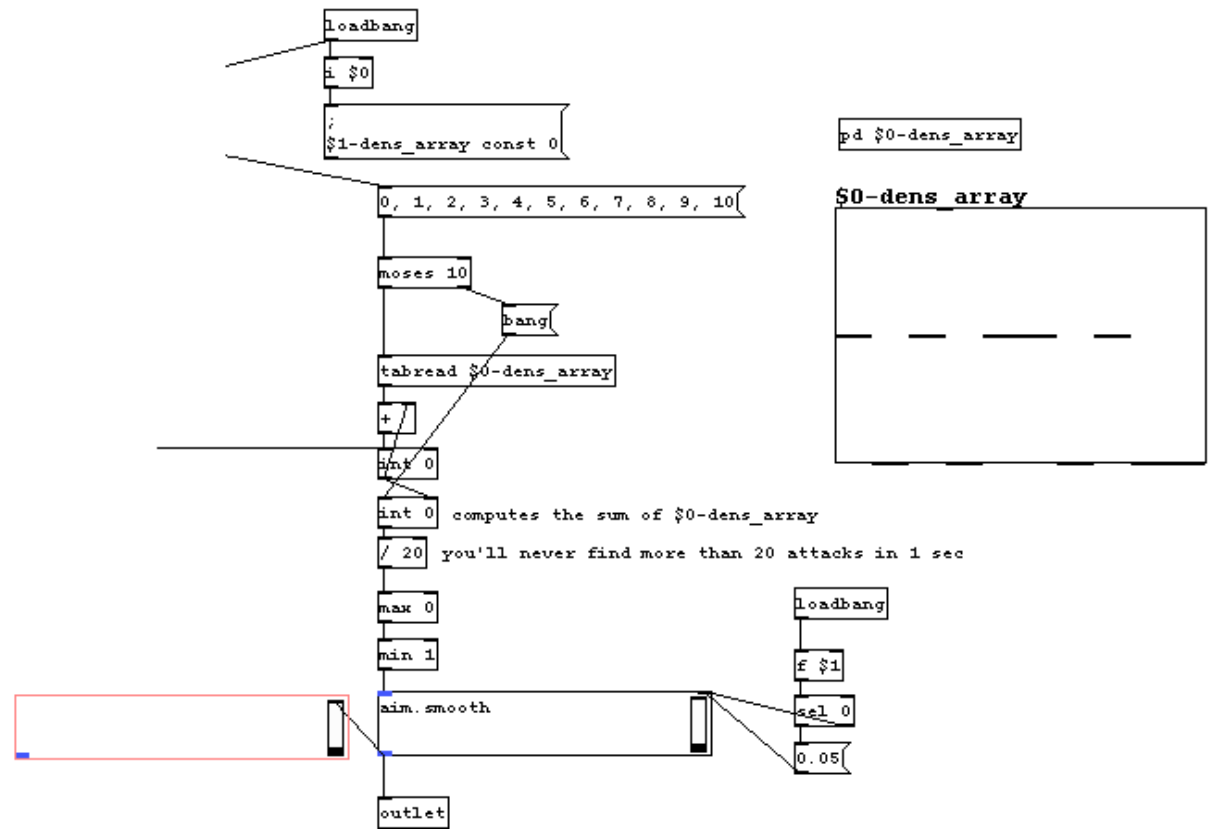

Figura 28: Segunda parte do patch do objeto aim.timedensity

O objeto aim.spectraldensity faz a análise da densidade espectral de forma semelhante ao aim.timedensity, porém ao invés de contar ataques, contam-se o número de picos espectrais proeminentes em cada janela de $50 \mathrm{~ms}$, utilizando o objeto fiddle como fonte principal de informações. Sua escala de [0...1] representa, no extremo inferior, sinais com apenas um pico espectral proeminente (sinais senoidais), e no extremo superior sinais com grande número de picos espectrais proeminentes (entre eles o ruído branco e outros ruídos).

Ainda na categoria de objetos de análise de áudio tem-se o objeto aim.register (Figura 29) que classifica as notas detectadas como pertencentes ao registro grave, médio-grave, médio, médioagudo, agudo ou super-agudo, gerando um disparo na saída correspondente. 


\section{0}

Figura 29: O objeto aim.register

O disparo gerado em uma saída está associado ao início da atividade naquela banda de freqüências, e não será repetido enquanto a atividade permanecer. As regiões de classificação possuem valores limites pré-definidos, que são os valores das notas lá entre A3 e A7, podendo ser alterados através da passagem de valores MIDI como parâmetros na criação do objeto.

\subsection{Objetos de síntese de imagens}

Em relação à síntese de imagens, a biblioteca AIM possui alguns objetos simples e objetos complexos formados a partir dos primeiros. Os objetos simples são: aim.ball, aim.square, aim.bezierseagull e aim.doll.

O objeto aim.ball controla uma esfera com raio, posição e cor dados através de sete parâmetros [0...1] recebidos na entrada (um para o raio, três para posição XYZ e três para cor RGB).

O objeto aim.square, ao receber um disparo na primeira entrada (trigger), gera um quadrado (bidimensional) que se movimenta no espaço em uma trajetória linear em direção ao fundo da cena. Sua cor RGB é determinada por três entradas [0...1] e sua posição inicial é sorteada dentro de uma faixa de valores determinada por um outro parâmetro de entrada [0...1]. As Figuras 30 e 31 mostram as partes que compõem o patch do objeto aim.square.

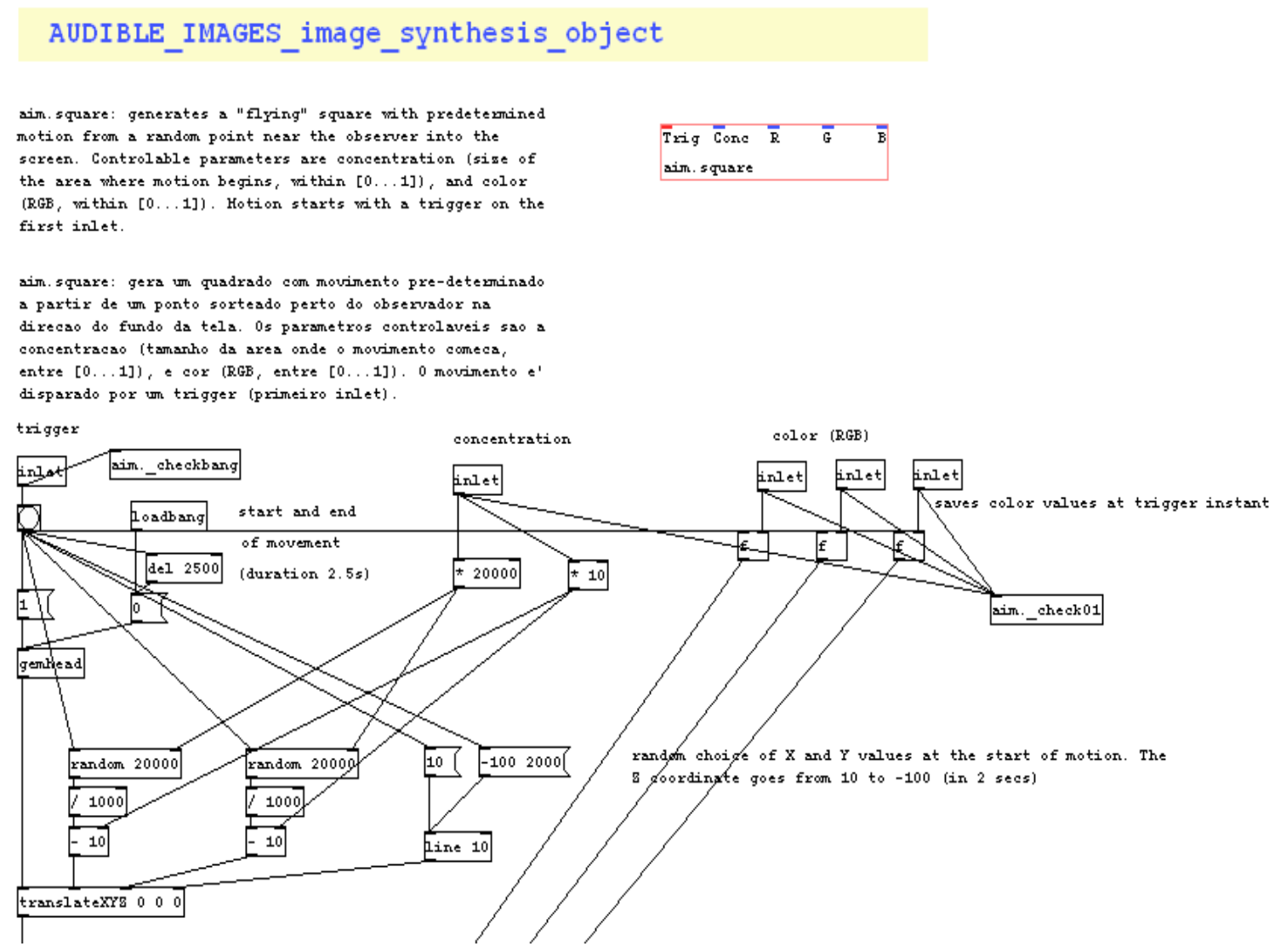

Figura 30: Primeira parte do patch do objeto aim.square 
Na Figura 30 pode-se observar os textos descritivos do objeto, o retângulo (canvas) que irá determinar o aspecto externo do objeto, as entradas do aim.square que passam pelos objetos de validação da informação recebida (aim._check01 e aim._checkbang) e objetos que manipulam as informações das entradas.

A primeira entrada é do tipo bang e dispara a geração do quadrado que existirá na tela durante sua trajetória pré-definida de 2,5 segundos (controle realizado pelo objeto $\mathrm{del}$ ).

O objeto gemhead gera uma saída chamada de gem-list, que é um tipo especial de mensagem entendida apenas pelos objetos GEM e que contém toda a informação necessária para a renderização dos objetos que estão na gem-list, neste caso, o quadrado. Pode-se ter mais de um objeto gemhead no mesmo programa de forma que os objetos conectados a eles formem gem-lists distintas.

Os objetos random geram valores aleatórios usados nas coordenadas $\mathrm{X}$ e $\mathrm{Y}$ de lançamento do quadrado, levando-se em consideração o segundo parâmetro do objeto aim.square que determina a concentração do lançamento (tamanho da área de início do movimento), parâmetro este entre [0..1]. A coordenada $Z$ vai de 10 a -100 em 2 segundos, fazendo assim com que o quadrado se movimente em direção ao fundo da tela neste período. Estes valores de coordenadas XYZ são parâmetros para o objeto GEM translateXYZ que é o responsável por transladar o quadrado.

A cor será definida pelos últimos três parâmetros [0..1] do aim.square que determinam as componentes RGB do quadrado.

A Figura 31 mostra a parte inferior do patch do objeto aim.square, onde são definidos os parâmetros para a rotação do objeto (parâmetros estes gerados de forma aleatória por objetos random). A rotação é realizada pelo objeto rotateXYZ e será aplicada ao quadrado já transladado, seguindo o fluxo da gem-list. No fim deste fluxo, está o objeto square que é quem gera efetivamente o quadrado na tela GEM e pode receber alguns parâmetros que definem, por exemplo, seu tamanho e se o quadrado será exibido preenchido (default, que corresponde à mensagem draw fill) ou apenas com as linhas de contorno (mensagem draw line).

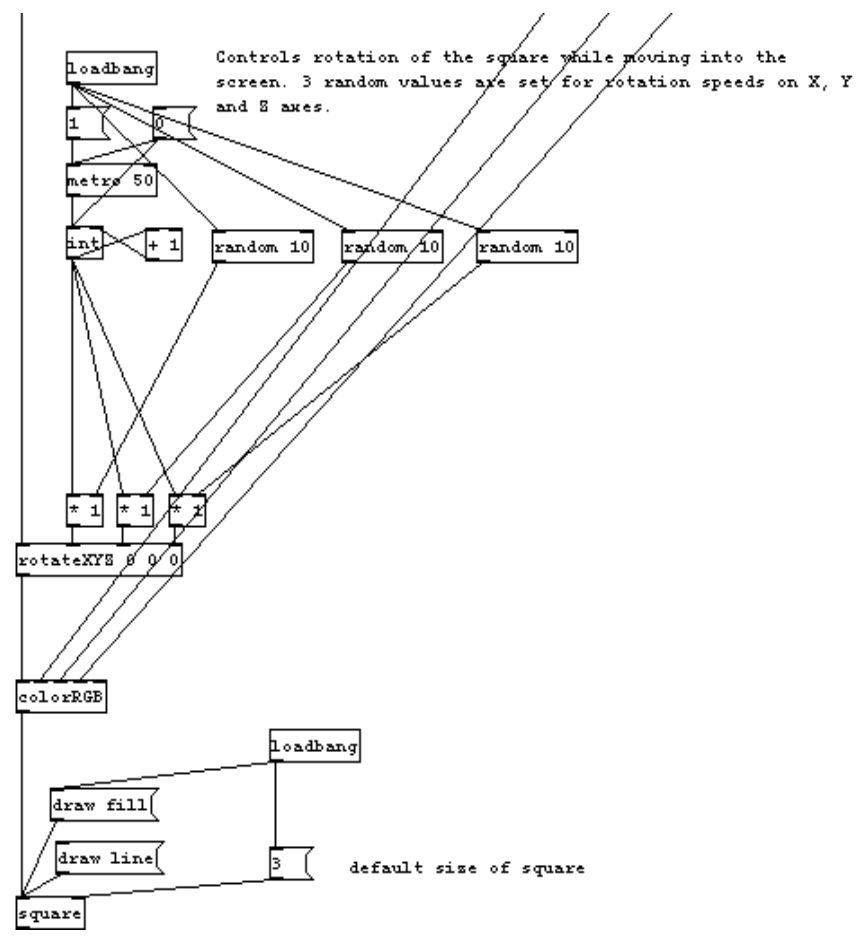

Figura 31: Segunda parte do patch do objeto aim.square 
O objeto aim.bezierseagull gera uma gaivota formada por curvas de Bezier que voa pela tela. O movimento da gaivota é circular, sendo o eixo de rotação modificado continuamente para dar a impressão de um movimento livre. Este movimento pode ser alterado por três parâmetros de entrada do tipo bang, que determinam momentos de mudança do movimento de rotação da gaivota, da concentração (raio da rotação) e das cores. O último parâmetro recebe informações [0..1] que controlam a intensidade da cor da gaivota, e funciona como um controle liga-desliga contínuo (dimmer). O patch do objeto aim.bezierseagull é mostrado na Figura 32 abaixo. Este patch é formado por vários subpatches que realizam operações específicas e seus funcionamentos serão explicados separadamente.

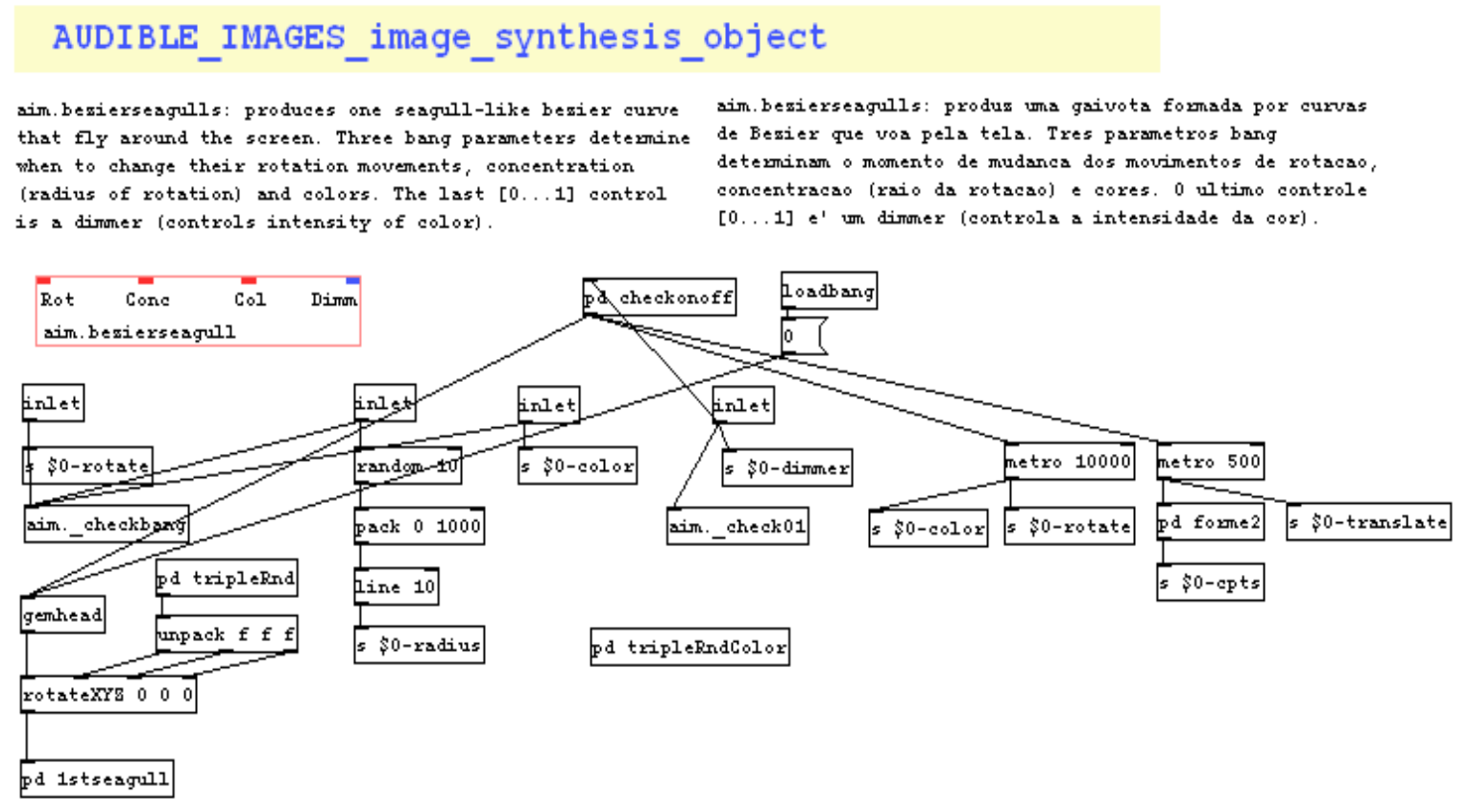

Figura 32: Patch do objeto aim.bezierseagull

O patch do objeto aim.bezierseagull possui como todos os outros um texto explicativo e o objeto canvas que determina o aspecto externo do objeto. Os valores recebidos nas entradas (mudança no movimento da rotação, concentração, cor e dimmer) são verificados pelos objetos de checagem e retransmitidos para determinados pontos dos subpatches por objetos send e receive. Estes objetos possuem nomes abreviados ( $s$ e $r$ ) e recebem como parâmetro um nome que identificará a informação enviada ou recebida. Dessa forma, por exemplo, o disparo recebido pela entrada de cor será transmitido pelo objeto $s \$ 0$-color e recebido em qualquer ponto do programa pelo objeto $r \$ 0$-color. Como citado anteriormente, o $\$ 0$ - precedendo o nome de uma variável tem a função de torná-la local àquela instância do objeto.
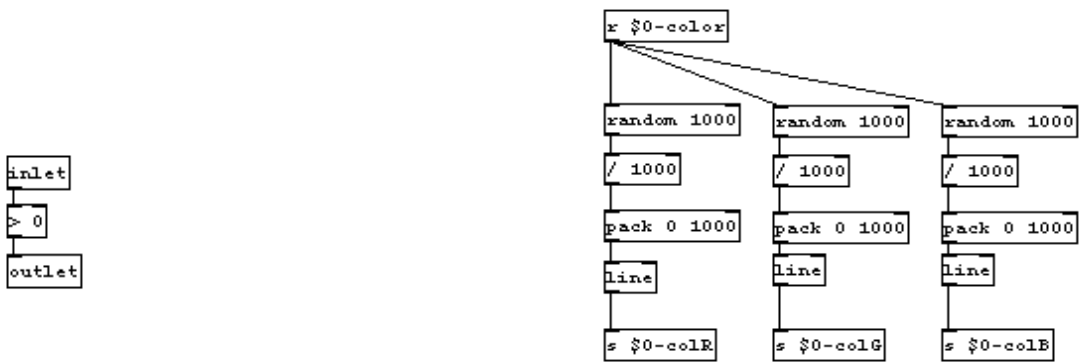

(a) Subpatch checkonoff

(b) Subpatch tripleRndColor

Figura 33: Subpatches checkonoff e tripleRndColor do objeto aim.bezierseagull 
O subpatch checkonoff mostrado na Figura 33 garante que a gaivota será gerada apenas quando algum valor estritamente positivo for recebido na entrada dimmer, a fim de impedir que sejam geradas gaivotas pretas, que seriam pouco visíveis em fundo preto e demandariam processamento desnecessário da máquina. Já o subpatch tripleRndColor gera valores aleatórios para as componentes RGB que irão compor a cor da gaivota. Para cada componente é sorteado um novo valor (pelo objeto random), que será atingido após 1 segundo através de uma transição suave dada por uma rampa linear (objeto line).

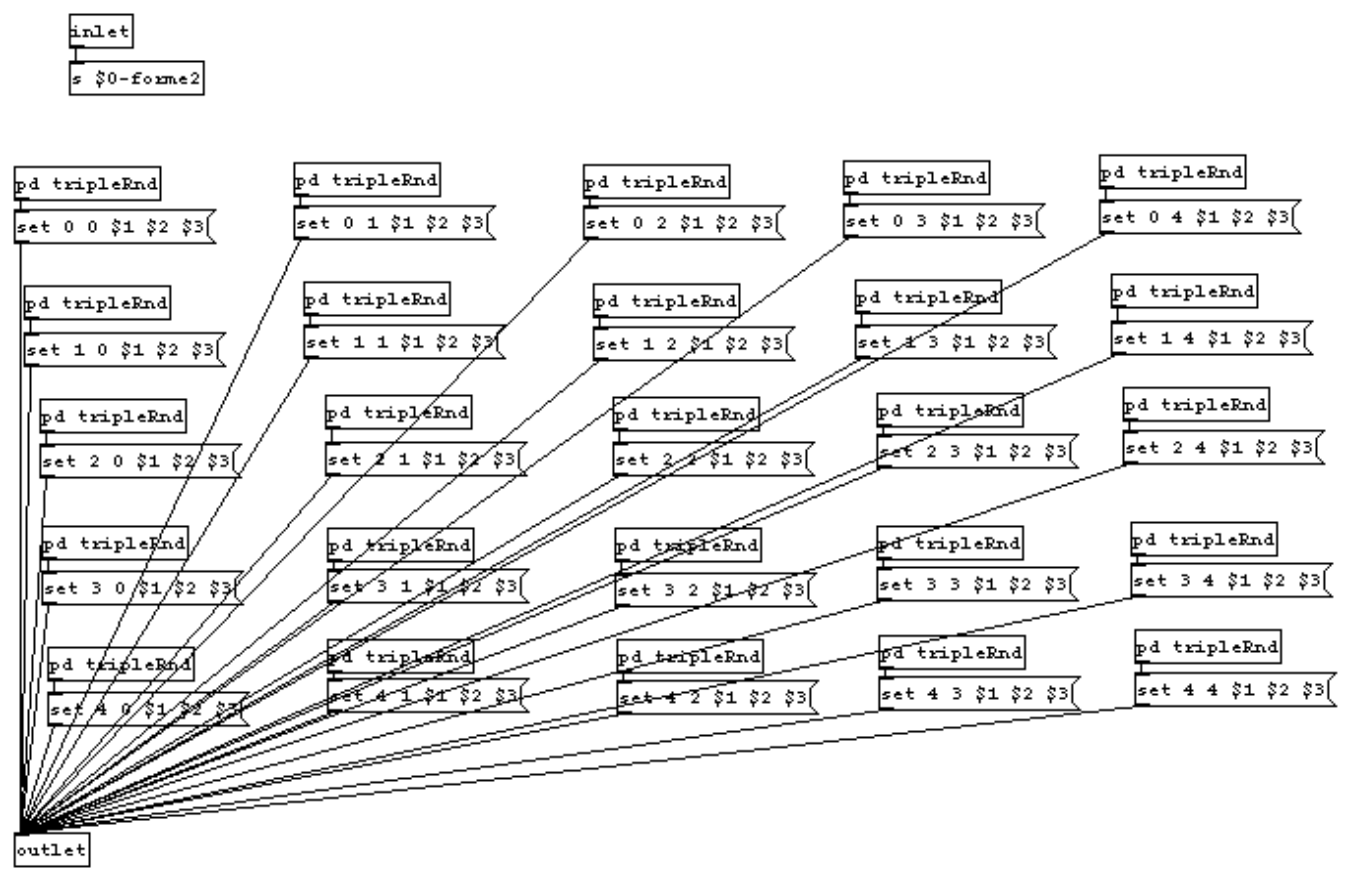

Figura 34: Subpatch forme2 do objeto aim.bezierseagull

O subpatch forme 2 mostrado na Figura 34 gera um conjunto de 25 valores que controlam a forma da curva de Bezier, sendo transmitidos ao objeto curve3D (responsável por efetivamente gerar a curva) no subpatch 1stseagull, através do sinal de controle \$0-ctps. 


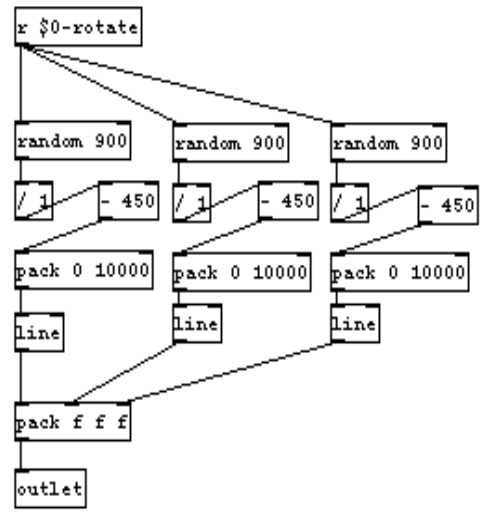

(a) Subpatch tripleRnd

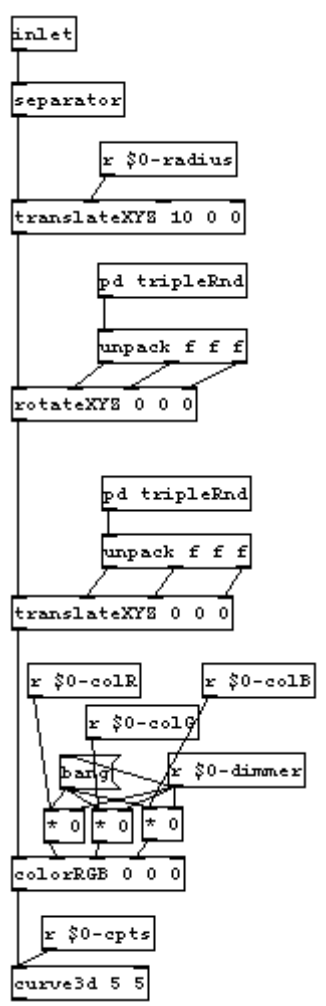

(b) Subpatch 1stseagull

Figura 35: Subpatches tripleRnd e 1stseagull do objeto aim.bezierseagull

Os três valores aleatórios que irão compor o eixo de rotação XYZ da gaivota são gerados no subpatch tripleRnd (Figura 35a), muito semelhante ao tripleRndColor, e utilizado em diversas outras partes do patch aim.bezierseagull. Já o subpatch 1stseagull (Figura 35b) possui os objetos que irão efetivamente criar a gaivota na saída GEM, através de translações, rotações, mudanças de cor e finalmente síntese da imagem.

Por fim, o objeto aim.doll produz um boneco articulado formado por esferas e paralelepípedos, com uma série de controles associados a parâmetros [0...1] que controlam os movimentos realizados pelos braços e pernas do boneco. Sendo este um elemento claramente figurativo, e por isso muito diverso dos demais objetos geométricos, foram adicionadas duas entradas para controlar a coesão ou o desmembramento das figuras geométricas que compõem o boneco, permitindo aproximá-lo visualmente dos objetos geométricos simples oferecidos pelos outros objetos de síntese de imagem.

A Figura 36 mostra o subpatch rightarm do aim.doll que é quem comanda o braço direito do boneco. Os braços do boneco, assim como as pernas, são compostos por dois paralelepípedos unidos por um ponto que na perna faz a função do joelho e no braço do cotovelo. Dessa forma, o braço formado pelos dois paralelepípedos possui dois pontos de articulação, que correspondem ao ombro e ao cotovelo do boneco. Estes pontos servem de referência para os movimentos das duas partes que compõem o braço, e que devem obedecer a determinadas equações a fim de garantir a coesão do boneco. Estes cálculos de coesão são aplicados sobre o sinal [0..1] recebido na segunda entrada, de forma que os ângulos formados por cada paralelepípedo componham um movimento sincronizado.

Os dois parâmetros que controlam a coesão são chamados de desmembramento (dismemberment) e pulso do desmembramento, e são ambos do tipo [0...1]. O primeiro controla a 
proximidade das partes que formam o boneco, sendo 0 o valor que representa o boneco coeso; se o boneco não está coeso, o código fornece às partes soltas do boneco uma certa ginga, cuja freqüência é controlada pelo segundo parâmetro.

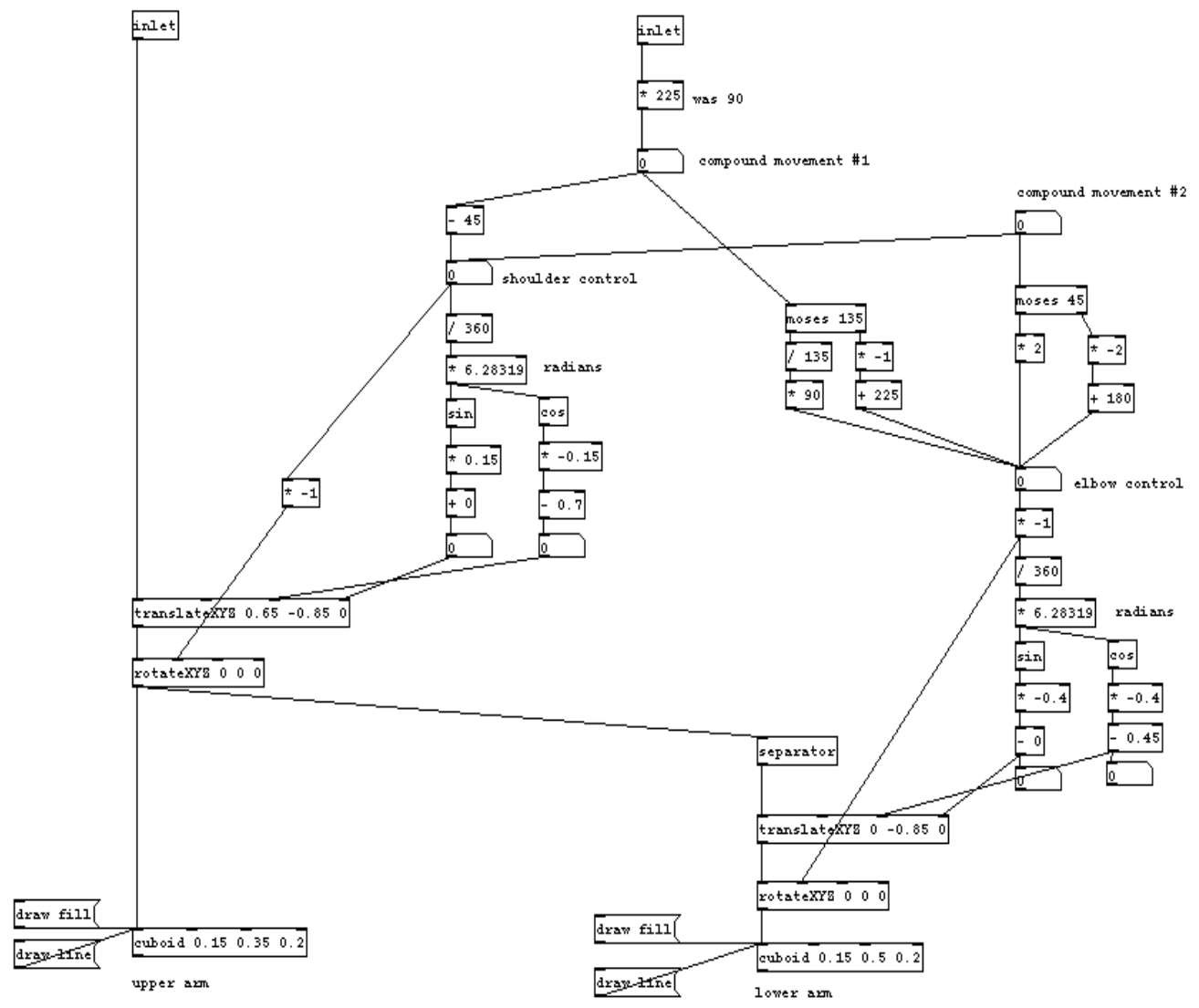

Figura 36: Subpatch rightarm do objeto aim.doll

Os objetos simples descritos acima podem ser utilizados para a criação de objetos compostos, com controles possivelmente distintos daqueles encontrados nos objetos simples. Quatro destes objetos que servem de exemplo para isto foram construídos a partir dos quatro objetos simples anteriores: aim.planets, aim.flyingsquares, aim.bezierseagulls e aim.runningdolls.

O objeto aim.planets produz 7 esferas distintas controladas por sete parâmetros abstratos: cada parâmetro terá um significado diferente para cada uma das bolas, podendo determinar o raio em uma delas, o componente de cor $\mathrm{G}$ em outra ou a posição no eixo $\mathrm{Z}$ em uma terceira, por exemplo. O objeto aim.runningdolls gerencia o movimento de 6 bonecos que correm em círculos, oferecendo controles de cor dos bonecos, raio das trajetórias e nível de desmembramento dos mesmos. A Figura 37 mostra exemplos de saídas geradas por estes objetos. 

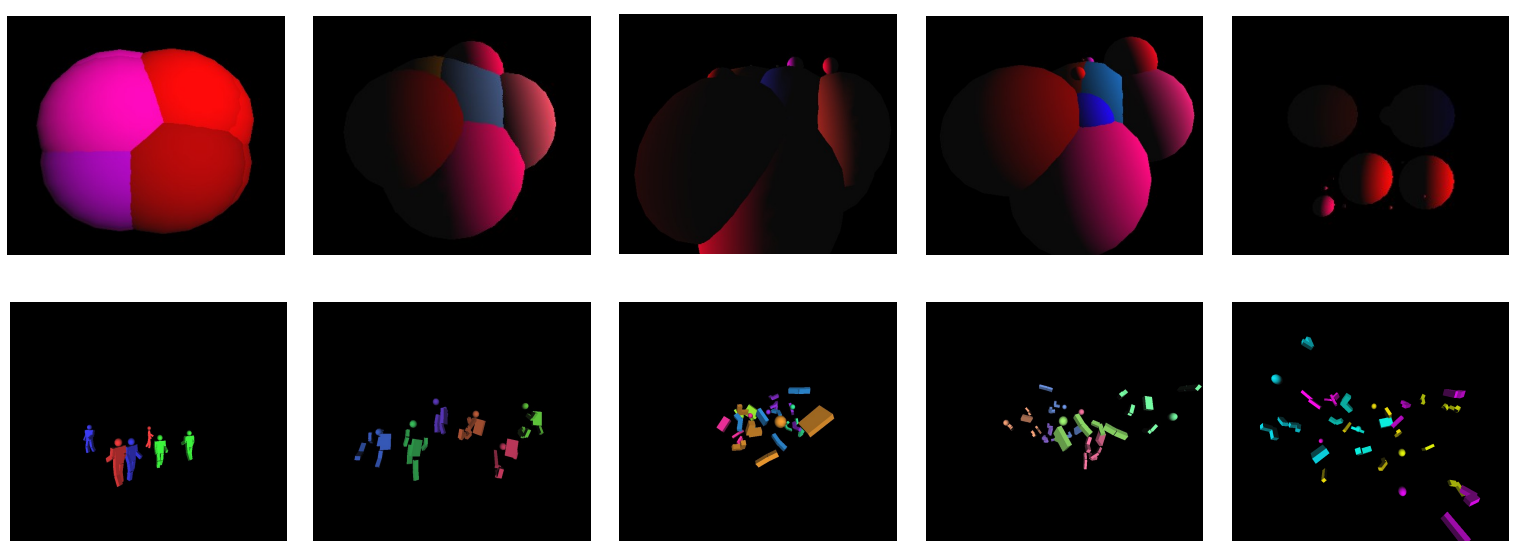

Figura 37: Exemplos de saída dos objetos aim.planets e aim.runningdolls

O objeto aim.flyingsquares permite o lançamento de até 10 quadrados simultaneamente, controlando de maneira independente seus movimentos, cores, etc. Um exemplo de uso com a saída correspondente por ser visto na Figura 49, seção 3.6. O objeto aim.bezierseagulls gera 6 gaivotas formadas por curvas de Bezier e possui os mesmos parâmetros que o objeto simples aim.bezierseagull. A Figura 38 abaixo mostra um patch de exemplo onde o objeto aim.bezierseagulls é utilizado para a geração da saída visual ao lado.
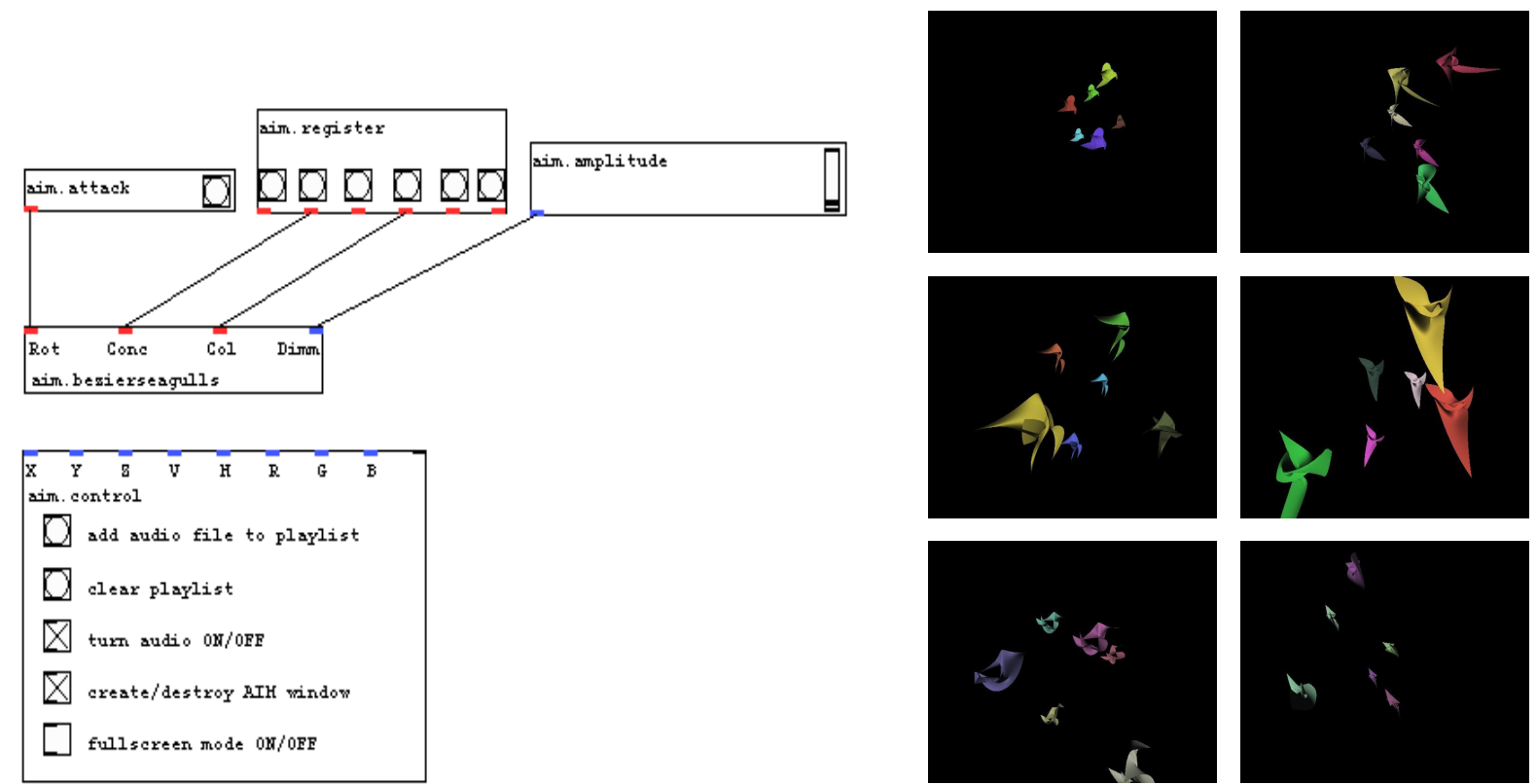

Figura 38: Exemplo de um patch com o objeto aim.bezierseagulls e a saída respectiva

\subsection{Objetos de síntese e processamento de sinais de controle}

Embora a parte central da biblioteca corresponda ao objeto aim.control e aos objetos de análise de áudio e síntese de imagens, vários outros objetos estão disponíveis que permitem modificar um sinal de controle AIM, ou mesmo gerar um sinal de controle a partir de uma descrição matemática. Estes objetos aumentam as possibilidades de manipulação de objetos gráficos e enriquecem a saída gráfica, através do uso de sinais que dependem indiretamente dos parâmetros musicais extraídos do áudio, ou eventualmente são totalmente independentes daqueles parâmetros, como no caso de sinais 
para geração de movimentos pré-definidos.

Nesta categoria a biblioteca AIM possui os objetos aim.sine e aim.cosine que geram sinais [0...1] senoidais, onde a freqüência em $\mathrm{Hz}$ (Hertz) é estabelecida pelo argumento de criação dos objetos e pode ser alterada através de uma entrada do tipo [0...1] (que corresponde a freqüências de $0 \mathrm{~Hz}$ a $10 \mathrm{~Hz}$ ), permitindo sua conexão com outros objetos de análise de áudio ou de síntese e processamento de sinais de controle. Deve-se lembrar que os valores gerados por este objeto serão utilizados para controlar imagens que são atualizadas à taxa de $20 \mathrm{~Hz}$, então valores de freqüência acima de $10 \mathrm{~Hz}$ sofrerão um efeito de aliasing, não sendo recomendado seu uso.

$\mathrm{O}$ objeto aim.phasor gera um sinal dente-de-serra com a freqüência em $\mathrm{Hz}$ e a fase inicial determinadas pelos argumentos de criação ou pelas entradas do objeto. A Figura 39 mostra exemplos de sinais AIM gerados por aim.sine, aim.cosine e aim.phasor.
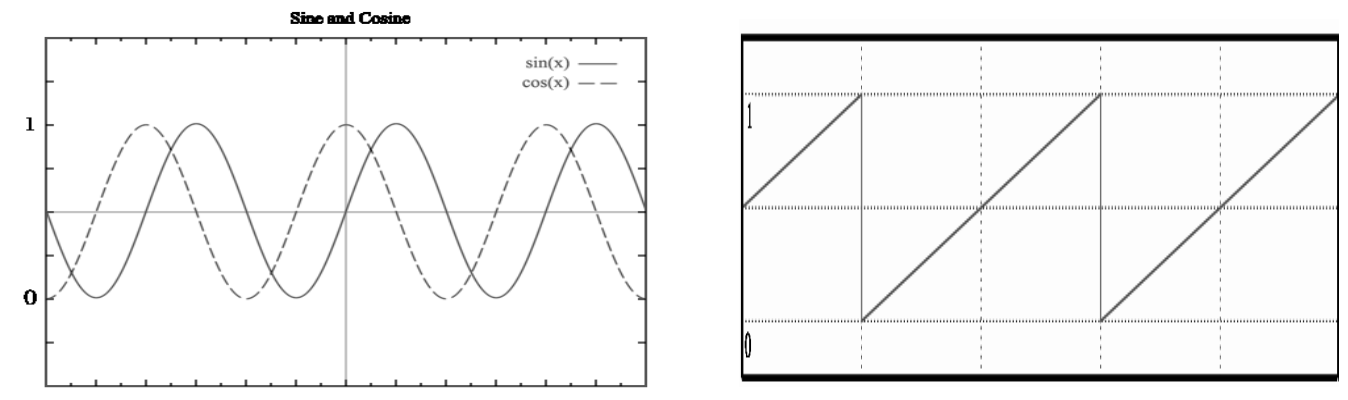

Figura 39: Sinais gerados pelos objetos aim.sine, aim.cosine e aim.phasor

Já o objeto aim.random gera um sinal AIM aleatório linear por trechos. Todos estes objetos possuem parâmetros de controle por parte do usuário, como a freqüência de oscilação nos dois primeiros exemplos ou ainda a taxa de geração dos pontos de quebra aleatórios no caso de aim.random, o que permite desde a síntese de um ruído branco até sinais relativamente lentos porém de comportamento imprevisível. A Figura 40 mostra dois exemplos de sinais que podem ser gerados pelo objeto aim.random.
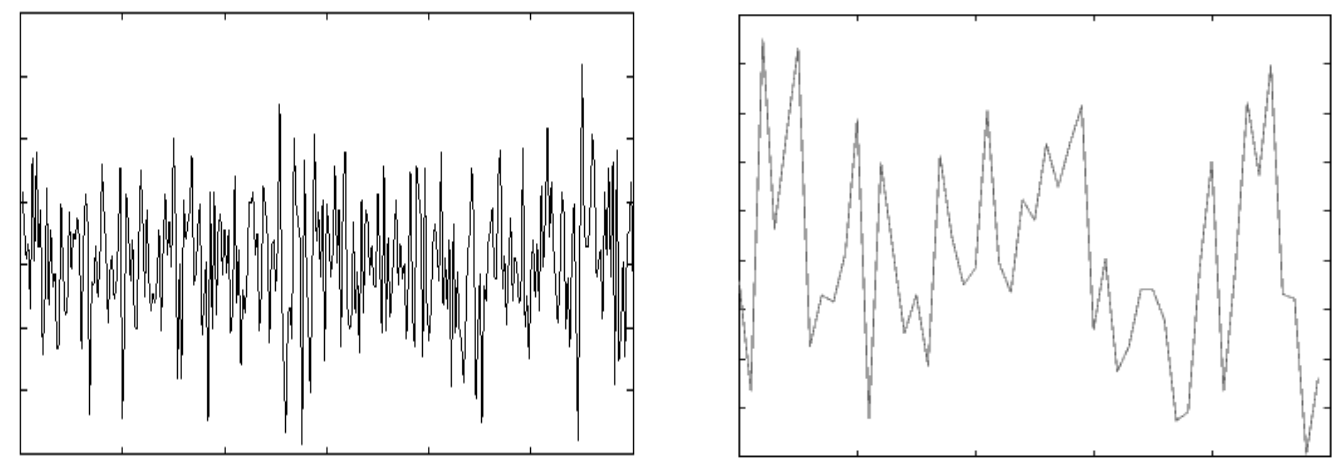

Figura 40: Tipos de sinais aleatórios que podem ser gerados pelo objeto aim.random

Ainda nesta categoria estão os objetos aim.rotation e aim.banger. O aim.rotation (Figura 41) gera dois sinais [0..1] senoidais que definem um movimento circular em duas coordenadas, sendo a freqüência e o raio da rotação parâmetros $[0 \ldots 1]$ recebidos pelas suas entradas. 


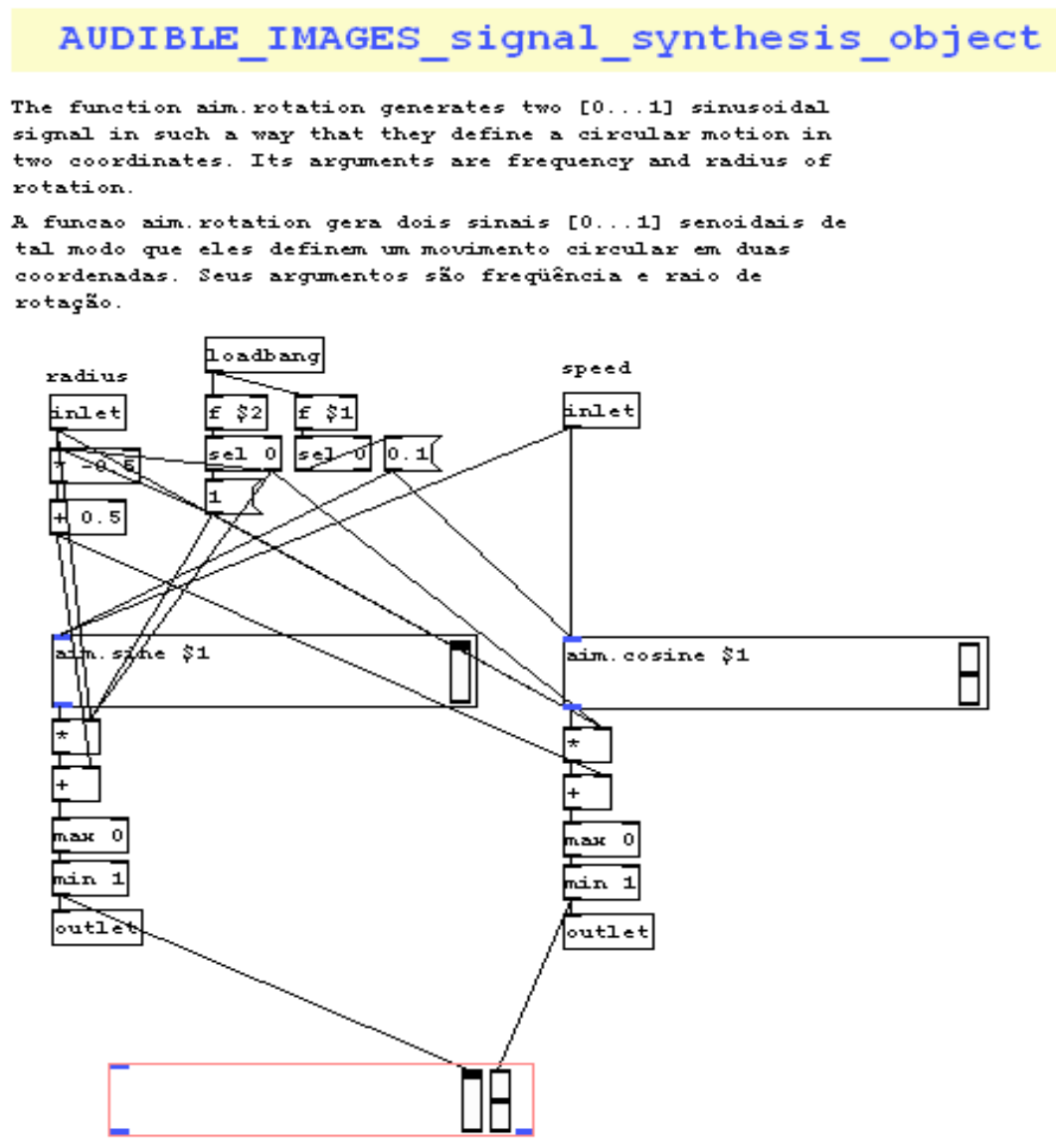

Figura 41: Implementação do objeto aim.rotation

As saídas do aim.rotation podem ser usadas para controlar movimentos circulares em objetos de síntese de imagens com entradas de posição XYZ, permitindo a criação de rotações nos planos XY, XZ e YZ, entre outras (com um pouco de imaginação).

Já o objeto aim.banger é um gerador de disparos que gera bangs em intervalos de tempo aleatórios onde o valor máximo de tempo entre disparos (em segundos, default 1 segundo) é definido pelo argumento de criação.

Para adicionar variedade aos controles dos objetos gráficos, foram desenvolvidos objetos para o processamento de sinais de controle. Os sinais manipulados são sinais AIM [0...1] e bangs, sendo que cada objeto possui uma função específica.

Dentro do grupo de objetos de processamento de sinais de controle existem aqueles que recebem um sinal AIM [0..1] e aplicam alguma manipulação matemática, retornando um sinal [0..1]. A rigor, os objetos de síntese de sinais [0...1] apresentados acima (aim.sine, aim.cosine, aim.phasor e aim.rotation) também agem como objetos de processamento de sinais de controle, dado que possuem entradas [0...1] que modificam suas saídas. Outros objetos de processamento de sinais de controle são:

- aim.invert: transforma o sinal $x(t)$ em $y(t)=1-x(t)$;

- aim.chebyshev: aplica o k-ésimo polinômio de Chebyshev $^{8} y(t)=$ $0.5^{*}\left(\cos \left(k^{*} a \cos (2 * x(t)-1)+1\right)\right.$ ao sinal de controle $x(t)$;

8 Polinômios de Chebyshev são usados freqüentemente em síntese de sinais para enriquecer o conteúdo espectral dos mesmos; por exemplo, o k-ésimo polinômio de Chebyshev aplicado a um sinal senoidal produz como saída seu késimo harmônico. 
- aim.compress: ajusta a escala de um sinal de entrada $x(t)$ para um intervalo desejado [a...b] através da fórmula $y(t)=a+(b-a) * x(t)$;

- aim.expand: recorta uma faixa [a...b] do sinal de entrada e o redimensiona através da fórmula $y(t)=\max (0, \min (1,(x(t)-a) /(b-a)))$;

- aim.power: calcula $\mathrm{z}(t)=x(t)^{\wedge} y$ onde $x(t)$ é o sinal AIM [0..1] e $y$ o argumento de criação do objeto;

- aim.smooth: suaviza o sinal da entrada calculando a média sobre um intervalo de tempo definido pelo parâmetro de criação do objeto;

- aim.mirror: faz a reflexão da parte do sinal que fica abaixo de um limiar (parâmetro de criação, valor default 0.5 ) para cima deste limiar (veja Figura 42).
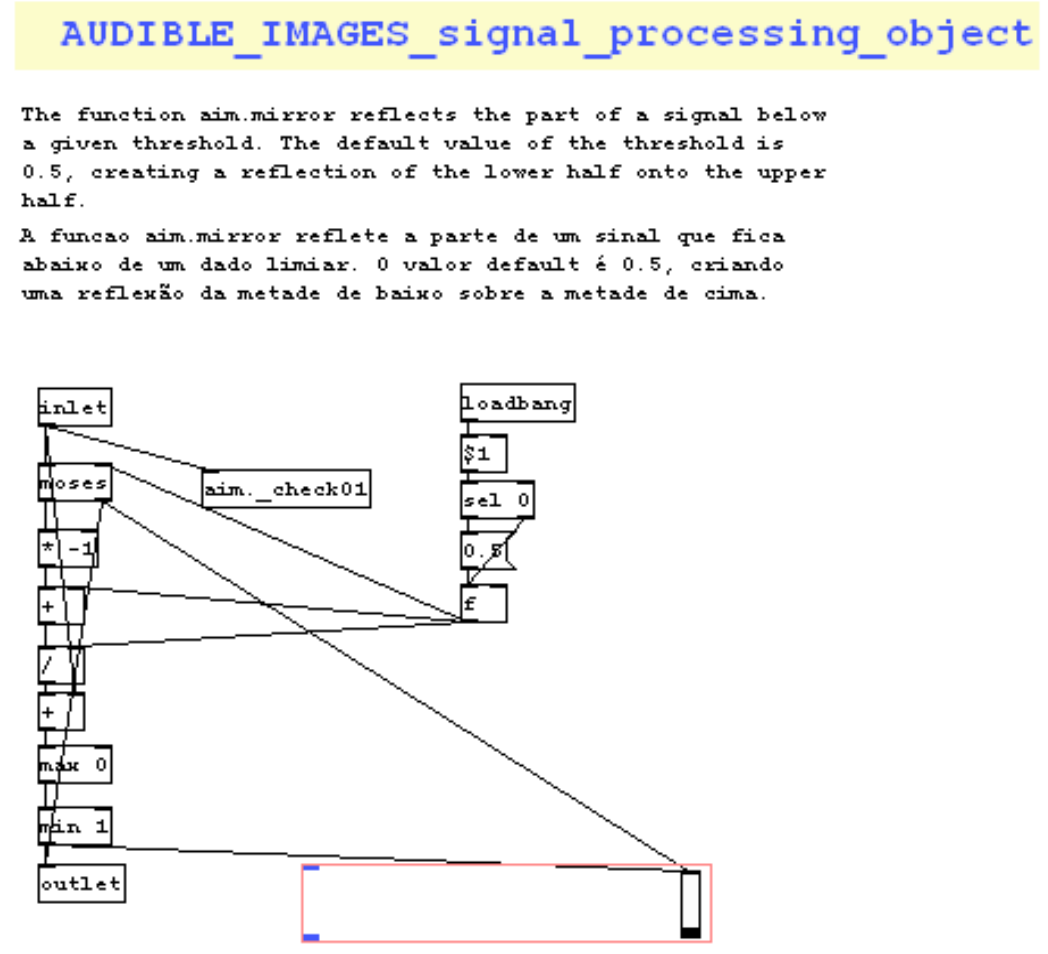

Figura 42: Patch do objeto aim.mirror

Outro tipo de processamento de sinais muito útil para a construção de interfaces é o objeto aim.gate (Figura 43), que chaveia um sinal [0...1] ou bang através de uma chave liga-desliga. Enquanto ligado, este objeto se comporta como uma conexão direta entre a entrada e a saída, passando as informações (bangs ou sinais [0...1]) sem os modificar. No momento em que o usuário desliga a chave do objeto aim.gate, qualquer transmissão de bangs é interrompida, enquanto os sinais [0...1] são rapidamente atenuados através de uma rampa linear (fade-out). O mesmo tipo de tratamento é dado no momento em que a chave é ligada: bangs são liberados instantaneamente, enquanto a passagem de sinais [0...1] é rapidamente liberada através de uma rampa (fade-in). Esse tipo de suavização das transições dos sinais [0...1] é essencial para permitir que conexões entre entradas e saídas de objetos AIM sejam feitas ou desfeitas durante a performance sem a necessidade de reprogramar um patch, o que inevitavelmente acarretaria descontinuidades na imagem gerada (tais descontinuidades, se desejadas, podem ser geradas por outros objetos de análise, síntese e processamento de sinais). Observe que a entrada e a saída deste objeto são identificados com ambas as cores, azul e vermelho. 


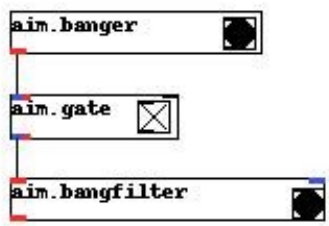

Figura 43: Chaveamento de conexões entre objetos AIM através do objeto aim.gate

Nesta categoria existem, por fim, dois objetos que geram bangs nas suas saídas: um é o objeto aim.threshold, que gera um disparo a cada vez que um sinal [0..1] recebido na entrada cruzar um limiar definido pelo argumento de criação do objeto; e o outro é o aim.bangfilter que filtra uma entrada bang, retendo bangs sucessivos contidos em uma janela de tempo definida pelo usuário (pelo argumento de criação ou pela segunda entrada do objeto, default $0,5 \mathrm{~s}$ ).

\subsection{Objetos para criação de interfaces}

Até este momento a discussão se concentrou na utilização dos objetos da biblioteca AIM na construção de patches que estabelecem relações entre parâmetros sonoros e parâmetros visuais. Apesar da saída responder dinamicamente à entrada, as relações propriamente ditas se mantiveram estáticas. Numa aplicação real é desejável não apenas que as relações possam ser alteradas como também que esta alteração seja simples e não envolva uma reprogramação manual das conexões.

Um recurso existente na biblioteca AIM é a utilização das interfaces gráficas. As interfaces podem prover uma abstração para os patches, de forma que se possa criar ferramentas de utilização simples e direta, oferecendo recursos para a modificação das conexões entre os objetos dinamicamente.

A Figura 44 mostra uma destas interfaces. A idéia é permitir ao usuário o controle da saída do sistema simplesmente clicando nas caixinhas disponíveis, sem a necessidade de visualizar ou compreender o código existente por trás da interface, o que torna a interface acessível para qualquer tipo de usuário, incluindo os que não possuem familiaridade com programação.

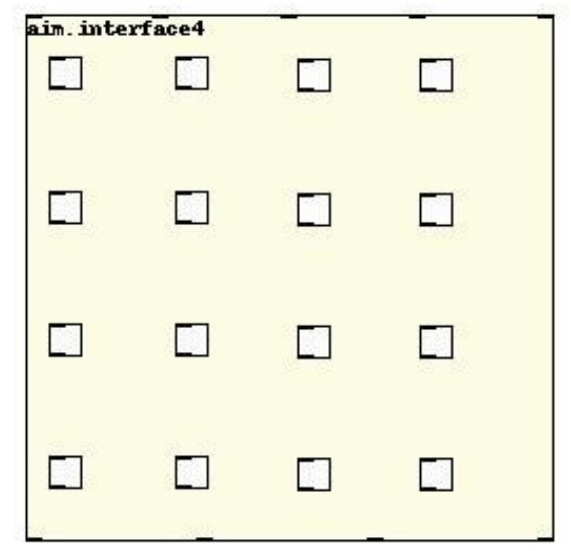

Figura 44: interface oferecida pelo objeto aim.interface4

O objeto aim.interface4 funciona como um painel para modificação das ligações em temporeal, fornecendo uma matriz $4 \times 4$ de chaves liga-desliga que controlam o fluxo de 4 sinais [0...1] provenientes de análise de áudio (ou síntese e processamento de sinais de controle) para 4 entradas 
de síntese de imagens. Cada uma das 16 chaves, indexadas pela linha $i$ e coluna $j$ na matriz, é responsável pelo fluxo do i-ésimo inlet para o j-ésimo outlet, permitindo qualquer reconfiguração possível das conexões entre as entradas e as saídas. Se mais de uma chave na mesma coluna encontra-se ligada, por exemplo aquelas correspondentes aos sinais de entrada $x_{1}(t), x_{2}(t), \ldots, x_{k}(t)$, a interface envia para a entrada de síntese de imagens correspondente o sinal $\max \left\{x_{1}(t), x_{2}(t), \ldots, x_{k}(t)\right\}$.

A construção de interfaces amigáveis para a modificação das conexões depende da utilização do objeto aim.gate, que possibilita a passagem ou obstrução de um sinal [0...1] a uma entrada de síntese de imagens através de uma chave liga-desliga, suavizando as transições para evitar descontinuidades na saída (objetos que somem ou aparecem repentinamente na cena).

Além do controle direto pelo usuário, a interface também possui uma última entrada adicional que recebe mensagens específicas para algumas ações, como a leitura de arquivos contendo configurações das chaves liga-desliga, ou ainda um modo automático de geração das conexões de forma aleatória, que pode ser utilizado como uma espécie de piloto automático, garantindo a variabilidade das conexões.

A Figura 45 mostra um patch completo utilizando o objeto aim.interface8, que gera uma matriz $8 \times 8$ para o estabelecimento de conexões entre 8 entradas e 8 saídas para a passagem de sinais [0...1]. Os detalhes de implementação das conexões, objetos de análise e síntese, bem como as mensagens recebidas pelo última entrada do objeto de interface, podem ser visualizados. A programação poderia tornar-se visualmente muito mais limpa através da utilização de subpatches (para esconder o processamento de sinais de controle utilizado na manipulação dos objetos gráficos). Ainda assim, o exemplo ilustra bem a utilização de diversos recursos da biblioteca AIM.

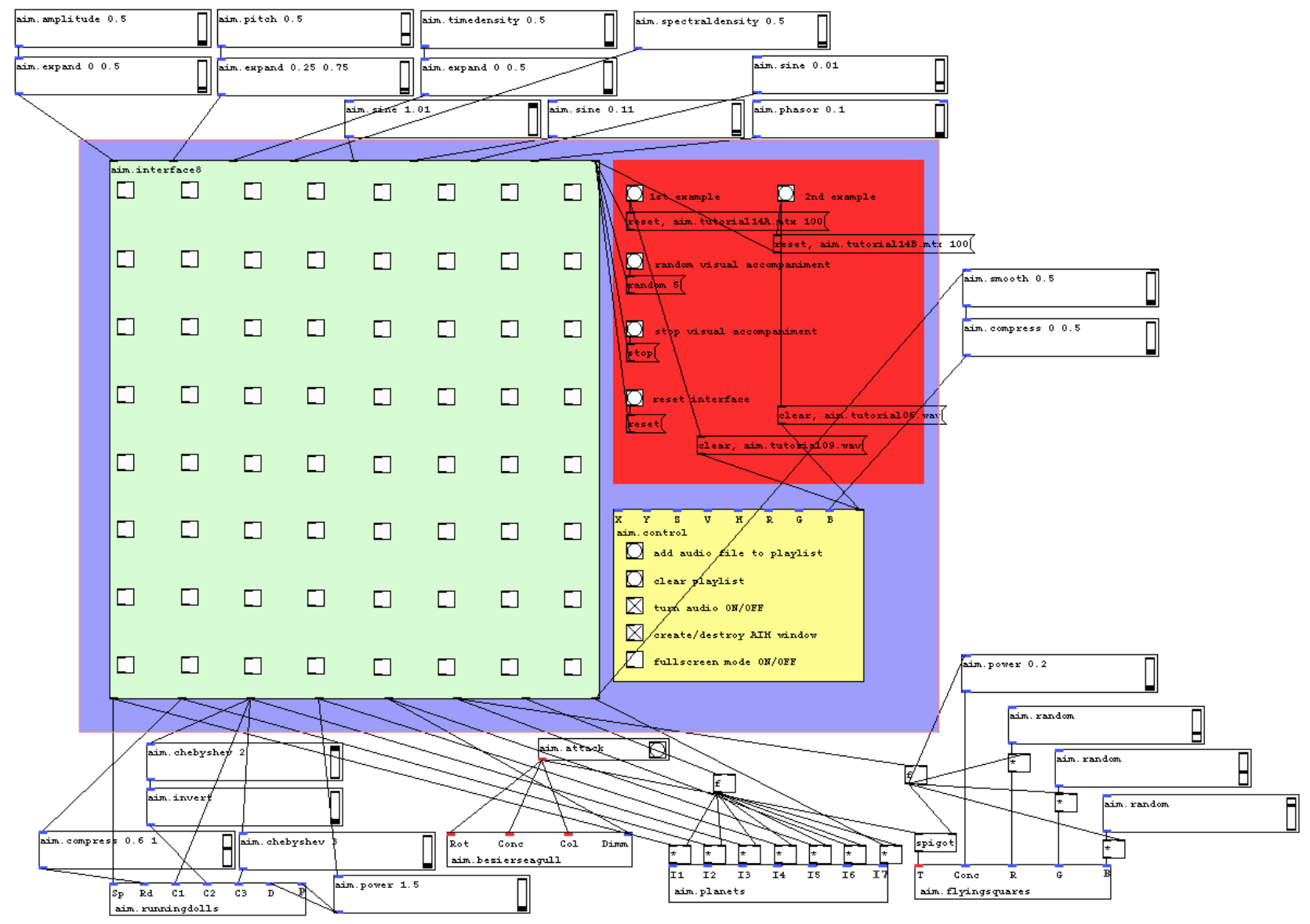

Figura 45: Exemplo de patch completo utilizando uma interface da biblioteca AIM 
A mensagem random ativa a geração aleatória de conexões da matriz, com o tempo de duração das configurações determinado pelo parâmetro de tempo (em milissegundos) contido na mensagem. No exemplo da Figura 45 as marcações aleatórias serão trocadas a cada 1,5 segundos. A interrupção da geração de novas configurações aleatórias é feita pela mensagem stop, que irá preservar a última configuração gerada.

A marcação da matriz também pode ser feita pela execução de scripts com extensão .mtx, feitos em formato texto. A mensagem bang enviada à última entrada da interface fará com que uma janela de seleção de arquivo seja aberta, permitindo a seleção de um script .mtx que reconfigurará a matriz de conexões automaticamente. Na Figura 45 a seleção de um dos exemplos manda a mensagem "aim.tutorial12[ab].mtx", que refaz as conexões da matriz de acordo com o arquivo .mtx correspondente. Além disto o exemplo envia a mensagem "clear, aim.tutorial0[69].wav" à última entrada do objeto aim.control, limpando a playlist e selecionando um novo arquivo de áudio. Outra alternativa é enviar à última entrada uma mensagem contendo uma lista de pares "script.mtx tempo", separados por vírgula, criando assim uma lista circular de scripts, onde cada configuração será mantida pelo tempo correspondente.

Um script é um arquivo texto simples que possui um cabeçalho indicando quantas conexões serão feitas e uma lista de pares "linha coluna" que mostra quais chaves liga-desliga deverão ser marcadas. Um exemplo de um script é descrito abaixo:

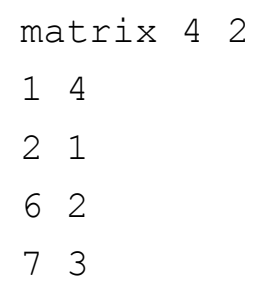

A primeira linha do script é um cabeçalho que descreve o arquivo de configuração, que deverá conter a palavra matrix seguida da indicação do número de linhas neste arquivo (igual ao número de chaves ligadas na matriz) e número de colunas (2, já que representam índices de linhas e colunas da matriz).

A Figura 46 mostra uma visão mais limpa da interface $8 \times 8$ do exemplo anterior, do modo como poderia ser oferecida a um usuário final. Nesta versão as conexões feitas nas entradas e saídas da matriz estão ocultas, ficando visíveis apenas os controles disponíveis para o usuário. 


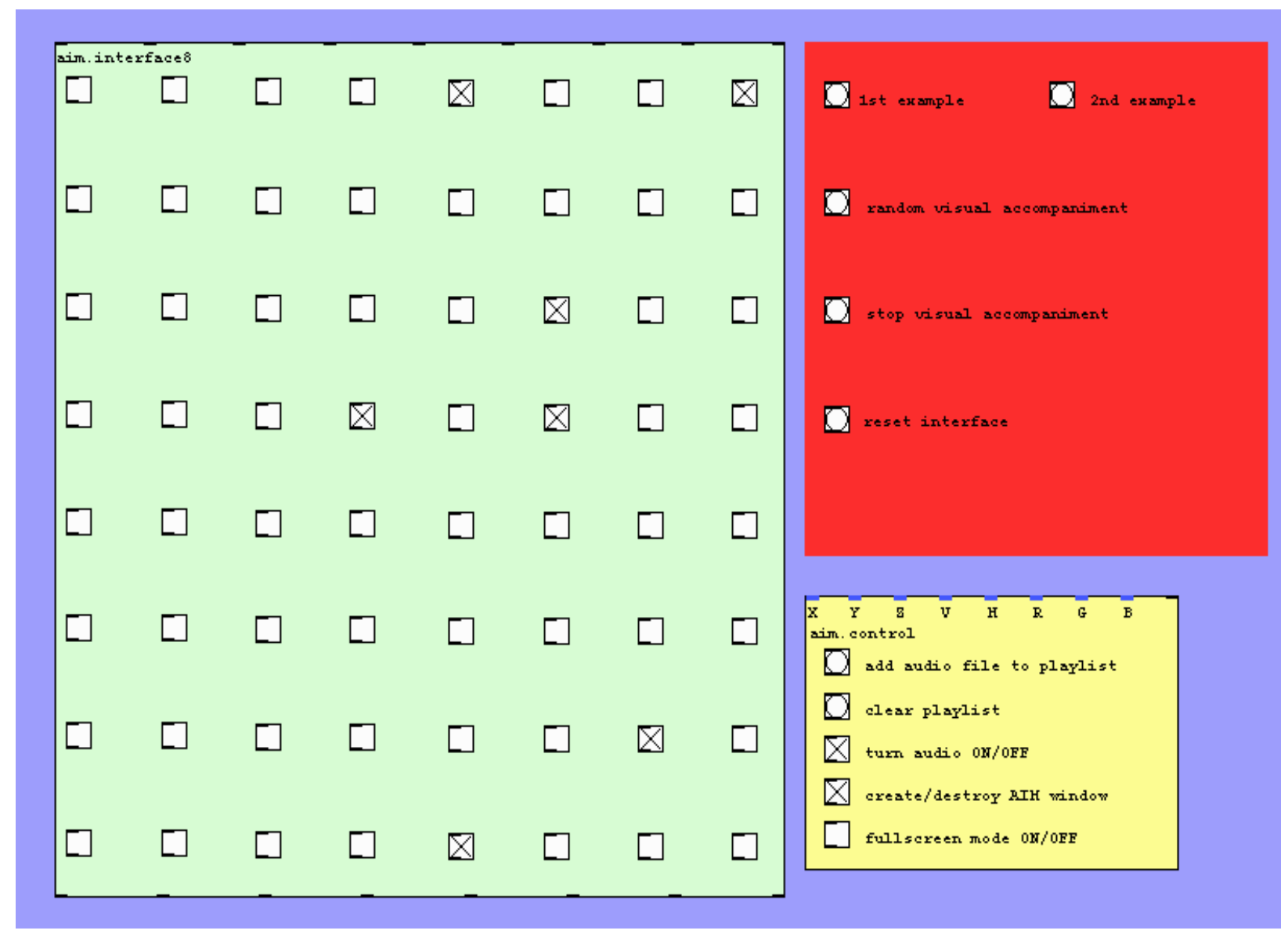

Figura 46: Exemplo de patch com interface e os objetos das conexões visualizados

A biblioteca AIM possui quatro interfaces, três para o estabelecimento de conexões entre objetos que enviam/recebem sinais AIM [0..1], e uma interface para o estabelecimento de conexões entre objetos que enviam/recebem bangs. Os objetos de interface para os sinais [0..1] são: aim.interface4, que gera uma matriz 4x4 (Figura 44), aim.interface8, que gera uma matriz 8x8 (Figura 45) e aim.interface 48 , que gera uma matriz 4x8. A interface para bangs é gerada pelo objeto aim.interface $4 b$ que gera uma matriz $4 \times 4$ onde trafegam apenas disparos.

O desenvolvimento das interfaces foi realizado de forma modular, sendo que cada interface possui vários subpatches que controlam características distintas. A Figura 47 mostra o patch do objeto aim.interface $4 b$, que serve de exemplo geral por ser muito parecido com as demais interfaces (apesar de algumas peculiaridades por transmitir disparos ao invés de sinais [0..1]). Como o patch possui vários módulos, as informações trafegam através de objetos que enviam e recebem dados (objeto send e objeto receive). As chaves liga-desliga estão contidas em um canvas que delimita a área de visualização externa, sendo que apenas objetos de interação com o usuário são mostrados no nível externo (o que não ocorre com os objetos send/receive ${ }^{9}$ ).

9 http://crca.ucsd.edu/ msp/Pd_documentation/ 


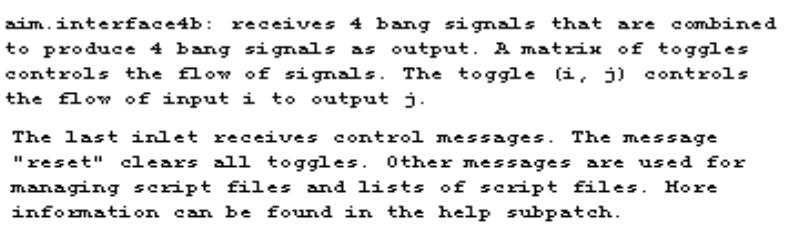

aim interface4b: recebe 4 sinais bang gue são combinado para produrix 4 sinais bang como saida. Uma matria de toggles controla o fluxo de sinais. o toggle (i, j) controla o fluro da entrada $i$ para a saida $j$.

o úlimo inlet recebe mensagens de controle. A mensagem "reset" limpa todos os toggles. Outras mensagens são utiliadas para gerenciax arquivos de sexipt e listas de arquivos de script. Hais detalhes podem ser encontrados no subpatch "help"
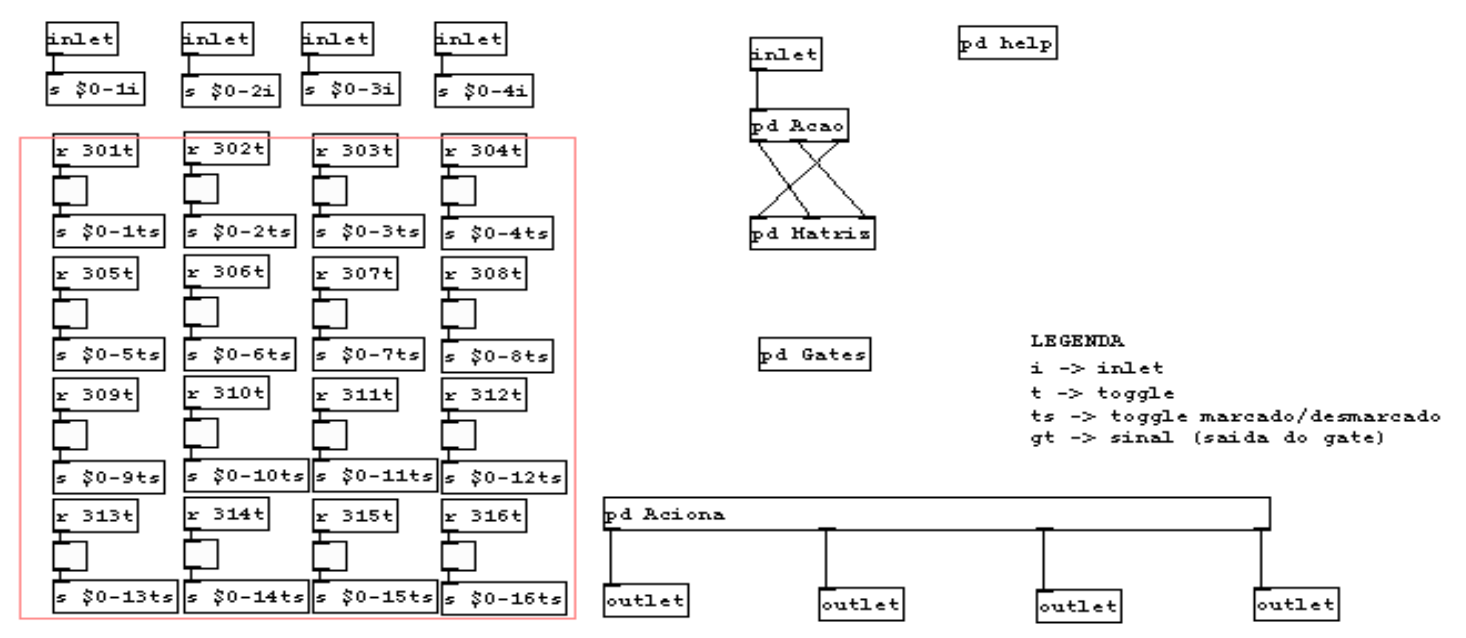

Figura 47: Patch do objeto aim.interface4b

As quatro primeiras entradas do patch recebem sinais de controle do tipo bang e a última entrada, responsável pela leitura de scripts e outras funções, é enviada ao subpatch Acao, que verifica o tipo da informação recebida e conduz à execução da ação correspondente, no subpatch Matriz ou em outros subpatches, como aim.interface4b.subpatch.limpa, responsável por desligar todas as chaves no patch principal, aim.interface4b.subpatch.random, que cuida da geração aleatória de configurações para a matriz, e aim.interface4b.subpatch.mtxlist, que gerencia a lista de scripts e durações correspondentes.

\subsection{Tutoriais}

Além da documentação contida nos próprios objetos, foi desenvolvido um conjunto de tutoriais com o objetivo de complementar a documentação da biblioteca, funcionando como uma breve introdução ao uso da biblioteca AIM, através de exemplos quase sempre interativos. A lista completa de tutoriais está no apêndice desta dissertação. No texto que segue é apresentada resumidamente a seqüência de conceitos e categorias de objetos, da forma didática em que estão dispostos nos tutoriais.

A Figura 48 mostra o patch do tutorial 01 com uma possível saída correspondente. O objetivo aqui é introduzir a idéia de sinais [0...1] através dos parâmetros de controle recebidos pelos objetos aim.control e aim.ball. Neste primeiro contato os sinais de controle não são gerados por objetos de análise de áudio, mas pelo usuário, através sliders interativos, para que fiquem claras as associações entre valores dos parâmetros e resposta dos objetos citados. 


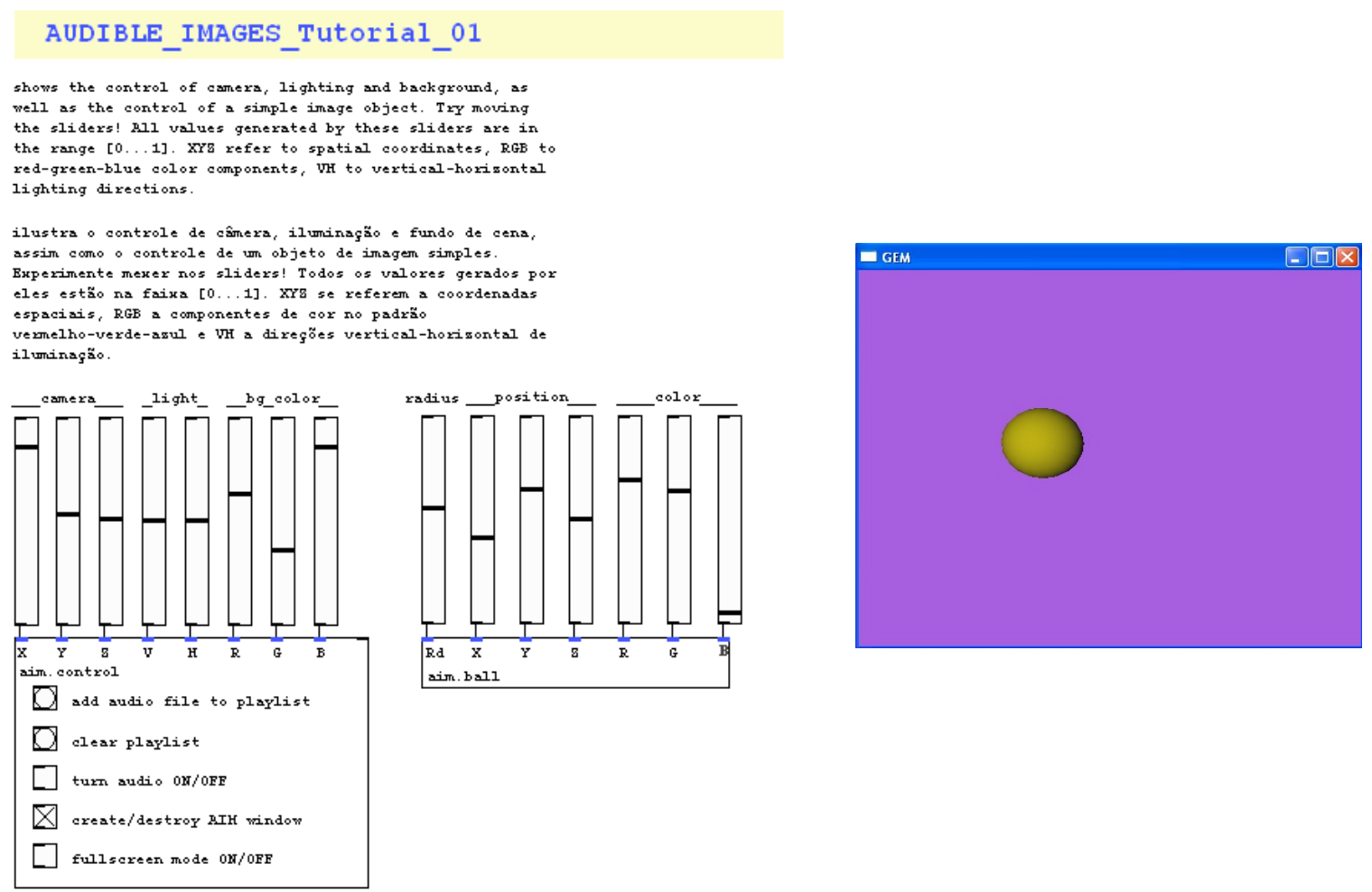

Figura 48: Patch do objeto aim.tutorial01 e uma saída gerada

O segundo tutorial apresenta os objetos de análise de áudio, aim.amplitude e aim.pitch, usados para controlar diversos parâmetros do objeto aim.ball. Aqui o usuário pode usar o microfone para controlar a bola, ou ainda usar um arquivo de áudio de exemplo para observar a relação entre entrada e saída. Através de seus elementos gráficos externos, como sliders e bangs (veja a figura a seguir), os objetos AIM facilitam a observação dos sinais transmitidos entre os objetos.

A Figura 49 mostra o patch do tutorial 03, que introduz o objeto de processamento de sinais de controle aim.invert, utilizado para associar à altura musical uma escala de cores que vai continuamente do azul ao vermelho, além do objeto de análise de áudio aim.attack e do objeto de síntese de imagens aim.flyingsquares.

O tutorial 04 ensina o usuário a criar seus próprios patches utilizando objetos da biblioteca AIM, através de um texto explicativo (em inglês e português). O exemplo criado utiliza, além dos objetos já vistos, o objeto de síntese de sinais de controle aim.rotation, utilizado para criar um movimento circular da bola que independe do áudio da entrada (outros parâmetros, como cor e raio, são associados a características do áudio).

O próximo tutorial explora mais a fundo as características do objeto de controle central aim.control, em particular o uso e atualização de playlists de arquivos de áudio. O sexto tutorial apresenta o objeto aim.doll, bem como novos objetos de síntese e processamento de sinais (aim.expand, aim.phasor, aim.chebyshev e aim.power). O boneco pula ao som da música, mexendo braços e pernas de forma sincronizada, além de girar continuamente em torno de seu eixo e mudar de cor com a altura musical detectada. As conexões, como sempre, são arbitrárias, e servem apenas para ilustrar possibilidades de associações entre áudio e imagem. 

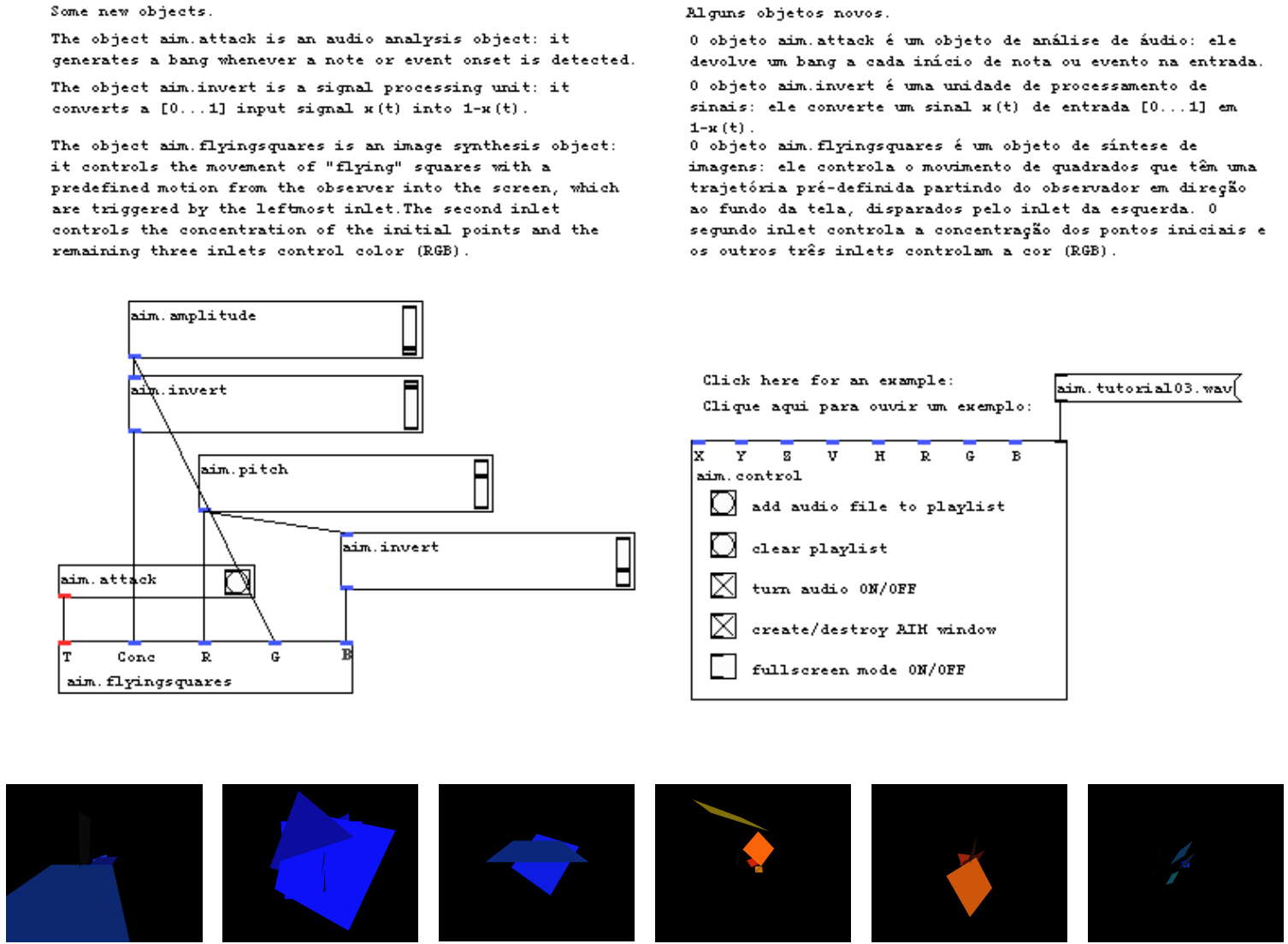

Figura 49: Patch do objeto aim.tutorial03 e saídas correspondentes

O tutorial 07 retoma a idéia de criar movimentos automáticos a partir de funções matemáticas, em particular o uso de senos e cossenos com freqüências diferentes para criar movimentos suaves (curvas de Lissajour) que parecem não se repetir (na realidade, pela restrição de uso de valores racionais, os movimentos demoram muito tempo para se repetir). $\mathrm{O}$ tutorial 08 exemplifica um destes movimentos através de três esferas, de cores diferentes, que fazem movimentos do tipo "casca de laranja" simultaneamente em 3 eixos diferentes. O patch do tutorial (sem a explicação textual) e exemplos de saída seguem abaixo na Figura 50. 

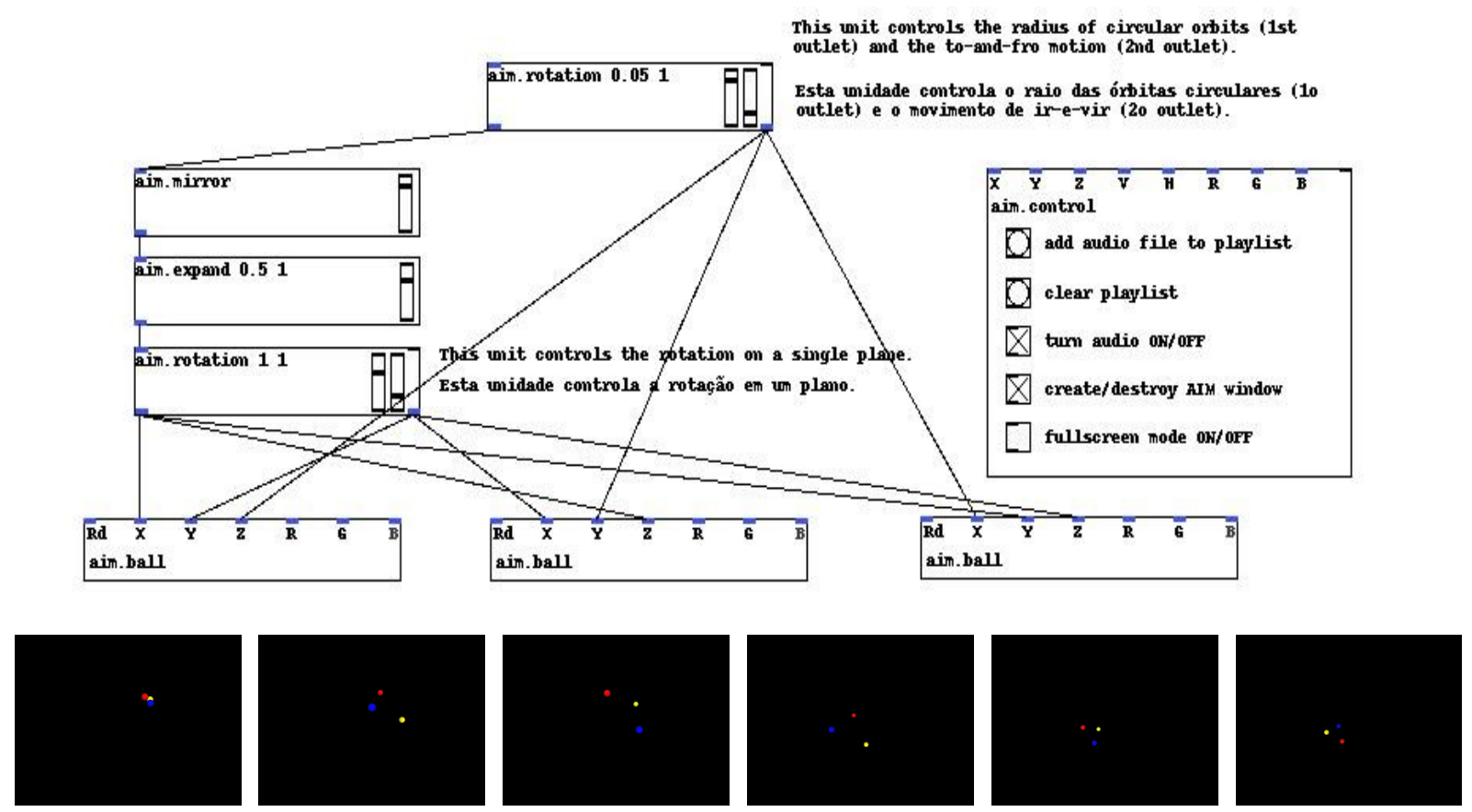

Figura 50: Patch do objeto aim.tutorial07 e saídas correspondentes

Os tutoriais 09, 10 e 11 e 12 apresentam os objetos complexos de síntese de imagens aim.planets, aim.runningdolls, aim.flyingsquares e aim.bezierseagulls, onde as inúmeras entradas são controladas por parâmetros diversos, obtidos por análise de áudio, síntese e processamento de sinais de controle.

As interfaces são apresentadas nos tutoriais 13 e 14 . No primeiro dos casos é utilizada uma interface $4 \times 4$ com rótulos textuais descrevendo a que correspondem às entradas e saídas da matriz. O usuário é apresentado aos objetos de interface e à construção de patches que escondam do usuário final a parte complicada do código, deixando apenas a matriz de chaves liga-desliga e rótulos explicativos visíveis. No último tutorial é apresentado um exemplo bastante complexo de conexões entre objetos AIM, manipulado através de uma interface $8 \times 8$ que pode ser imaginada como um instrumento (no sentido musical) de controle da saída gerada. Esta matriz não possui rótulos descritivos, pelo fato de que as informações que transitam pela matriz são sinais de controle obtidos por processamentos muito diversos que, além de difíceis de descrever textualmente, dificilmente seriam relevantes para a manipulação da interface em tempo-real. 


\section{Experimentos e Validação}

Com o objetivo de comparar o resultado da implementação descrita no Capítulo 3 com os objetivos iniciais do trabalho, e também de buscar opiniões de potenciais usuários a fim de obter indicadores de que pontos do sistema poderiam ser melhorados, foram elaborados alguns experimentos com pessoas voluntárias.

Na Seção 4.1 será descrita a metodologia utilizada para coleta dos dados, juntamente com uma justificativa da metodologia adotada. A Seção 4.2 descreve a realização dos testes e os resultados obtidos, e por fim a Seção 4.3 mostra a análise dos resultados e algumas conclusões.

\subsection{Metodologia e Justificativa}

A metodologia utilizada para obtenção de informações que indicassem pontos positivos e negativos da biblioteca AIM foi a elaboração de dois experimentos no $\mathrm{Pd}$, realizados por voluntários (potenciais usuários da biblioteca). Os voluntários deveriam fazer os experimentos propostos e em seguida responder um questionário.

Os voluntários possuíam graus bastante diversos de conhecimentos de computação e/ou música, refletindo a heterogeneidade do público alvo. Isto é interessante na avaliação de um sistema que pode ser utilizado tanto como ferramenta de performance (através de interfaces pré-construídas) como também através da coleção de objetos independentes por programadores em Pd. Para permitir uma avaliação circunstanciada das respostas, foram utilizadas duas perguntas do questionário onde cada usuário classifica seu próprio conhecimento de computação e de teoria musical.

O objetivo dos experimentos era avaliar o uso de interfaces prontas e também a experiência de programar usando os objetos AIM, para que os voluntários tivessem um contato mínimo com a ferramenta e assim pudessem responder perguntas relacionadas ao sistema. As respostas a cada pergunta do questionário estão associadas a uma escala de valores, permitindo identificar os pontos em que a avaliação não foi positiva e que devem ser melhorados em uma futura versão da biblioteca.

\subsection{Aplicação dos Testes}

Para a realização dos experimentos utilizou-se um laptop com o ambiente necessário para a utilização da ferramenta Pd/GEM e da biblioteca AIM. Cada experimento foi feito através de uma visita agendada, o que limitou o número de experimentos realizados. No total 24 pessoas de perfis variados realizaram os experimentos. Após ouvir um breve resumo dos objetivos do trabalho e uma explicação dos testes que ele iria realizar, o voluntário utilizava sozinho o laptop na execução das tarefas propostas. Dependendo do perfil do usuário havia a necessidade de esclarecer um pouco mais alguns pontos dos experimentos, mas todos os usuários tinham total liberdade para fazer questionamentos e tempo livre para realizar os experimentos.

O Experimento 1, mostrado na Figura 51, apresenta uma das interfaces da biblioteca (objeto aim.interface4) para que o usuário faça e desfaça conexões, que estabelecem associações entre a entrada de áudio e a saída visual, observando o resultado de sua interação numa janela separada.

As características do áudio disponíveis neste experimento são: a altura musical (mais proeminente), a intensidade e a velocidade (densidade de eventos no tempo); além disso, uma das linhas da interface correspondia ao sinal gerado por uma senóide, não relacionada à entrada. Os objetos visuais gerados por esta interface são: uma bola, um boneco, quadrados e uma gaivota. O texto existente no patch do experimento serve como um guia passo-a-passo do que o usuário pode 
fazer, mas ele tem a liberdade de testar a interface como quiser.

Para gerar o áudio da entrada, o usuário pode utilizar o microfone ou então uma das duas opções de arquivo de áudio disponíveis no patch. A opção "Limpar Interface" desfaz todas as conexões que estiverem selecionadas.
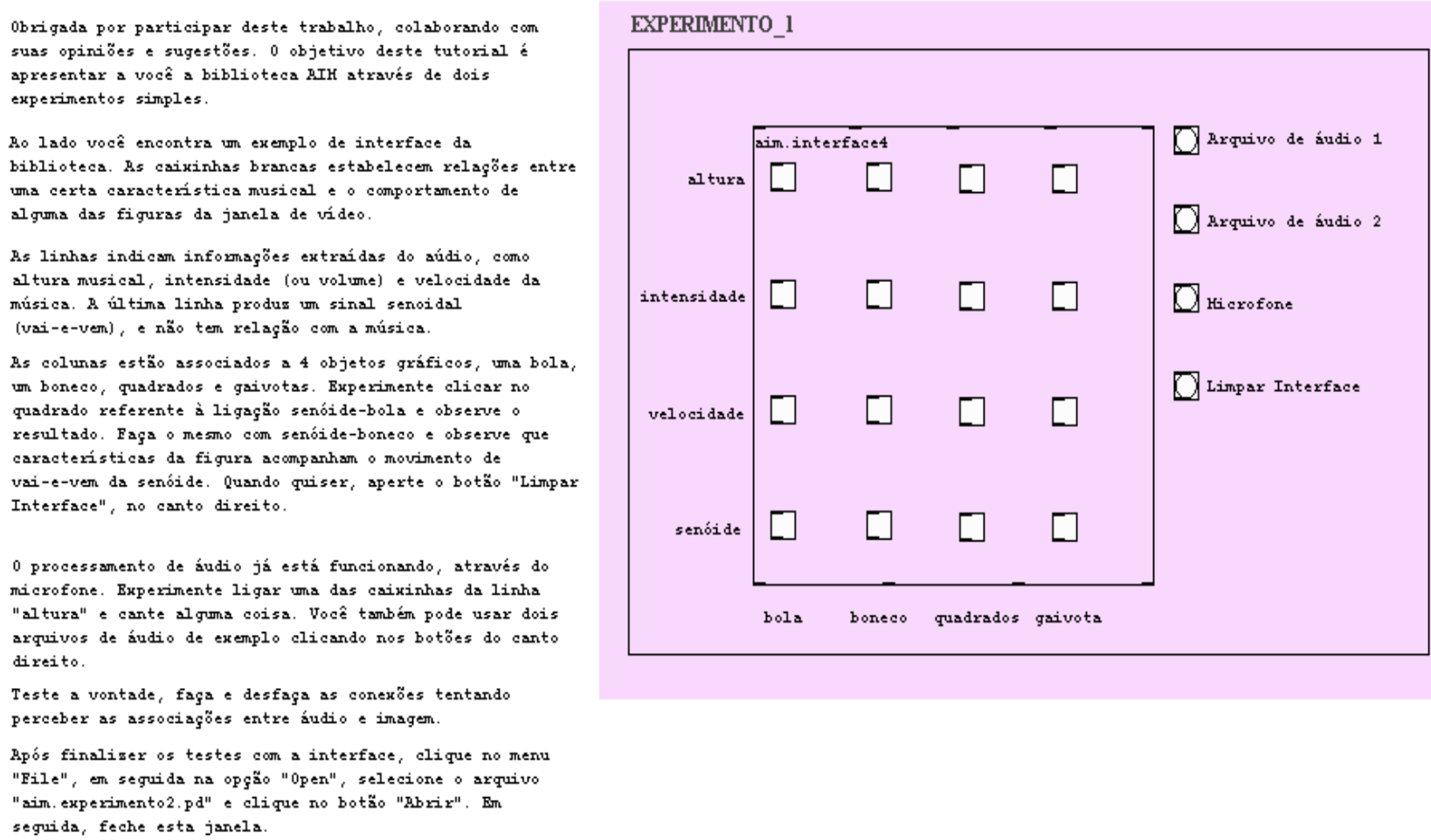

Figura 51: Patch do Experimento 1

As associações disponíveis neste primeiro experimento têm como objetivo facilitar o reconhecimento das características sonoras e seu relacionamento com a resposta visual. Sendo assim, algumas manipulações são feitas na parte interna (invisível) da interface, através da utilização de objetos auxiliares da biblioteca, a fim de melhorar a visualização dos resultados e facilitar a compreensão das associações.

Os objetos visuais possuem algumas características pré-definidas e outras manipuladas pelas associações. $O$ boneco tem sua trajetória alterada na vertical (eixo Y), com movimentos sincronizados pré-definidos dos braços e pernas, como se estivesse saltando. A bola possui um movimento pré-definido nos eixos $\mathrm{X}$ e $\mathrm{Z}$, enquanto o movimento no eixo $\mathrm{Y}$, o raio e a cor são manipulados pelas associações da interface. Os quadrados são lançados a cada detecção de ataque, com cor e concentração determinadas pelas associações estabelecidas na interface. A gaivota tem sua trajetória afetada pela detecção de ataques, enquanto a cor depende das associações feitas. A Figura 52 mostra um exemplo de saída deste experimento.

Houve a preocupação de não poluir o resultado visual. Para isto há uma separação espacial na exibição dos objetos de forma que um objeto interferisse o menos possível na trajetória do outro, além de um tratamento para que os objetos visuais só surgissem na janela GEM quando alguma conexão da sua respectiva coluna estivesse ativada. 


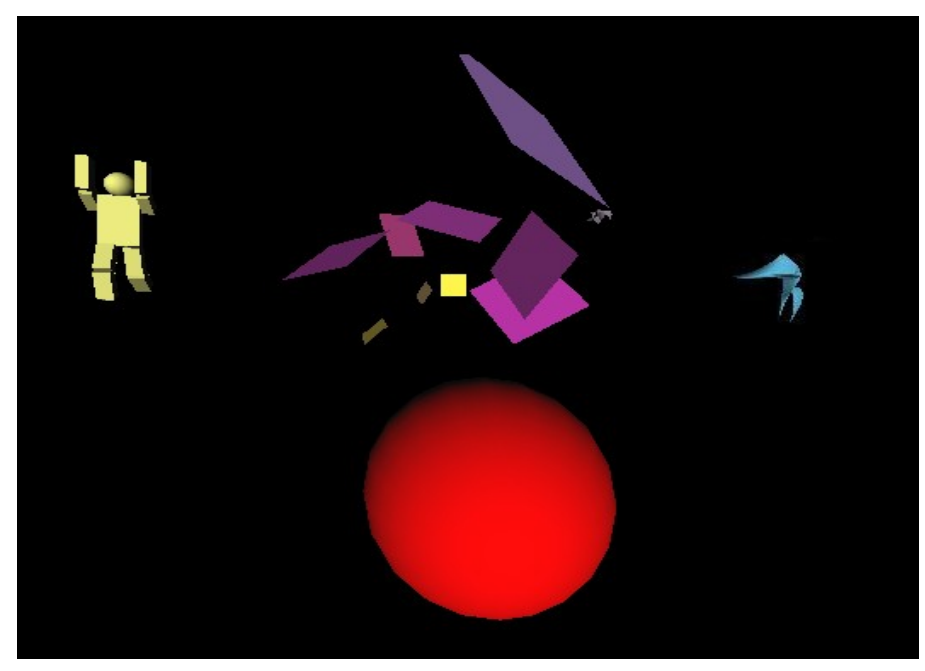

Figura 52: Exemplo de saída do Experimento 1

O Experimento 2 tem como objetivo dar ao voluntário uma idéia superficial do que é o desenvolvimento de um patch Pd utilizando a biblioteca AIM. Neste experimento o usuário é convidado a seguir uma lista de instruções para montar um patch com objetos AIM.

$\mathrm{O}$ patch deste experimento foi elaborado a fim de atender a alguns critérios. O esquema de conexões do patch deveria ser relativamente simples, bem como o número de objetos pequeno, para que os diversos grupos de usuários pudessem montá-lo sem maiores dificuldades. Além disto as associações áudio-visuais também deveriam ser claras, para que a saída final mostrasse nitidamente o resultado das associações feitas.

Seguindo estas idéias o patch sugerido possui dois objetos de análise de áudio, dois objetos auxiliares e um objeto de síntese de imagens (Figura 53). O objeto de síntese de imagens escolhido foi a bola (aim.ball), por possuir parâmetros de entrada mais simples (raio, cor e posição). Assim, as associações descritas no texto fazem com que o raio da bola seja controlado pela amplitude do áudio (aim.amplitude), sua trajetória pelo objeto aim.rotation, e sua cor controlada pela altura musical (aim.pitch). Para dar mais variedade à cor é utilizado o objeto auxiliar aim.invert, que faz uma inversão no sinal gerado pelo aim.pitch, criando uma transição entre azul e vermelho. A seguir é reproduzido o roteiro do Experimento 2.

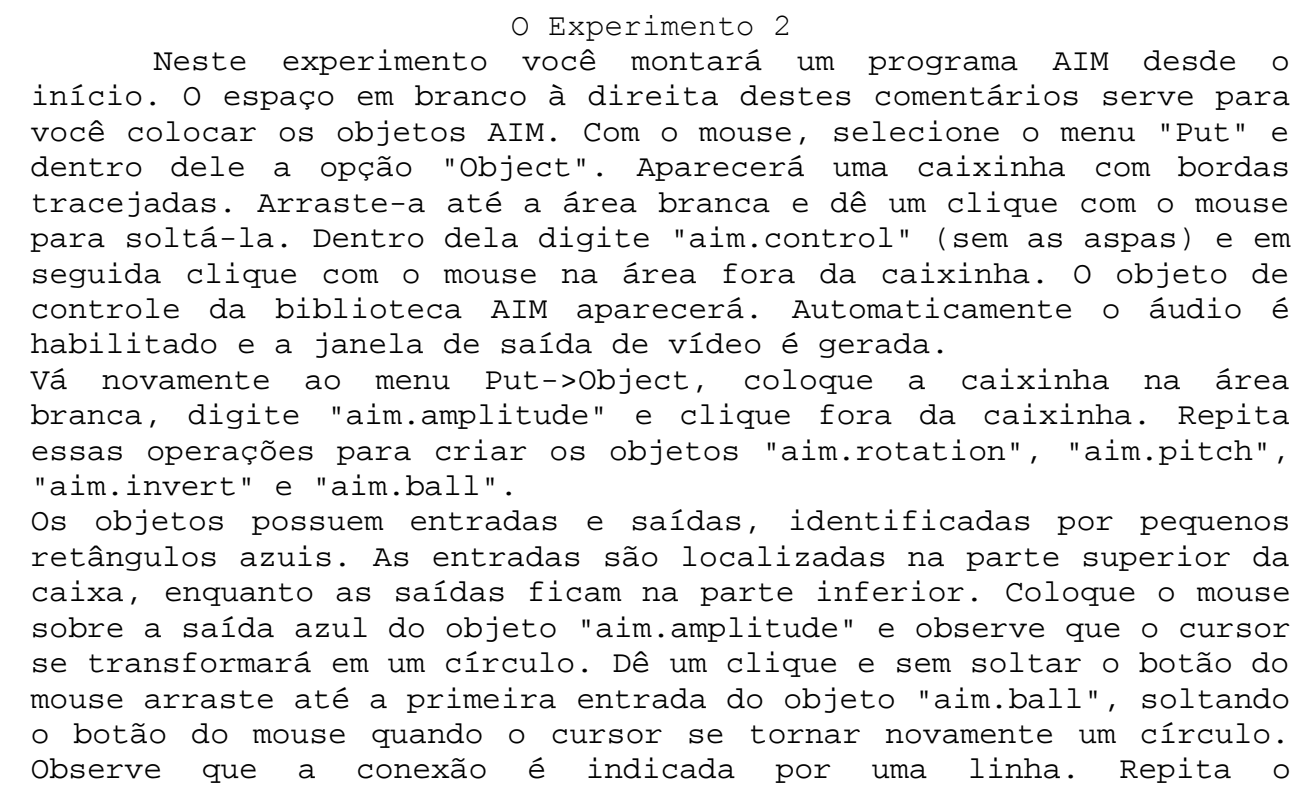



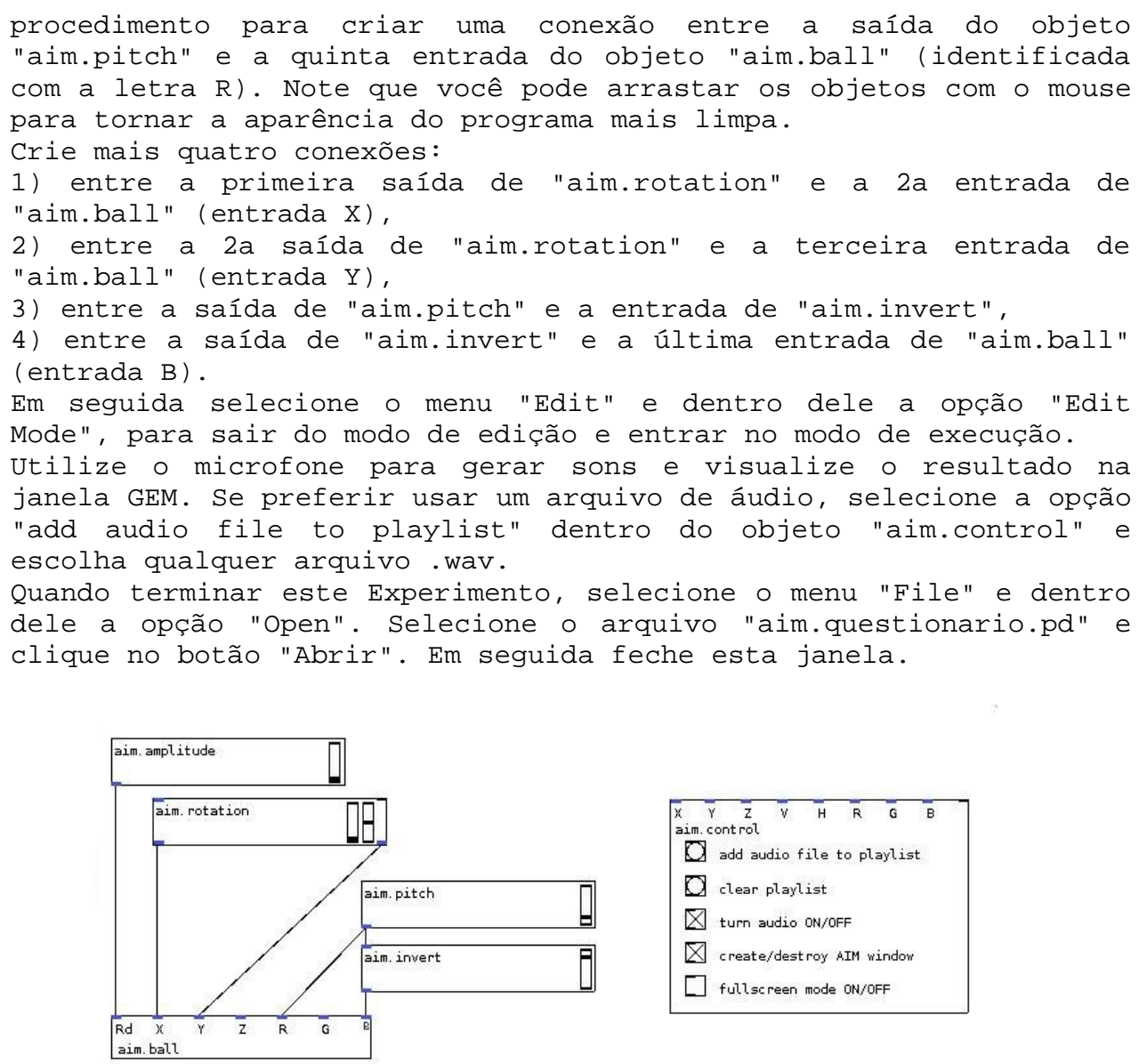

Figura 53: Texto do Experimento 2 e patch correspondente

Da mesma forma que no experimento anterior, o usuário pode explorar livremente o patch montado, refazendo e desfazendo associações entre as entradas e saídas dos objetos, visualizando em tempo-real o resultado das suas alterações.

Após a realização dos dois experimentos, o usuário deve responder o questionário, também em um patch $\mathrm{Pd}$. Neste questionário ele fornece informações sobre seus conhecimentos de computação e música, responde perguntas relacionadas aos Experimentos 1 e 2, e avalia a proposta do trabalho e o sistema. As perguntas relacionadas ao Experimento 1 dizem respeito à utilização da interface e à clareza das associações estabelecidas. Em relação ao Experimento 2, as perguntas buscavam obter informações sobre a qualidade do texto descritivo e a dificuldade de programação dentro do ambiente $\mathrm{Pd}$ (frise-se que alguns voluntários não eram sequer usuários regulares de computadores). As perguntas seguintes abordavam a ferramenta como um todo e a idéia do trabalho. Além disto, o questionário abre um espaço para que o usuário deixe registrado algum comentário, sugestão ou opinião que julgue adequada. $\mathrm{O}$ patch do questionário é mostrado na Figura 54 abaixo. 


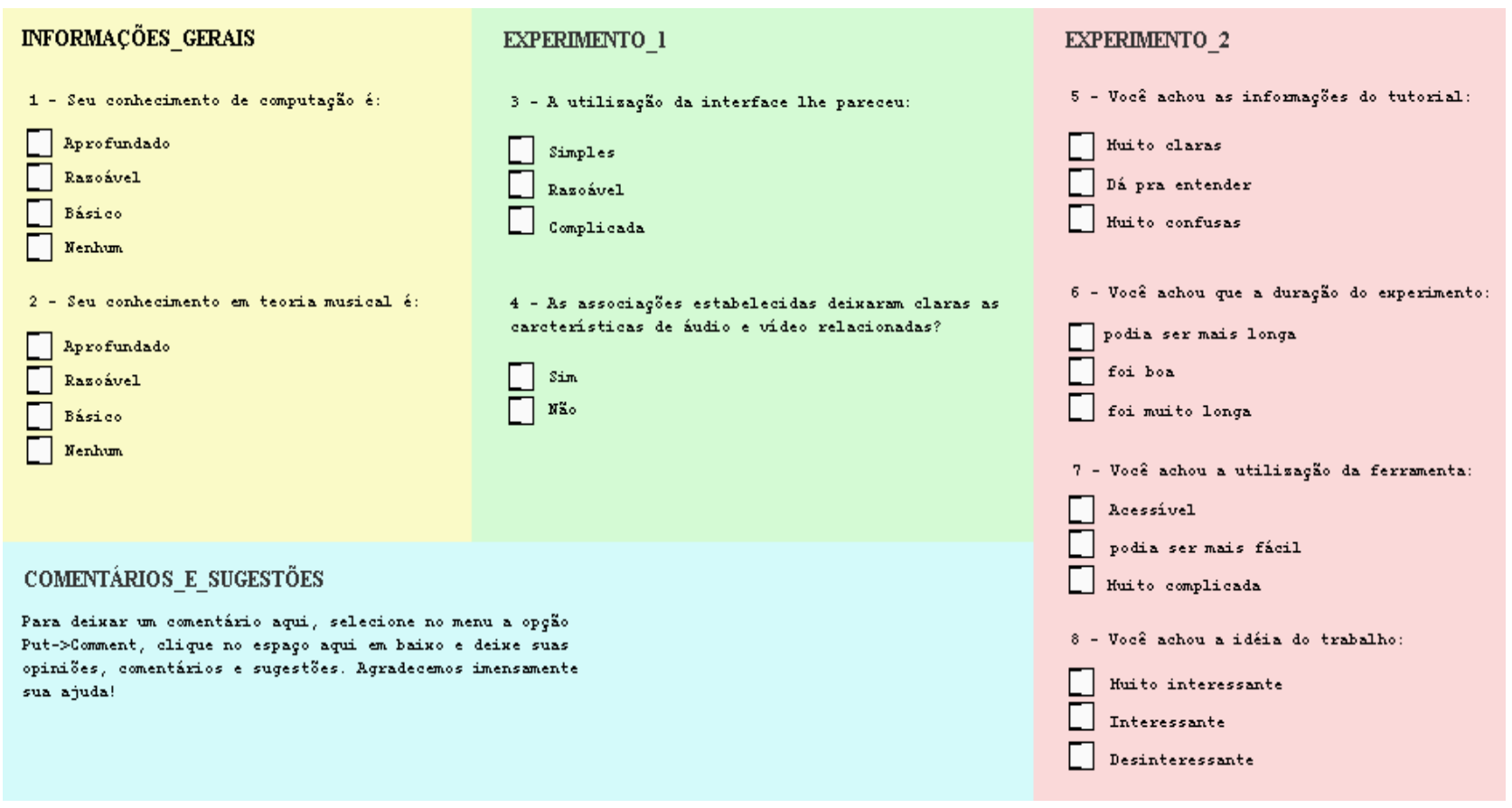

Figura 54: Patch do questionário

\subsection{Análise dos Resultados e Conclusões}

Com as respostas coletadas através do questionário montou-se uma planilha (Figura 55). Cada pergunta foi tabulada em relação a 4 grupos de usuários, definidos pelas respostas dadas nas questões 1 e 2 . Nestas questões cada voluntário classificava seu conhecimento em música e computação como aprofundado, razoável, básico ou nenhum. Em relação a cada um destes conhecimentos os voluntários foram separados em dois grupos: os que declararam conhecimento aprofundado ou razoável em um grupo e os demais em outro. As quatro categorias foram assim definidas: usuários com conhecimento em computação e em teoria musical, usuários com conhecimento apenas em computação, usuários com conhecimento apenas em teoria musical e usuários sem conhecimento em computação nem em teoria musical. 


\begin{tabular}{|c|c|c|c|c|c|c|c|c|}
\hline \multirow[b]{2}{*}{ Perguntas } & \multicolumn{8}{|c|}{ Categoria } \\
\hline & $\begin{array}{c}\text { Ambos } \\
\text { conhecimentos }\end{array}$ & $\%$ & $\begin{array}{c}\text { Conhecimento } \\
\text { em } \\
\text { computação }\end{array}$ & $\%$ & $\begin{array}{c}\text { Conhecimento } \\
\text { em teoria } \\
\text { musical }\end{array}$ & $\%$ & $\begin{array}{c}\text { Sem } \\
\text { conhecimento } \\
\text { dos assuntos } \\
\text { em questão }\end{array}$ & $\%$ \\
\hline \multicolumn{9}{|l|}{3 - Utilização } \\
\hline Simples & 7 & $100 \%$ & 5 & $71 \%$ & 5 & $83 \%$ & 3 & $75 \%$ \\
\hline Razoável & 0 & $0 \%$ & 2 & $29 \%$ & 1 & $17 \%$ & 1 & $25 \%$ \\
\hline Complicada & 0 & $0 \%$ & 0 & $0 \%$ & 0 & $0 \%$ & 0 & $0 \%$ \\
\hline \multicolumn{9}{|l|}{ 4-Associações } \\
\hline Sim & 7 & $100 \%$ & 6 & $86 \%$ & 6 & $100 \%$ & 4 & $100 \%$ \\
\hline Nẫo & 0 & $0 \%$ & 1 & $14 \%$ & 0 & $0 \%$ & 0 & $0 \%$ \\
\hline \multicolumn{9}{|l|}{ 5- Informações } \\
\hline Muito claras & 5 & $71 \%$ & 4 & $57 \%$ & 4 & $67 \%$ & 1 & $25 \%$ \\
\hline Dá pra entender & 2 & $29 \%$ & 3 & $43 \%$ & 2 & $33 \%$ & 3 & $75 \%$ \\
\hline Muito confusas & 0 & $0 \%$ & 0 & $0 \%$ & 0 & $0 \%$ & 0 & $0 \%$ \\
\hline \multicolumn{9}{|l|}{ 6- Duração } \\
\hline Podia ser mais longa & 0 & $0 \%$ & 0 & $0 \%$ & 1 & $17 \%$ & 0 & $0 \%$ \\
\hline Foi boa & 7 & $100 \%$ & 7 & $100 \%$ & 5 & $83 \%$ & 4 & $100 \%$ \\
\hline Foi muito longa & 0 & $0 \%$ & 0 & $0 \%$ & 0 & $0 \%$ & 0 & $0 \%$ \\
\hline \multicolumn{9}{|l|}{ 7-Utilizaçăo } \\
\hline Acessivel & 5 & $71 \%$ & 6 & $86 \%$ & 6 & $100 \%$ & 2 & $50 \%$ \\
\hline Podia ser mais fácil & 2 & $29 \%$ & 1 & $14 \%$ & 0 & $0 \%$ & 2 & $50 \%$ \\
\hline Muito complicada & 0 & $0 \%$ & 0 & $0 \%$ & 0 & $0 \%$ & 0 & $0 \%$ \\
\hline \multicolumn{9}{|l|}{ B - Idéia do trabalho } \\
\hline Muito interessante & 6 & $86 \%$ & 3 & $43 \%$ & 6 & $100 \%$ & 4 & $100 \%$ \\
\hline Interessante & 1 & $14 \%$ & 4 & $57 \%$ & 0 & $0 \%$ & 0 & $0 \%$ \\
\hline Desinteressante & [0 & $0 \%$ & 0 & $0 \%$ & [0 & $0 \%$ & 0 & $0 \%$ \\
\hline
\end{tabular}

Figura 55: Respostas coletadas pelos experimentos

As respostas catalogadas na planilha acima foram utilizadas na geração dos gráficos a seguir. Das 24 pessoas que fizeram os experimentos e responderam o questionário, 7 foram classificadas no primeiro grupo (ambos os conhecimentos), 7 no segundo (apenas computação), 6 no terceiro (apenas música) e 4 no último (sem conhecimentos específicos nas duas áreas). A Figura 56 mostra o gráfico referente à pergunta 3, relacionada ao Experimento 1, sobre a dificuldade de utilização da interface.

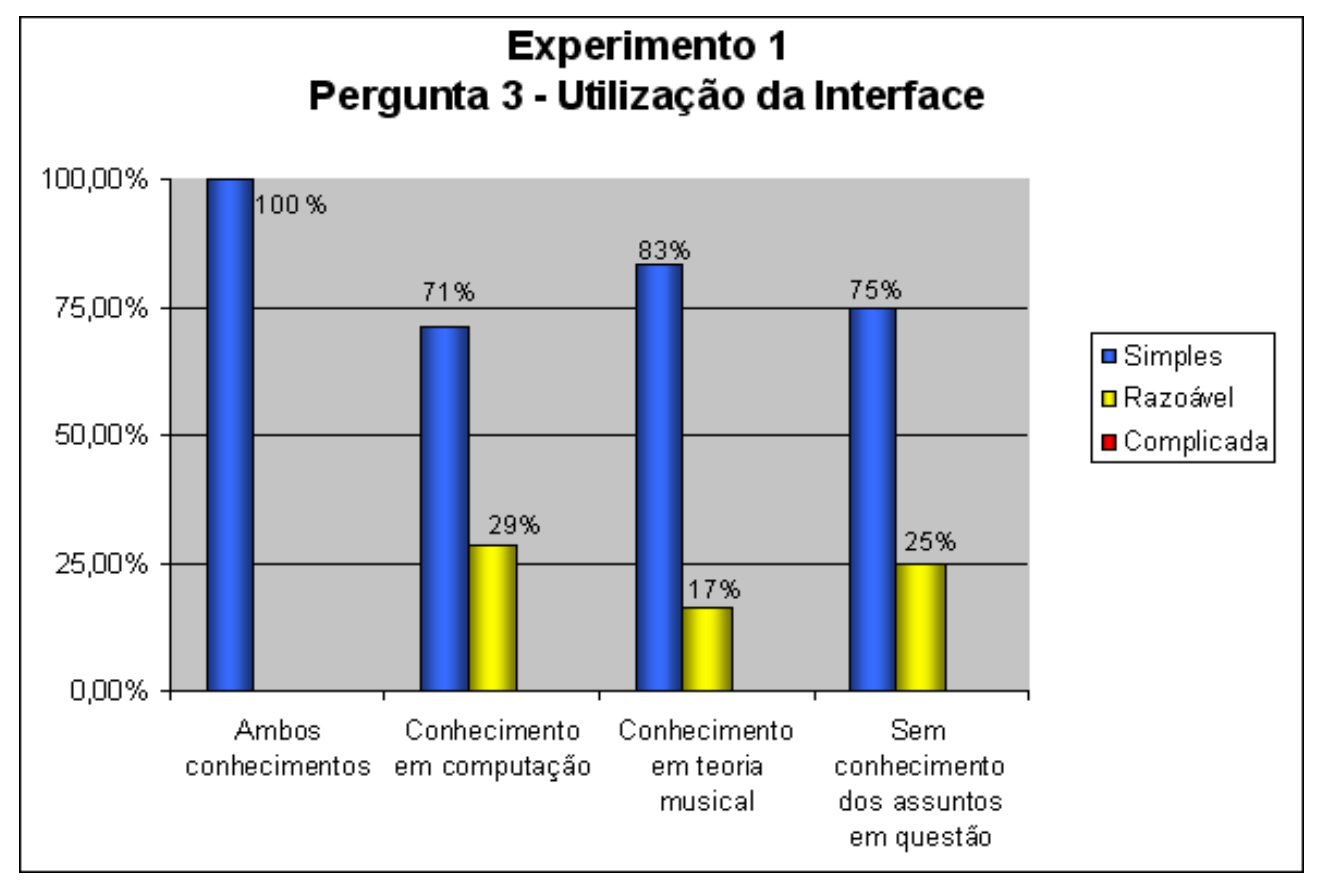

Figura 56: Facilidade de utilização da interface 
Analisando os resultados, pode-se verificar que o conhecimento de teoria musical facilita a utilização da interface, pois os dois grupos que detém este conhecimento obtiveram os maiores índices de opiniões favoráveis. A falta de familiaridade com os termos relativos à entrada musical pode ter contribuído para este resultado. O alto índice negativo (associado à resposta "razoável") no grupo com conhecimento apenas em computação poderia estar relacionado à comparação com interfaces de outros softwares. Infelizmente não houve esclarecimentos na parte de "comentários e sugestões" que ajudassem a identificar dificuldades específicas em relação ao formato da interface.

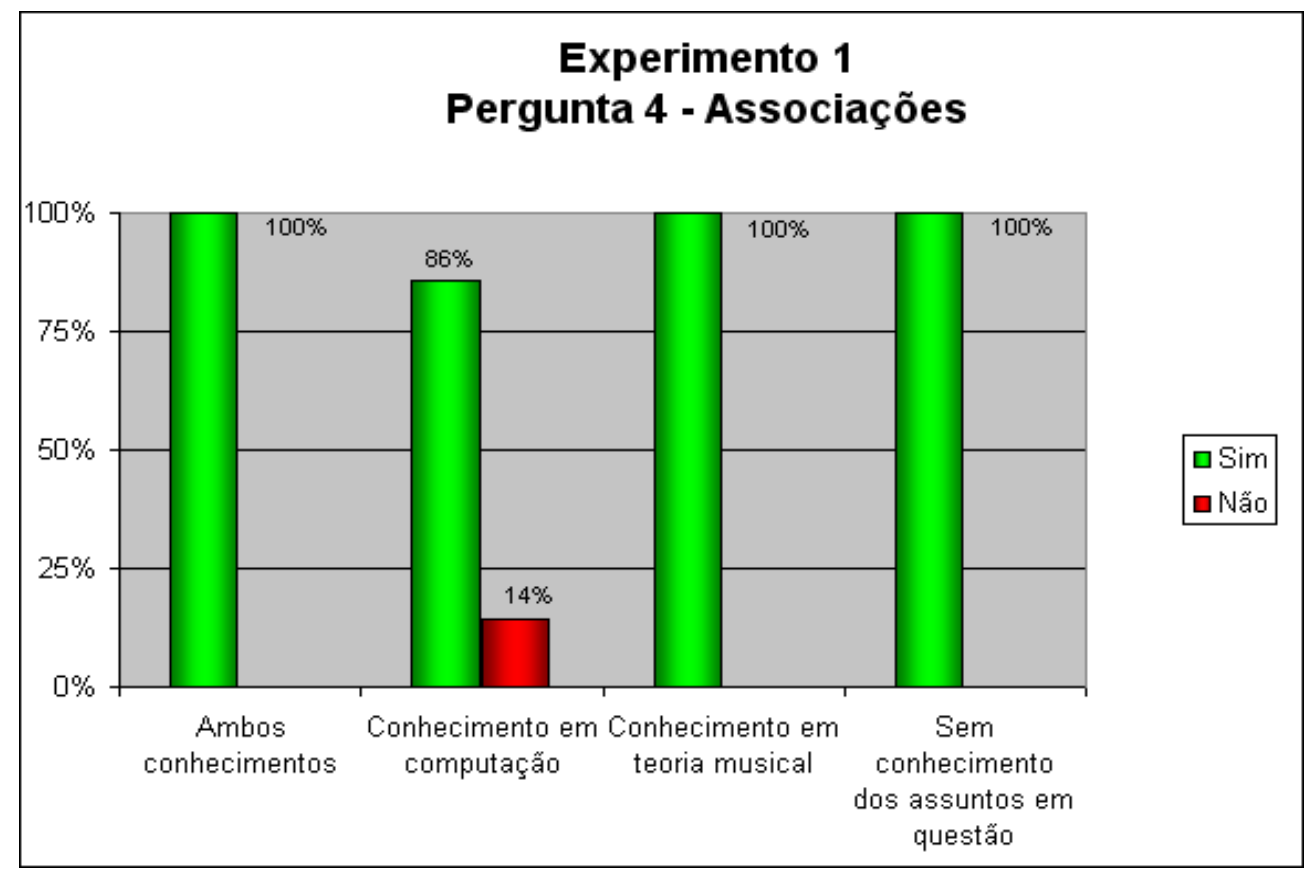

Figura 57: Clareza das associações entre as características musicais e a saída em vídeo

Em relação à clareza das associações (Figura 57) entre as informações de áudio e a saída em vídeo, houve um único indivíduo que declarou que estas não eram claras, no grupo com conhecimento apenas em computação. Como citado anteriormente, o conhecimento em teoria musical se mostra importante para facilitar a compreensão das conexões estabelecidas, pela familiaridade do usuário com as características sonoras extraídas da entrada. De qualquer forma, pode-se concluir que, de maneira geral, as associações estabelecidas deixaram claras as características áudio-visuais associadas.

Vale notar que a biblioteca AIM oferece inúmeros recursos para a criação de conexões entre informações de áudio e vídeo que não sejam óbvias ou facilmente perceptíveis, através da composição de objetos de análise de áudio com objetos de processamento de sinais de controle, a fim de se gerar resultados esteticamente mais interessantes. Evidentemente não era este o objetivo dos experimentos. 


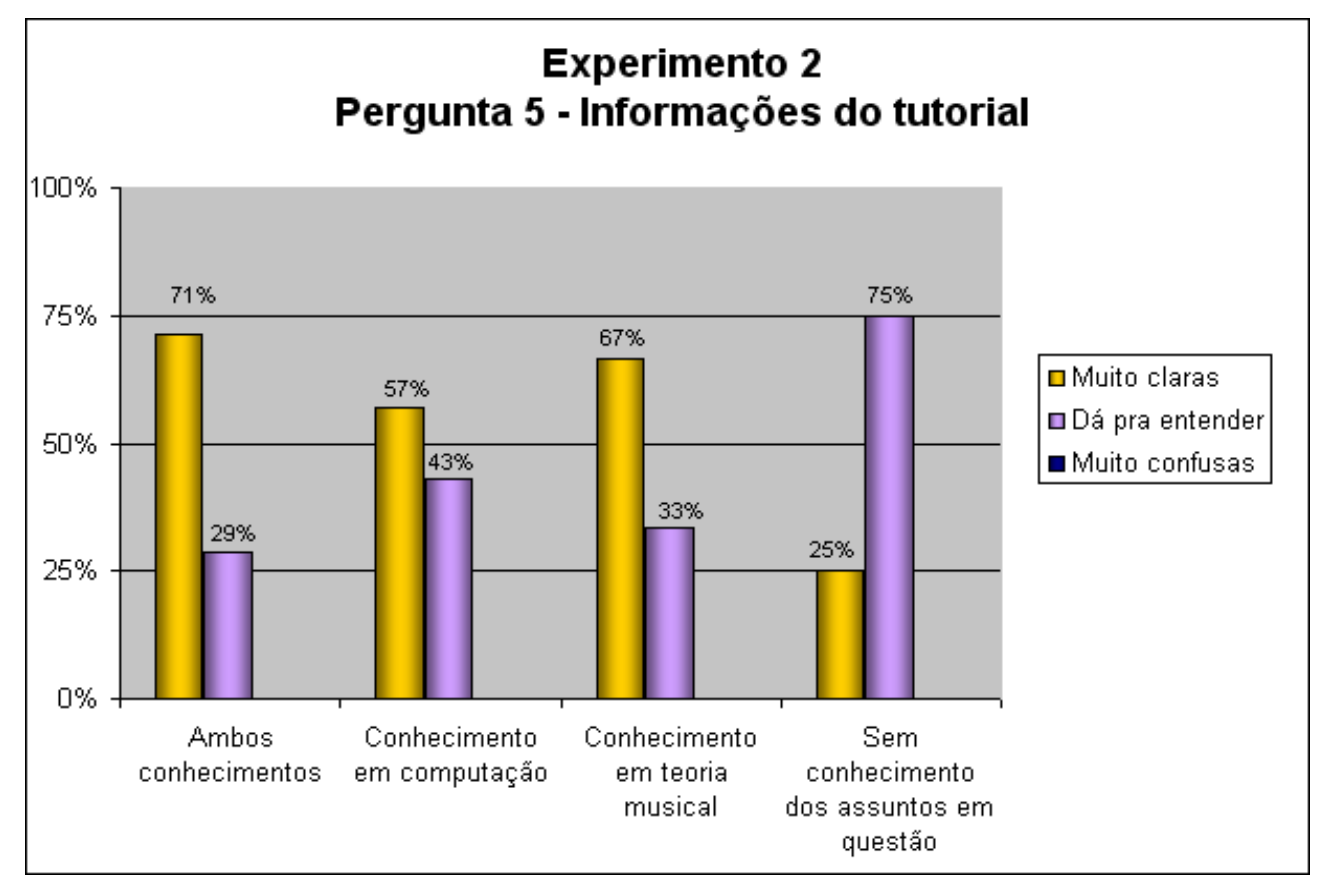

Figura 58: Clareza das instruções no tutorial do Experimento 2

A Figura 58 exibe as opiniões referentes à clareza das informações do roteiro descrito no Experimento 2. Parece implícito nas respostas que existe uma certa relutância dos voluntários em responder à alternativa mais negativa, provavelmente por polidez. De qualquer modo fica claro que as informações não atenderam plenamente às expectativas dos voluntários, muito especialmente entre aqueles que não possuem conhecimentos específicos às duas áreas envolvidas.

Das respostas dadas a esta pergunta pode-se concluir que a documentação que acompanha a biblioteca poderia possuir explicações mais detalhadas, especialmente das questões relacionadas à música, pois os usuários que não possuem muita familiaridade com este assunto encontram grandes dificuldades para utilizar os recursos da ferramenta. Por ser uma ferramenta computacional, grande parte dos potenciais usuários terá já alguma ligação com computação, o que justifica uma maior ênfase nas informações que auxiliem no entendimento das características musicais manipuladas pelos objetos da biblioteca.

Por outro lado, não é interessante sobrecarregar a documentação dos tutoriais já existentes com informações demasiadamente óbvias para potenciais usuários familiarizados com as duas áreas, pois estes tutoriais pretendem ser uma apresentação rápida e fluente dos recursos da biblioteca.

$\mathrm{Na}$ tentativa de resolver este dilema, será disponibilizado juntamente com a biblioteca um texto de apoio, baseado especialmente sobre o conteúdo do Capítulo 2 desta dissertação, a fim de complementar as informações dos tutoriais para aqueles usuários que sentirem esta necessidade. 


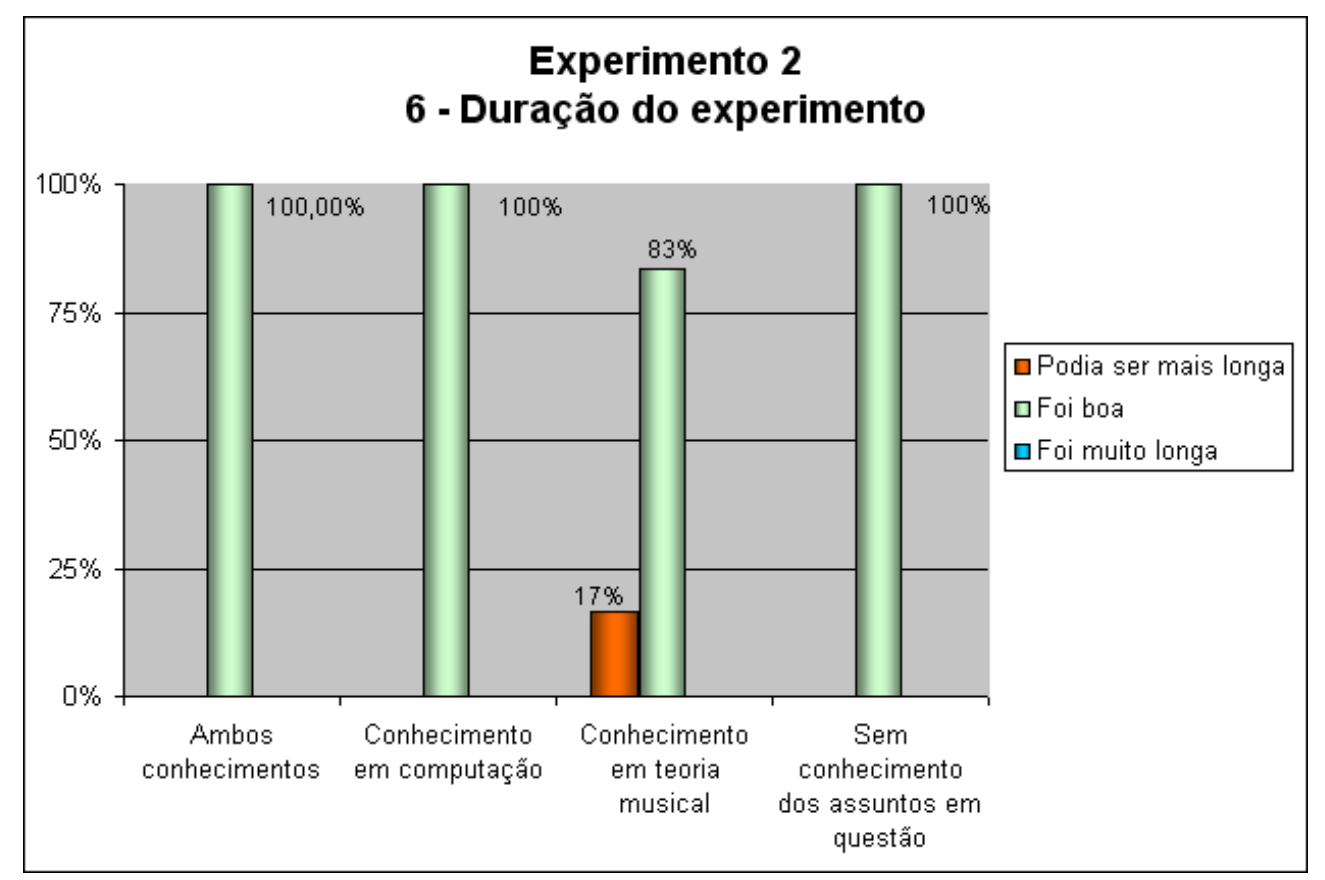

Figura 59: Avaliação da duração do segundo experimento

Como o segundo experimento possui um roteiro passo-a-passo para a montagem do patch relativamente extenso, achou-se conveniente avaliar se a duração do experimento estava adequada levando-se em consideração as dificuldades particulares de cada usuário (Figura 59). Como citado anteriormente, os usuários podiam realizar quantos testes quisessem durante o experimento; o foco da pergunta estava na quantidade de tarefas no roteiro sugerido. Houve apenas um indivíduo que sentiu falta de um roteiro mais longo, no grupo de pessoas com conhecimento apenas em teoria musical. De modo geral, o roteiro teve uma quantidade de tarefas adequada para estes usuários.

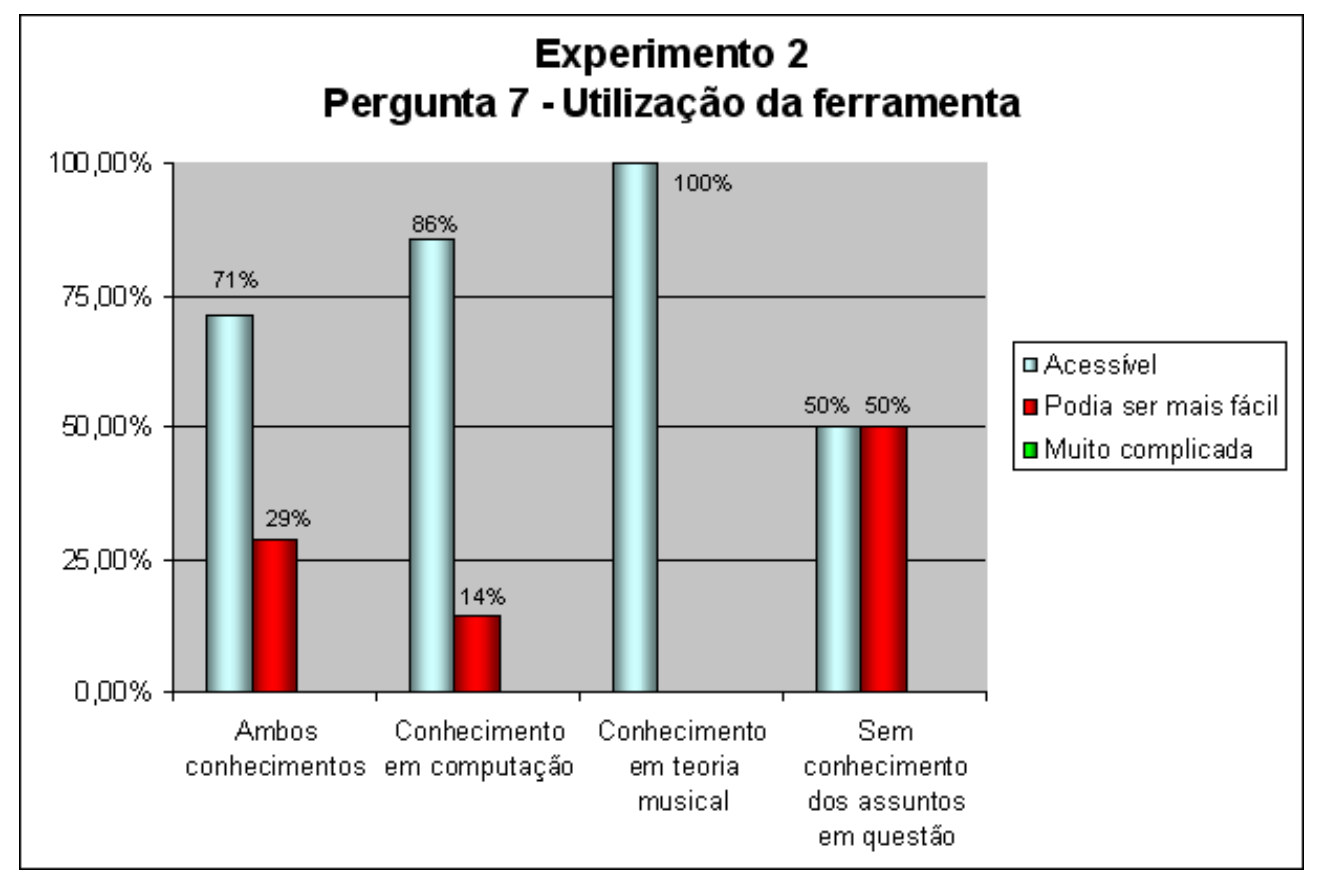

Figura 60: Facilidade de utilização da biblioteca na construção de patches 
A Figura 60 exibe o resultado da pergunta sobre a utilização da ferramenta, englobando neste contexto a programação em Pd com as bibliotecas GEM e AIM. É compreensível que o grupo que não possui conhecimento nem de computação nem de teoria musical seja o que encontrou maior dificuldade em programar utilizando a biblioteca. Porém, talvez surpreendentemente, o grupo de pessoas com conhecimento em ambos os assuntos teve o segundo maior índice de dificuldade/insatisfação. Uma hipótese para explicar este resultado é o fato de este grupo possuir o maior grau de conhecimento de ferramentas relacionadas e portanto o maior potencial de crítica. Mais uma vez, não havia informações adicionais na parte de "comentários e sugestões" que ajudassem a localizar precisamente o que poderia ser melhorado, tanto computacionalmente quanto em questões musicais, na opinião destes voluntários.

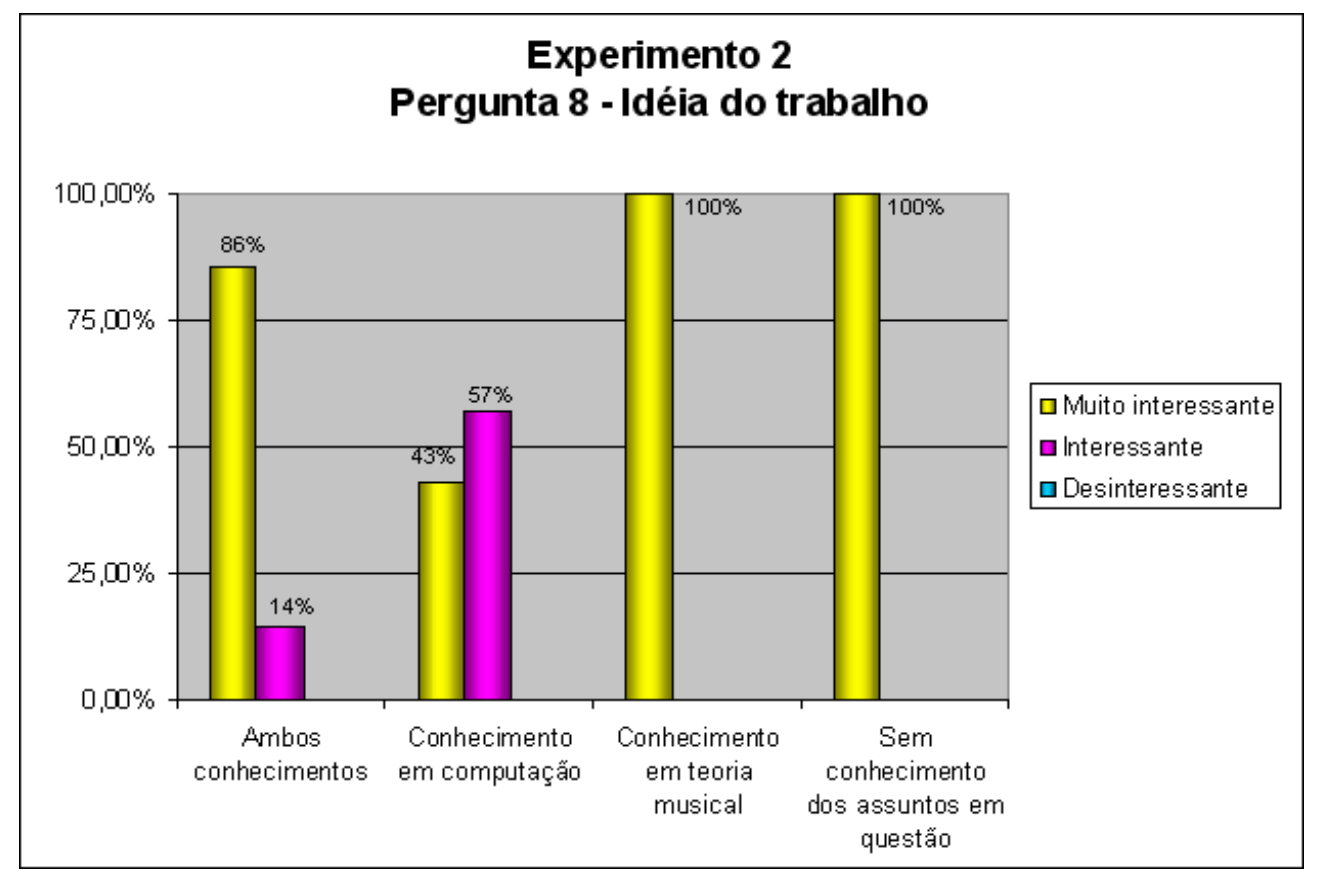

Figura 61: interesse dos usuários na proposta do trabalho

Por fim, perguntou-se aos usuários suas opiniões sobre o interesse do trabalho (Figura 61). Neste gráfico pode-se observar que o trabalho pareceu menos interessante para os usuários com conhecimento apenas em computação, podendo-se concluir que a afinidade com as questões musicais é um fator decisivo que contribui no interesse em utilizar a ferramenta.

Porém, verifica-se também que para o grupo de usuários que não conhecem os assuntos abordados a idéia do trabalho pareceu interessante. Uma hipótese para explicar isto é que se trata de um grupo mais heterogêneo, que não está ligado à questões computacionais e que desconhece trabalhos semelhantes, para os quais a possibilidade de se gerar resultados visuais através da análise de áudio com pouco esforço se torna um atrativo. Esta hipótese é confirmada por comentários de alguns usuários, sem nenhuma experiência computacional, que ficaram surpresos de conseguir montar um programa e de forma interativa controlar as imagens que visualiza na tela.

A partir das informações coletadas e analisadas, conclui-se que a biblioteca AIM possui potencial para ser explorada, tanto para os objetivos a que ela se propõe inicialmente, quanto como mais uma coleção de objetos disponível no Pd para ser utilizada livremente. Os resultados mostram que a biblioteca possui uma interface fácil de usar, uma proposta interessante e que gera atrativos para públicos bem diferentes. 


\section{Conclusões e Trabalho Futuro}

A biblioteca AIM foi desenvolvida com a finalidade específica de ser uma ferramenta para a geração de resultados visuais a partir de informações extraídas de uma entrada de áudio. Tal ferramenta poderia ser utilizada por duas categorias principais de usuários:

- pessoas interessadas em geral, sem nenhum conhecimento de computação, que podem manipular as interfaces pré-programadas em tempo-real, como instrumentos visuais;

- usuários interessados em programar patches Pd utilizando os objetos AIM para criar suas próprias interfaces e eventualmente novos objetos para a biblioteca.

Como esta biblioteca possui diversos objetos além daqueles responsáveis pela síntese de imagens, tais como objetos de análise de áudio e síntese e processamento de sinais de controle, usuários da linguagem $\mathrm{Pd}$ também podem utilizar estes objetos de forma independente das finalidades inicialmente previstas, para aplicações de diversos fins.

Uma aplicação possível para a biblioteca AIM para uso pessoal é gerar acompanhamentos visuais para compilações de músicas, como outros media players já existentes, que foram discutidos no Capítulo 1. A biblioteca oferece um gerenciador simples de playlists, e permite a alternância automática das associações através de scripts para controlar as interfaces, permitindo a composição de compilações acopladas de listas de músicas e formas de acompanhamento visual.

A biblioteca AIM também pode servir de ferramenta para Video Jockeys ( $V J_{S}$ ), nome dado aos artistas que criam performances visuais multimídia. A Figura 62 mostra algumas fotos de VJs durante suas performances em casas noturnas e festivais de música eletrônica. Estas performances são normalmente exibidas em telões e podem utilizar recursos diversos, como projeção de imagens, manipulação de vídeos pré-gravados ou imagens coletadas em tempo-real, em paralelo à performance sonora. Os VJs conduzem suas performance utilizando ferramentas computacionais para manipulação de áudio e vídeo em tempo-real. Vários VJs utilizam imagens abstratas em suas performances, e a associação destas com o áudio simultâneo é um recurso oferecido pela ferramenta AIM.
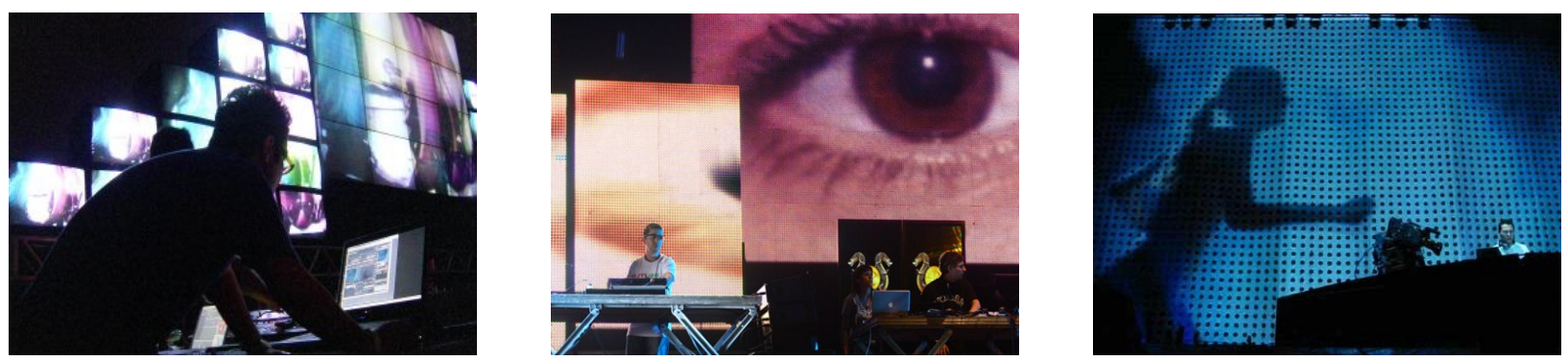

Figura 62: Momentos de performances de VJs

Outra possibilidade de utilização contemplada para a biblioteca AIM é como ferramenta auxiliar didática na musicalização infantil. A ferramenta pode servir como recurso lúdico no aprendizado pois possibilita ao aluno a visualização simultânea de mudanças em determinadas características musicais que ele está aprendendo. No caso do ensino de música para crianças portadoras de deficiências, tais associações podem compensar parcialmente alguma dificuldade inerente à sua deficiência [Louro, Alonso e Andrade 2006]. Para crianças com surdez, por exemplo, as técnicas de musicalização exploram habitualmente outros sentidos acoplados à audição. Determinados tipos de paralisia cerebral dificultam ao portador a formação de conceitos abstratos, e nestes casos a associação de um recurso visual pode ajudar a tornar concretos conceitos como altura 
musical ou intensidade. O uso de jogos didáticos em tais situações é freqüente, como por exemplo o movimento dos braços da criança para cima ou para baixo para indicar notas agudas e graves. Tais movimentos poderiam facilmente ser imitados pelo boneco disponível na biblioteca e utilizados através de projeções em sala de aula. Da mesma forma, a associação de movimentos de objetos a sons percussivos pode oferecer uma representação alternativa e divertida para figuras rítmicas.

Baseando-se nos resultados obtidos com os experimentos aplicados a voluntários, mostrados no Capítulo 4, conclui-se que a biblioteca AIM alcançou seus objetivos iniciais, abrindo ainda um grande espaço para desenvolvimentos posteriores que complementem e melhorem esta primeira versão da biblioteca. Considera-se essencial para esta melhoria a colaboração de usuários, através de críticas, sugestões e contribuições como desenvolvedores.

Um ponto a ser melhorado, que foi observado nas análises dos experimentos, é a exploração didática de questões musicais relativas à ferramenta. Nesse sentido foi incluído um texto didático apresentando não somente a biblioteca como também alguns conceitos fundamentais sobre áudio e som. Os tutoriais desenvolvidos têm como objetivo apresentar rapidamente os recursos da biblioteca, mostrando os objetos disponíveis, através de patches onde o usuário pode interagir e visualizar os resultados. Poderiam ser disponibilizados patches didáticos que explicassem conceitos básicos relacionados ao trabalho, bem como outros exemplos de utilização mais complexa da ferramenta, que estendessem o repositório de objetos utilizados a outros objetos usuais do Pd.

Uma linha promissora para um trabalho futuro é a utilização de externals na criação de objetos da biblioteca. Este é um recurso disponível no Pd que não foi explorado nesta primeira versão da biblioteca AIM, mas que aumenta o número de possibilidades de desenvolvimento, além de aliviar o custo computacional. A biblioteca poderia ser enriquecida com novos objetos de análise de áudio, síntese de imagens e processamento de sinais de controle. Novos objetos de análise de áudio poderiam estar associados à detecção de características musicais específicas, como reconhecimento de notas, acordes ou padrões rítmicos. Em relação à síntese e processamento de sinais de controle, o desenvolvimento é guiado principalmente pela necessidade de especificar e controlar movimentos ou padrões complexos na saída visual.

A biblioteca GEM utilizada no desenvolvimento deste trabalho possui diversos recursos gráficos que também não foram utilizados, alguns deles por demandarem um alto custo de processamento, outros por não se ter encontrado uma finalidade específica inicialmente. Existem efeitos de texturas e iluminação individual dos objetos, projeções de imagens ou vídeos sobre as superfícies dos objetos, entre outros. Como o GEM utiliza a biblioteca OpenGL, a criação de novos objetos gráficos através de externals que utilizem diretamente esta biblioteca permitirá o desenvolvimento de objetos e efeitos visuais mais sofisticados, como espelhamento e esfumaçamento.

Dentro das possibilidades de utilização descritas, a utilização direta da biblioteca AIM por usuários provavelmente traria muitas sugestões de melhorias e de novos recursos a ser desenvolvidos. Seja no uso pessoal, nas aplicações didáticas, ou na utilização da ferramenta por VJs, o contato direto dos usuários com os recursos disponíveis é o ponto de partida para as sugestões e conseqüente evolução da biblioteca. Buscando esta utilização em conjunto é que a biblioteca estará disponível para download no endereço http://compmus.ime.usp.br, podendo ser utilizada e modificada livremente. 


\section{Referências Bibliográficas}

Buxton W., Dannenberg R. e Vercoe B. (1986) “The Computer as Accompanist". Proceedings of the CHI'86, pps 41-43.

Caznok Y. B. (2003) “Música - Entre o Audivel e o Visivel”, Editora UNESP, São Paulo.

Charlebois P. O. (2005) "Graphical Representation of Sound for the 'Soundscape' Immersive Environment using the PD-Gem (OpenGL) Framework”. Thesis, McGill University.

Collopy F., Fuhrer R. e Jamenson D. (1999) “Visual Music in a Visual Programming Language”, In: IEEE 1999 Symposium on Visual Languages, pps. 111-118.

Collopy F. (2007) “Visual Music as a Performing Art”, In: Offscreen, Vol 11, pps. 8-9.

Dannenberg R. B. (1984) “An On-Line Algorithm for Real-Time Accompaniment”. In: Proceedings of the International Computer Music Conference (ICMC) 1984, pps 193-198.

Dannenberg R. B. e Mukaino H. (1988). "New Techniques for Enhanced Quality of Computer Accompaniment". Proceedings of the Internacional Computer Music Conference (ICMC) 1988.

Fornari J. E. (2003). "Sintese Evolutiva de Segmentos Sonoros", tese de doutorado, Faculdade de Engenharia Elétrica e Computação, Universidade Estadual de Campinas (UNICAMP).

Iazzetta F. (2003) “A Performance Interativa em Pele”, In: IX Simpósio Brasileiro de Computação Musical, Campinas, São Paulo.

Jácome J., Dahia M., Ramalho G. e Meira S. (2007) “ViMus: Sistemas Interativos em Tempo-Real para Processamento AudioVisual Integrado". Anais do XI Simpósio Brasileiro de Computação Musical, pp. 231-234.

Jacquemin C. (2004) "Architecture and Experiments in Networked 3D Audio/Graphic Rendering with Virtual Choreographer". In: Proceedings of the International Conference Sound and Music Computing, 2004.

Lima C. C. (1999) "Geração de imagens com texturas utilizando OpenGL", dissertação de mestrado, Centro de Ciências da Economia e Informática, Universidade da Região da Campanha (URCAMP).

Louro V. S., Alonso L. G., Andrade A. F. (2006) "Educação Musical e Deficiência: Propostas Pedagógicas", Editora Estúdio Dois, São Paulo.

Maur K. V. (1999) “The Sound of Painting: Music in Modern Art”, Pegasus Library, Prestel Books.

Nagashima Y. (1998) "Real-time Interactive Performance with Computer Graphics and Computer Music", In: Proceedings of the 7th IFAC/IFIP/IFORS/IEA Symposium on Analysis, Design, and Evaluation of Man-Machine Systems, International Federation of Automatic Control, 1998.

Ng K., Popat S., Stefani E., Ong B., Cooper D. e Smith-Autard J. (2000) "Music via Motion: Interactions Between Choreography and Music", In: Proceedings of the Inter-Society for the Eletronic Art (ISEA).

Orio N., Lemouton S., Schwarz D. (2003) "Score Following: State of the Art and New Developments". Proceedings of the International Computer Music Conference (ICMC) 2003.

Paquette D. (2001), "Le Piano a Couleurs et la Correpondance des Arts", Fondation NicolasClaude Fabri de Peiresc, Bruxelas, Bélgica. http://www.peiresc.org/pianocoul.htm (acesso em 09/01/2008).

Peacock K. (1988) "Instruments to Perform Color-Music: Two Centuries of Technological Experimentation”, In: Leonardo, Vol 21, Nro 4, pps. 397-406. 
Puckette M. e Lippe C. (1992) "Score Following in Practice". Proceedings of the International Computer Music Conference (ICMC) 1992.

Puckette M. (1996) "Pure Data: another integrated computer music environment”, In: Proceedings of the International Computer Music Conference (ICMC) 1996, pps. 269-272.

Puckette M., Apel T. e Zicarelli D. (1998) “Real-time audio analysis tools for PD and MSP”, In: Proceedings of the International Computer Music Conference (ICMC) 1998.

Puckette M. e Brown J. (1998) “Accuracy of Frequency Estimates Using the Phase Vocoder”, In: Proceedings of the IEEE Trans. Speech and Audio Processing, pps. 166-176.

Rowe R. (1994) “Interactive Music Systems: Machine Listening and Composing”. The MIT Press, Cambridge, London, England.

Rowe R. (2001) “Machine Musicianship”, The MIT Press, Cambridge, Massachusetts.

Ruschioni R. (1999) “Ambientes Unificados para a Produção Integrada Imagem-Som em Mídia Computacional”, dissertação de mestrado, Escola de Comunicação e Artes (ECA), USP.

Sakane F. T. (1997) "Princípios de Telecomunicações I - ELE 31 - Notas de Aula", Instituto Tecnológico de Aeronáutica. http://www.ele.ita.br/ fpires/APOSTI 1.DOC (acesso em 09/01/2008).

Salles F. (2002) "Imagens Musicais ou Música Visual: Um estudo sobre as afinidades entre o som e a imagem baseada no filme 'Fantasia' de Walt Disney", dissertação de mestrado, PUC/SP.

Santos E. T. (1994) “Avaliação do Algoritmo de Ray Tracing em Multicomputadores”, dissertação de mestrado, Escola Politécnica da Universidade de São Paulo (Poli/USP).

Schertenleib S., Gutiérrez M., Vexo F. e Thalmmann D. (2004) “Conducting a Virtual Orchestra”, In: IEEE Multimedia: Multisensory Communication and Experience through Multimedia, pps. 40-47.

Schwarz D., Orio N. e Schnell N. (2004) "Robust Polyphonic Midi Score Following with Hidden Markov Models". Proceedings of the International Computer Music Conference (ICMC) 2004, pps 442-445.

Sedes A., Courribet B. e Thiébaut J.-B. (2003) "EgoSound, an Egocentric, Interactive and RealTime approach of Sound Space”, In: Proc. of the $6^{\text {th }}$ Intl. Conf. on Digital Audio Effects, London, UK.

Tafner M. A. (1996). "Reconhecimento de Palavras Faladas Isoladas Usando Redes Neurais Artificiais", dissertação de mestrado, Departamento de Engenharia de Produção e Sistemas, Universidade Federal de Santa Catarina (UFSC).

Tarabella L., Magrini M. e Scapellato G. (1997) "Devices for Interactive Computer Music and Computer Graphics Performances”, In: IEEE First Workshop on Multimedia Signal Processing, pps. 65-70.

Watt A. (2000) “3D Computer Graphics”, Addison-Wesley (3ª edição).

Winkler T. (1999) "Composing Interactive Music - Techniques and Ideas Using Max". The MIT Press, Cambridge, London, England.

Wright M., Freed A. e Momeni A. (2003) “OpenSound Control: state of the art 2003”, In: Proceedings of the 2003 Conference on New Interfaces for Musical Expression, pps. 153-160, Montreal, Canada.

Wuensche C. A. (2005) "Seminários sobre o ensino de Física", Departamento de Ciências Espaciais e Atmosféricas, Instituto Nacional de Pesquisas Espaciais (INPE). http://www.cea.inpe.br/ alex/FisicadaMusica/fisica_da musica.pdf (acesso em 10/01/2008). 


\section{Apêndice: Tutoriais}

\section{Tutorial 1}

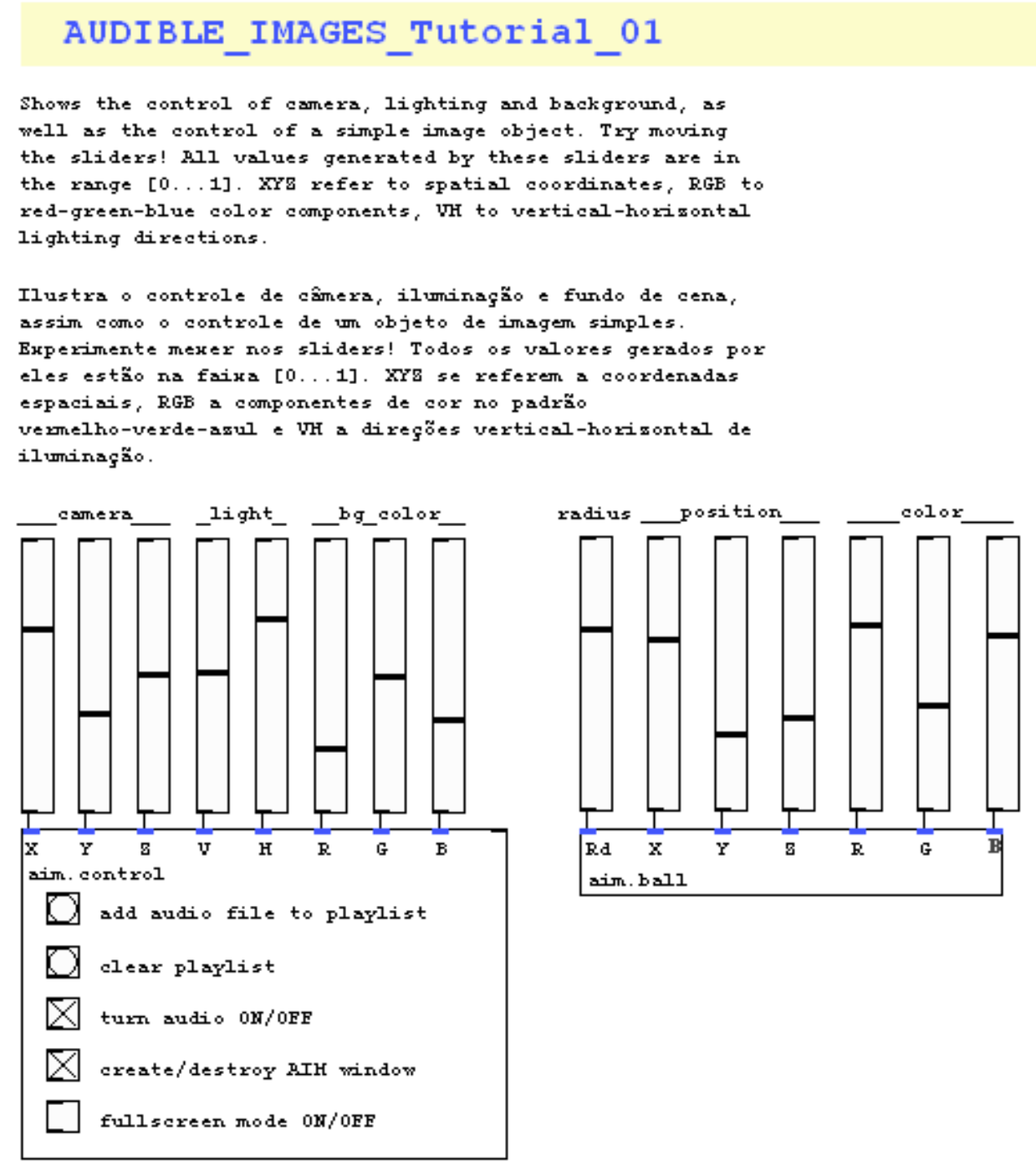

\section{Exemplo de saída do Tutorial 1}

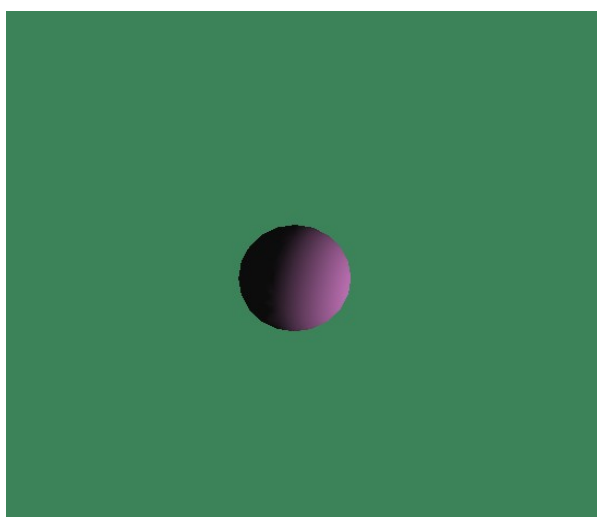




\section{Tutorial 2}

\section{AUDIBLE_IMAGES_Tutorial_02}

Illustrates the use of two basic audio analysis objects.

The object aim. amplitude tracks the rms amplitude of the signal, converting it to the range $[0 \ldots 1]$.

The object aim.pitch tracks the main musical pitch of the signal, converting it to the range [0...1]

Both objects take an argument which is the time window over which values are smoothed.
Ilustra o uso de duas funçöes básicas de análise de áudio.

A função aim. amplitude acompanha a envoltória de amplitude rms do sinal, devolvendo valores entre [0..1]

A função sim.pitch rastreia a principal altura musical no sinal, devolvendo valores entre $[0 \ldots 1]$.

Ambos os objetos recebem um argumento que $́$ a janela de tempo na qual os valores são suavigados.
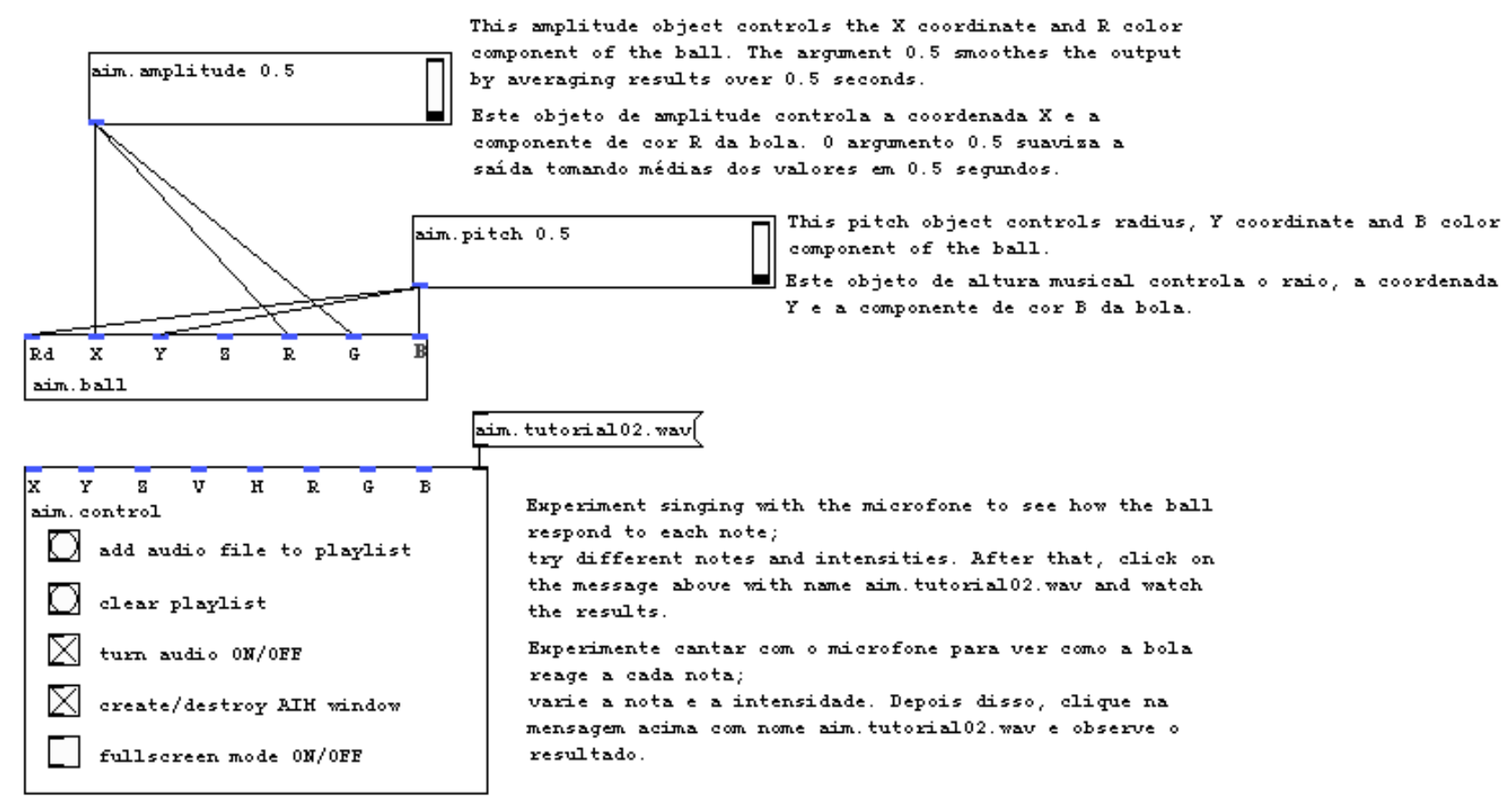

\subsection{Exemplos de saídas do Tutorial 2}
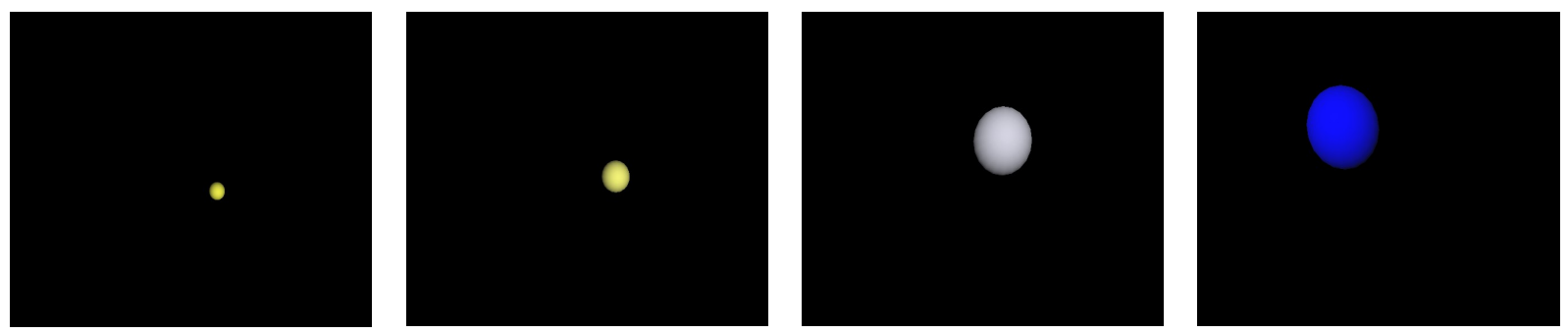


\section{Tutorial 3}

\section{AUDIBLE IMAGES Tutorial 03}

Some new objects

The object aim.attack is an audio analysis object: it generates a bang whenever a note or event onset is detected. The object aim.invert is a signal processing unit: it converts a $[0 \ldots 1]$ input signal $x(t)$ into $1-x(t)$

The object aim. flyingsquares is an image synthesis object: it controls the movement of "flying" squares with a predefined motion from the observer into the screen, which are triggered bY the leftmost inlet. The second inlet controls the concentration of the initial points and the remaining three inlets control color (RGB).

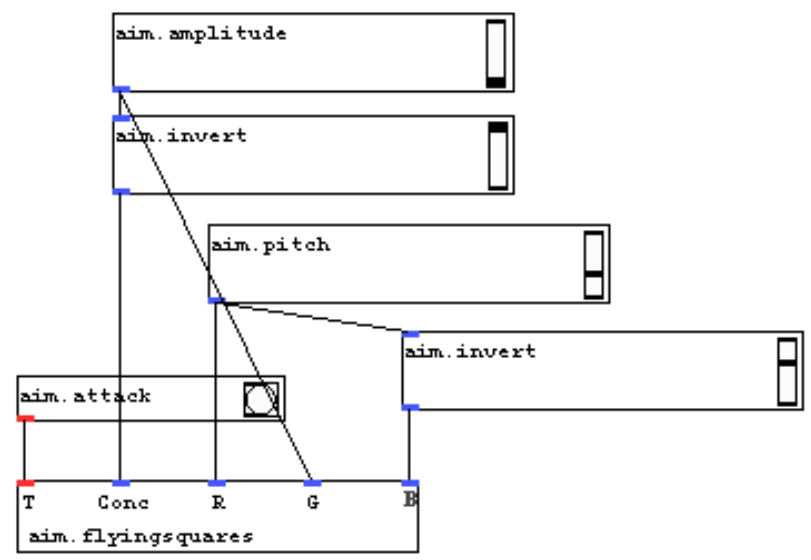

\subsection{Exemplos de saídas do Tutorial 3}
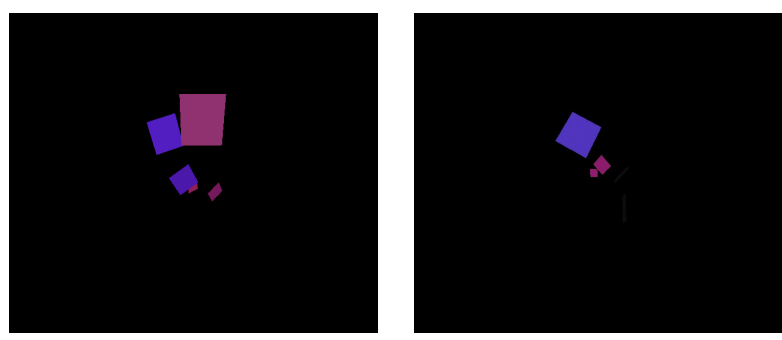

Plguns objetos novos.

o objeto aim.attack é um objeto de análise de áudio: ele devolve um bang a cada início de nota ou evento na entrada.

o objeto aim.invert é uma unidade de processamento de sinais: ele converte um sinal $x(t)$ de entrada $[0 \ldots 1] \mathrm{em}$ $1-x(t)$.

0 objeto sim. flyingsquares $\dot{e}$ um objeto de sintese de imagens: ele controla o movimento de quadrados que têm uma trajetória pré-definida partindo do observador em diregão ao fundo da tela, disparados pelo inlet da esquerda. 0 segundo inlet controla a concentração dos pontos iniciais e os outros três inlets controlam a cor (R.GB).

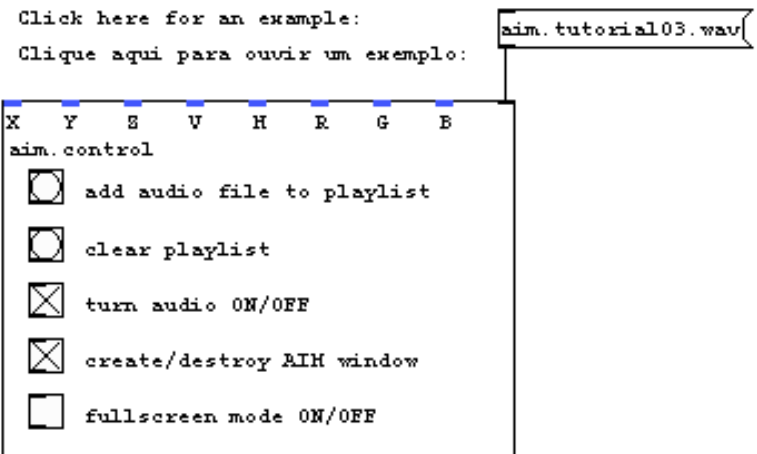

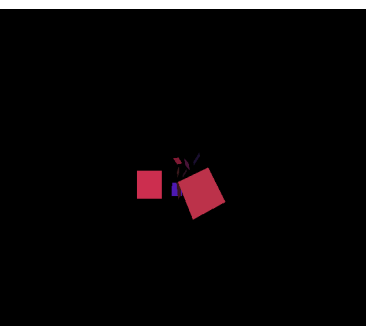

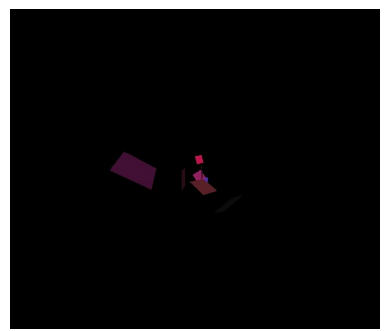




\title{
4. Tutorial 4
}

\section{AUDIBLE IMAGES Tutorial 04}

This tutorial will teach $Y$ ou how to create rour own DIH programs. If rou speak english please alick on the box labeled "HOW T0"

Este tutorial vai ensinálo a criar seus próprios programas uIH. Se você fala português clique na caixa "COHo FAgER". ao lado.

\subsection{Subpatch "COMO_FAZER" do Tutorial 4}

\author{
COMO_FAZER_SEU_PRÓPRIO_PROGRAMA_AIM \\ Neste tutorial você montará um programa RIH desde o inicio \\ 0 espaço em branco ì direita destes comentários serve para \\ você colocar os objetos AIH. Com o mouse, selecione o menu \\ "Put" e dentro dele a opģão "object". Aparecerá uma \\ caixinha com bordas tracejadas. Arraste-a até a área branca \\ e dê um elique com o mouse para soltá-la. Dentro dela \\ digite "aim.control" (sem as aspas) \& em seguida clique com \\ - mouse na área fora da caixinha. o objeto de controle da \\ biblioteca AIH aparecerá. Automaticamente o ádio é \\ habilitado e a janela de saída de vídeo é gerada. \\ Vá novamente ao menu Put->0bject, coloque a caixinha na \\ área branca, digite "aim. amplitude" e clique fora do \\ caixinha. Repita essas operaçöes para criar os objetos \\ "sim. rotation", "sim.pitch", "aim.invert" e "aim.ball". \\ 0s objetos possuem entradas e saidas, identificadas por \\ pequenos retângulos axuis. As entradas são localixadas na \\ parte superior da caixa, enquanto as saidas ficam na parte \\ inferior. Coloque o mouse sobre a saida axul do objeto \\ "aim. amplitude" e observe que o cursor se transformará em \\ um círculo. Dê um dique e sem soltar o botão do mouse \\ arraste até a primeira entrada do objeto "aim.ball", \\ soltando o botão do mouse quando o cursor se tormax \\ novamente um circulo. observe que a conexăo é indicada por \\ uma linha. Repita o procedimento para criar uma conexão \\ entre a saida do objeto "aim.pitch" a a quinta entrada do \\ objeto "aim.ball" (identificada com a letra R). Note que \\ você pode arrastar os objetos com o mouse para tornar a \\ aparência do programa mais limpa. \\ Crie mais quatro conexões: \\ 1) entre a primeira saida de "aim.rotation" e a 2a entrada \\ de "aim.ball" (entrada $\mathrm{X}$ ), \\ 2) entre a 2a saida de "aim.rotation" a a terceira entrada \\ de "aim.ball" (entrada $Y$ ) \\ 3) entre a saida de "aim.pitch" a a entrada de "aim.invert", \\ 4) entre a saida de "aim.invert" e a úlima entrada de \\ "aim.ball" (entrada B) \\ Em seguida selecione o menu "Edit" e dentro dele a opção \\ "Edit Hode", para sair do modo de ediç̃o e entrar no modo \\ de execuģ̃̃. \\ Utilixe o microfone para gerar sons e visualixe o resultado \\ na janela GEH. Se preferix usar um arquivo de áudio, \\ selecione a opç̃o "add audio file to playlist" dentro do \\ objeto "aim. control" e escolha qualquex arquivo wav.
}




\section{Tutorial 5}

\section{AUDIBLE_IMAGES_Tutorial_05}

Hore about the aim. control object

Mpart from controlling the camera $\mathrm{XY}$ coordinates, vertical and horizontal direction of external lighting and color RGB of the background, the aim. control object is also responsible for a few other things:

Control of the playlist:

The default audio input for $\mathrm{AIH}$ is the microphone, but the aim.control object can manage a list of audio files for playing in a circular fashion. There are buttons on its graphical interface for adding an audio file to the end of the playlist, and also for emptring the playlist. You can also send messages to the last inlet for adding several audio files at once to the playlist. You already saw this trpe of message in tutorials 2,3 and 4 For instance, sending the message to the last inlet of aim.control will start playing aim. tutorial02.wav, then aim. tutorial03. wav, aim. tutorial04. wav and back to aim. tutorial02. wav and so on

Clearing the playlist makes the audio input source returns control to the microphone.
Hais informações sobre o objeto aim. control

plém de controlar as coordenadas XYZ da câmera, direçôes vertical e horizontal da iluminação externa e componentes RGB da cor de fundo, o objeto sim.control também é responsável por algumas outras funcionalidades:

Controle da playlist:

A entrada de áudio padrão da biblioteca AIH é o microfone, mas o objeto aim.control pode gerenciax uma lista de arquivos de áudio executada de forma circular. Existem botões na interface gráfica para adicionar um arquivo de ádio ao fim da playlist e para limpar a playlist. Você também pode mandax mensagens para o úl timo inlet adicionando muitos arquivos de áudio de uma só ver na playlist. Você já deve ter visto este tipo de mensagem nos tutoriais 2 e 3. Dessa fouma, enviando a mensagem para o ill timo inlet do sim. control irá começax a tocax o arquivo aim. tutorial 02. wav, seguido do arquivo sim. tutorial03. wav, depois o axquivo aim. tutorial05. wav, novamente o aim. tutoriol02. wav e assim por diante

0 comando para limpax a playlist fax com que o controle da entrada de áudio volte para o microfone.

im, tutoriol02. wav, aim, tutoriol03. way, sim, tutorial05. wav

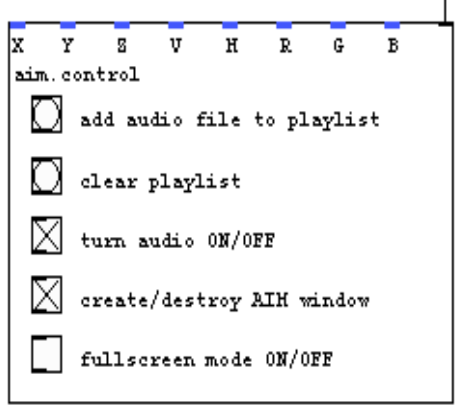




\section{Tutorial 6}

\section{AUDIBLE_IMAGES_Tutorial_06}

Illustrates a slightl more complex image sYrthesis object. Right-click and open the window aim.doll for information about its inlets.

The aim. expand object takes a portion of a $[0 \ldots 1]$ signal and stretches it to the full [0..1] range. For instance, "aim. expand $00.5 "$ doubles the range of the input signal. The function aim.sine generates a $[0 \ldots 1]$ sinusoidal signal with fxequency (in $\mathrm{H} x$ ) given bY the axgument.

The aim. chebYshev object computes the k-th ChebYshev polynomial of the input [0..1] signal, where $k$ is the creation argument.

You can open anY $\mathrm{AIH}$ object bY right-clicking on $i t$ and selecting "open" or "help". Inside each object you will find more documentation.

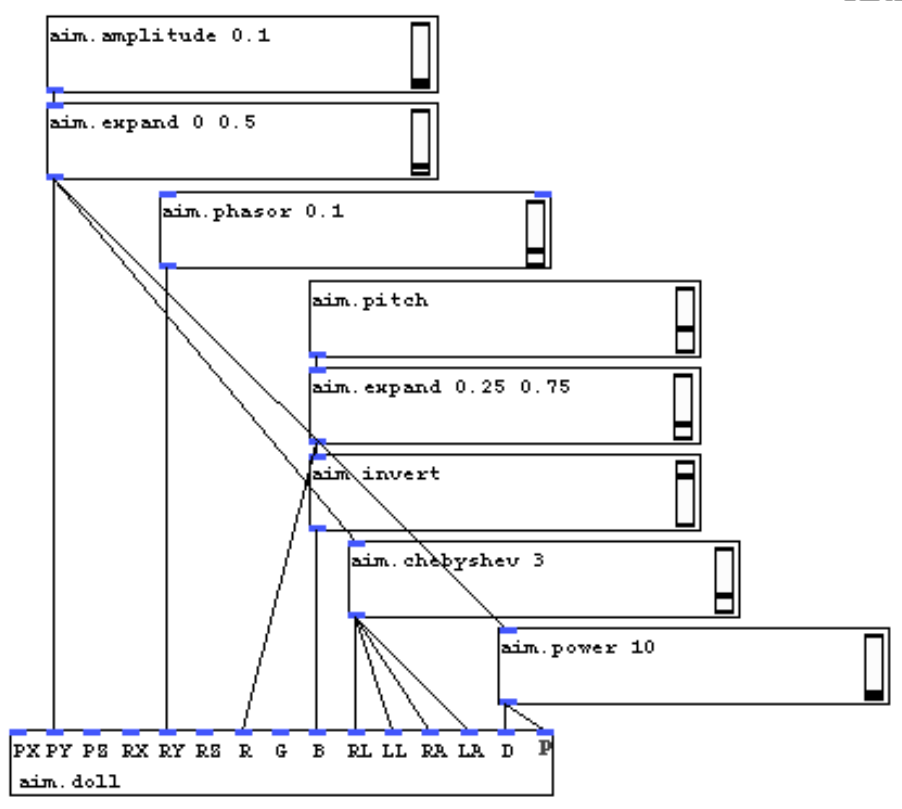

Ilustra um objeto de sintese de imagens um pouco mais complexo. Clique na janela aim. doll com o botão direito do mouse e selecione "open" para informagão sobre seus inlets. 0 objeto aim. expand recorta uma porção de um sinal [0..1] e estica até a faixa total [0..1]. Por exemplo,

"aim. expand $00.5 "$ dobra os valores do sinal de entrada. A função aim.sine gera um sinal senoidal entre [0...1] com freqüência (em $\mathrm{Hz}$ ) dada pelo argumento.

0 objeto aim. chebyshev aplica o k-́́simo polinômio de Chebyshev ao sinal [0..1] da entrada, onde $k$ é o valor do argumento de criação.

Você pode abrix qualquex objeto $\mathrm{AIH}$ clicando com o botz̃o direito do mouse sobre ele e selecionando "open" ou "help". Dentro de cada objeto você encontrará uma documentação adicional

Click here to hear an example

Clique aqui para ouvix um exemplo:

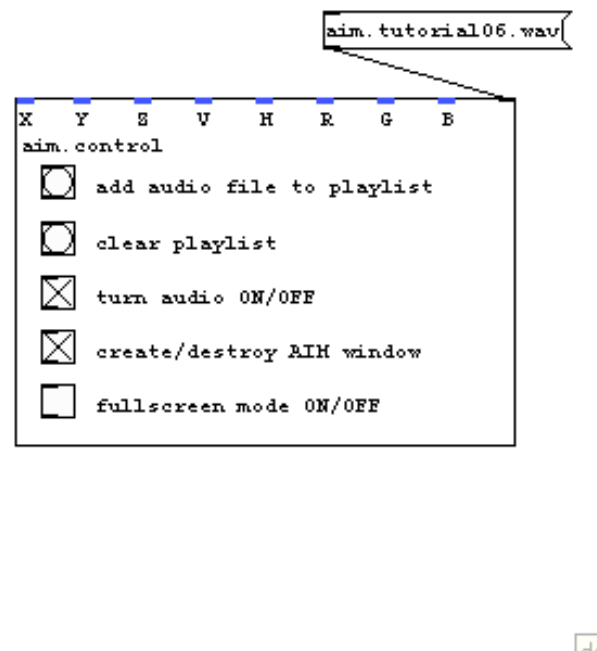

\subsection{Exemplos de saídas do Tutorial 6}
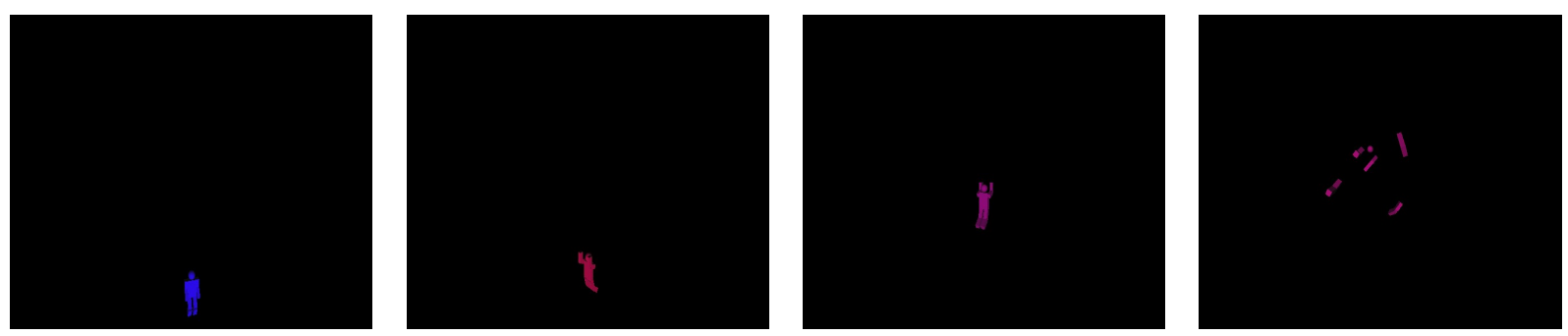


\section{Tutorial 7}

\section{AUDIBLE_IMAGES_Tutorial_07}

Ilustrates the use of predefined functions to synthesige

[0...1] parameter signals.

The function sim.sine generates a $[0 \ldots 1]$ sinusoidal signal with frequency (in $\mathrm{Hz}$ ) given by the axgument.

The function aim.invert computes an inverted [0..1] signal $b_{Y}$ the formula invert $(x)=1-x$

The function aim. chebyshev applies the $k$-th Chebyshev

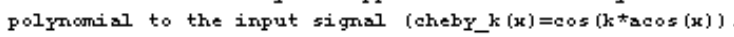

The function aim.compress takes $a[0 \ldots 1]$ input signal and rescales it to the range [a...b] (a,b are given arguments).

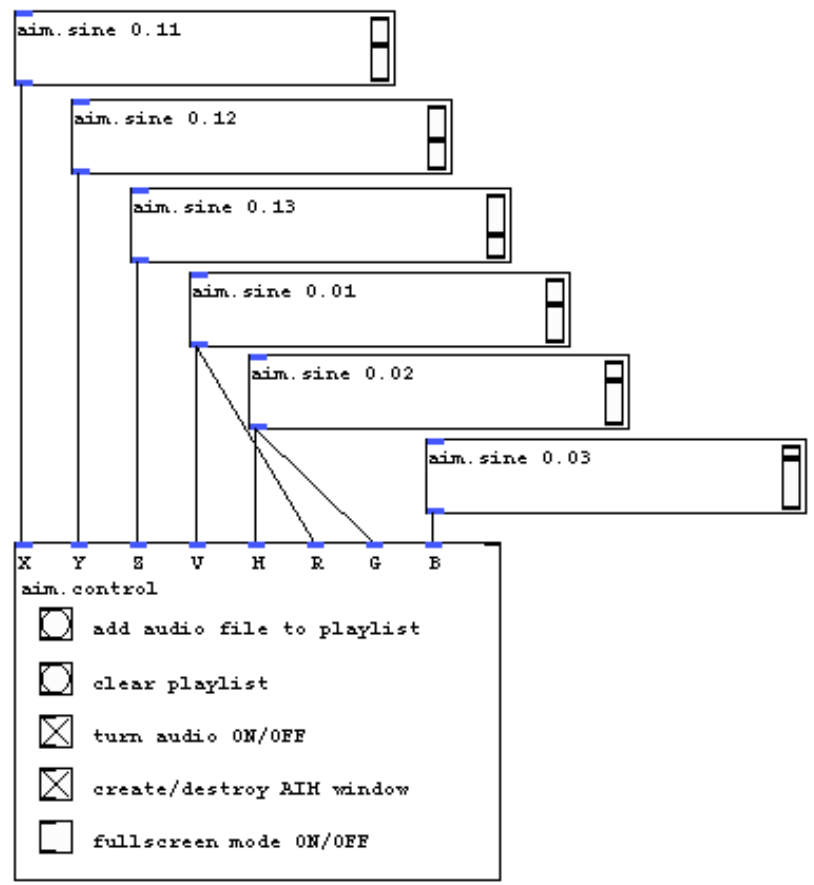

\subsection{Exemplos de saídas do Tutorial 7}
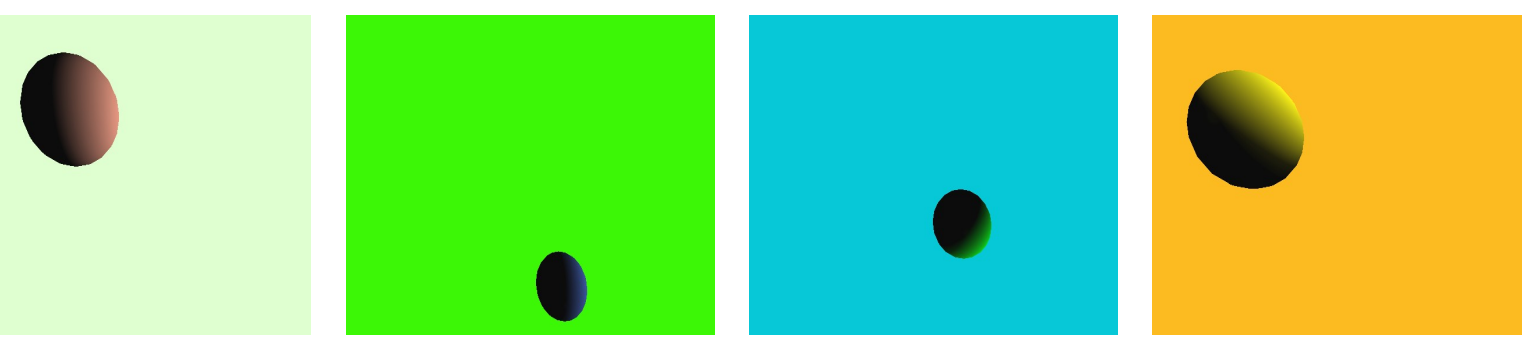

pstra o uso de fungóses pré-definidas para geração de parâmetros entre $[0 \ldots 1]$.

A funģäo sim.sine gera um sinal senoidal entre [0..1] com frequência (em $\mathrm{Hz}$ ) dada pelo argumento.

A função aim.invert faz a inversão de um sinal [0..1] dado na entrada pela fómula invert $(x)=1-x$.

A função aim. chebyshev transfouma os valores de entrada

[0...1] pelo polinâmio de Chebyshev de ordem $k$, pela fó

I funçäo aim.compress recebe um singl [0..1] de entrada e dados)

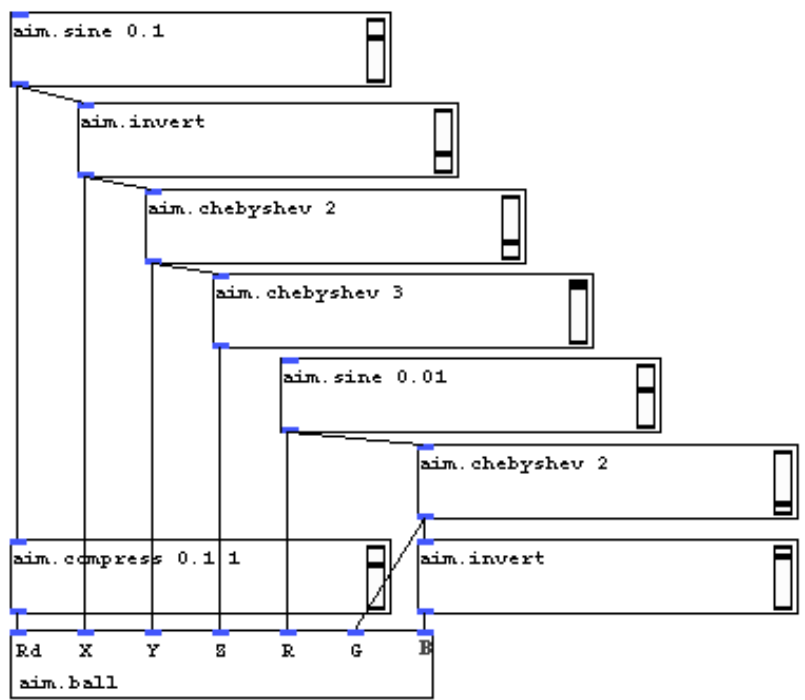

aim.ball muda sua escala para a faixa $[\mathbf{a} \ldots \mathrm{b}](\mathrm{a}, \mathrm{b}$ são axgumentos 


\section{Tutorial 8}

\section{AUDIBLE_IMAGES_Tutorial_08}

Ilustrates the use of predefined functions to synthesiat conventional motions and trajectories.

The function aim. rotation generates two [0..1] sinusoidal signal in such a way that the $Y$ define a circular motion in two coordinates. Its arguments are frequency and radius of rotation.

The function aim.mirrox reflects the part of a signal below a given threshold. The default value of the threshold is 0.5 , creating a reflection of the lower half onto the upper hall.

observe how the first ball (red) rotates on the $\mathrm{XY}$-plane (the GEH window plane) and at the same time goes to and fro in the 8 axis, adjusting the radius of rotation so that it always lies on the surface of larger, invisible ball.

The same principle applies to the 2nd ball ( $Y$ ellow) that rotates on the $\mathrm{Xz}-\mathrm{pl}$ ane, going up and down in the $\mathrm{Y}$ axis, and to the $3 x d$ ball (blue) that rotates on the YO-plane, going left and right in the $X$ axis.
Ilustra o uso de funģoses pré-definidas para sintetixar movimentos e trajetórias convencionais.

A funģäo aim.rotation gera dois sinais $[0 \ldots 1]$ senoidais de tal modo que eles definem um movimento circular wm duas coordenadas. Seus arqumentos são freqüência e raio de rotação.

A função sim.mirrox reflete a parte de um sinal que fica abaixo de um dado limiar. 0 valor default é 0.5, criando uma reflexão da metade de baixo sobre a metade de cima.

observe como a primeira bola (vermelha) circula no plano $X Y$ (o plano da janela GEH) e ao mesmo tempo vai para a frente e para trás no eixo 8 , ajustando o raio da rotagão de ta maior, invisivel.

0 mesmo princípio se aplica à 2a bola (marela) que roda no plano $X Z$, indo para cima e para baixo no eixo $Y$, i 30 bola (arul) que roda no plano $Y$, indo para a esquerda para a direita no eixo $x$

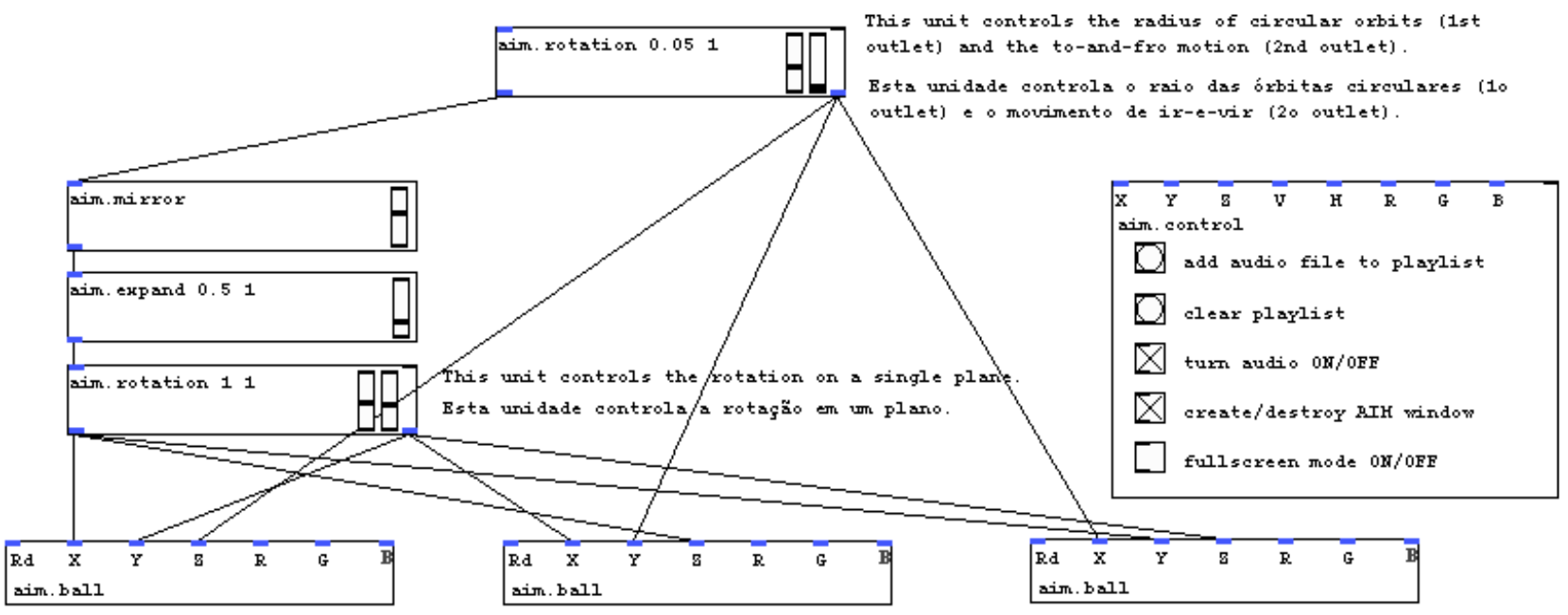

\subsection{Exemplos de saídas do Tutorial 8}
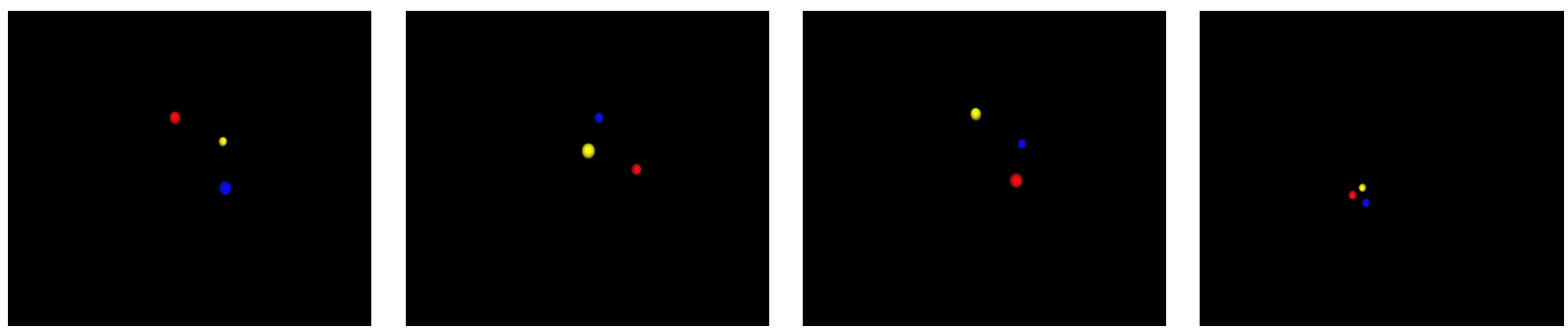


\section{Tutorial 9}

\section{AUDIBLE_IMAGES_Tutorial_09}

Ilustrates the use of auriliary functions and analysis objects for controlling a slightly more complex image object.

The object aim.planets creates 7 balls controlled bY ? abstract parameters, which are used in different combinations to determine each balls attributes.

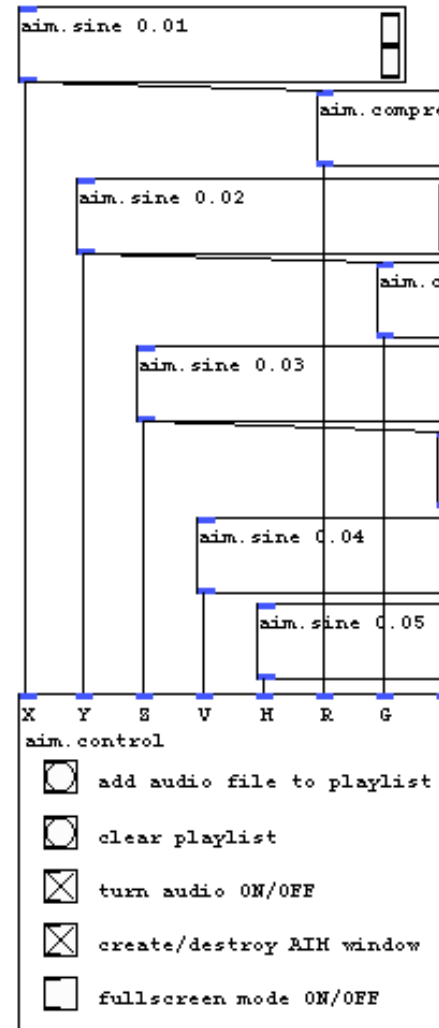

Ilustra o uso de fungões auxiliares e objetos de análise para controlar um objeto gráfico um pouco mais complexo.

0 objeto aim.planets gera 7 bolas controladas por 7 parâmetros abstratos, que são enviados em permutaçós diferentes para cada bola.

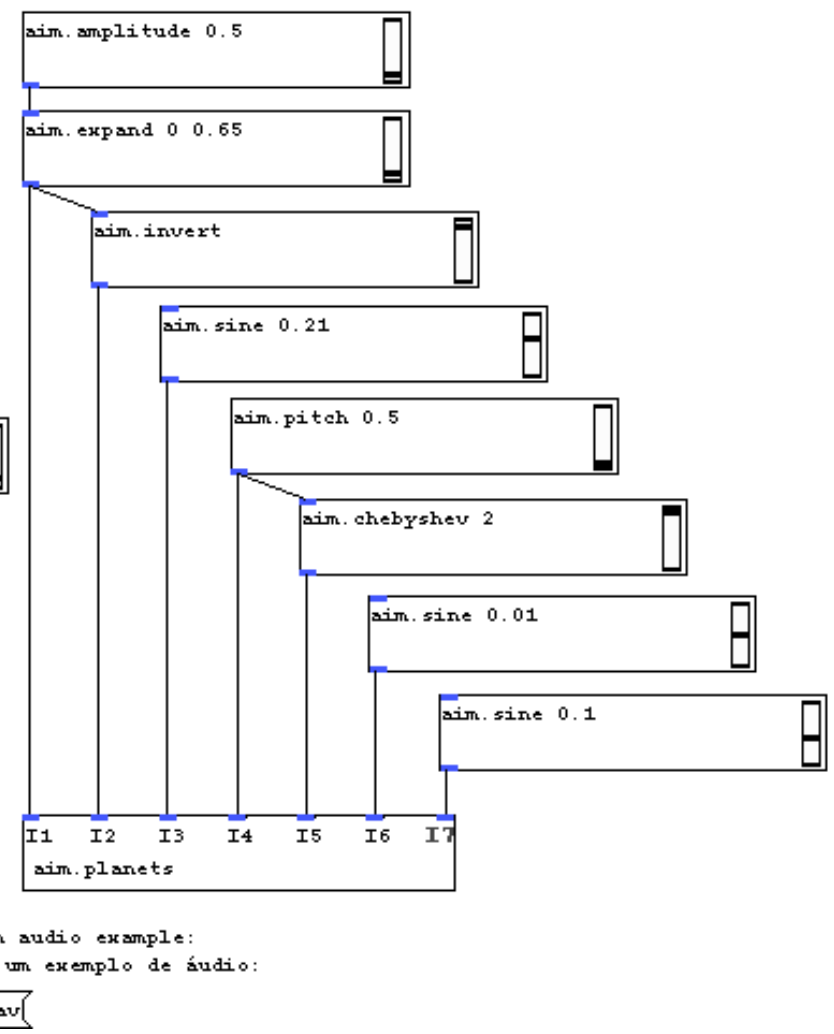

\subsection{Exemplos de saídas do Tutorial 9}
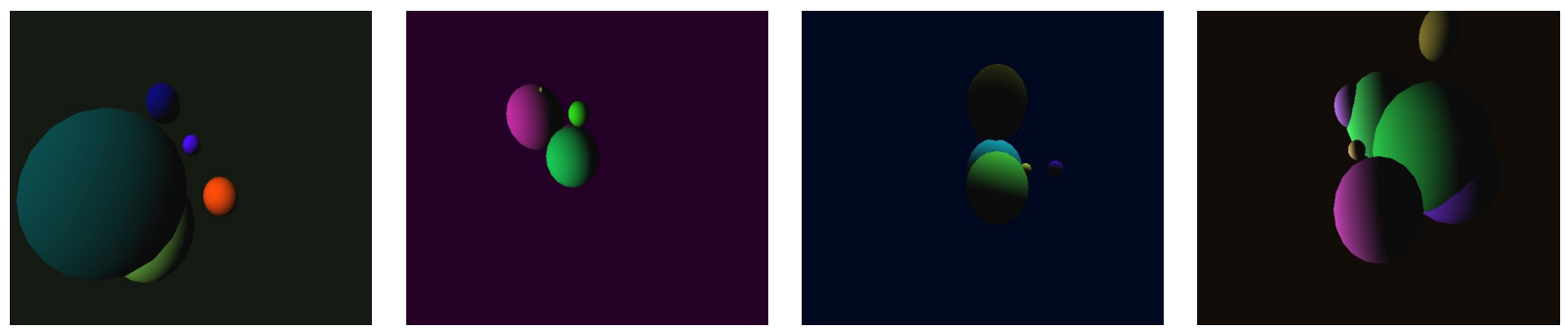


\section{Tutorial 10}

\section{AUDIBLE_IMAGES_TUTORIAL_10}

Illustrates another complex image synthesis object,

sim. vunningdolls. Please find more documentation inside the object.

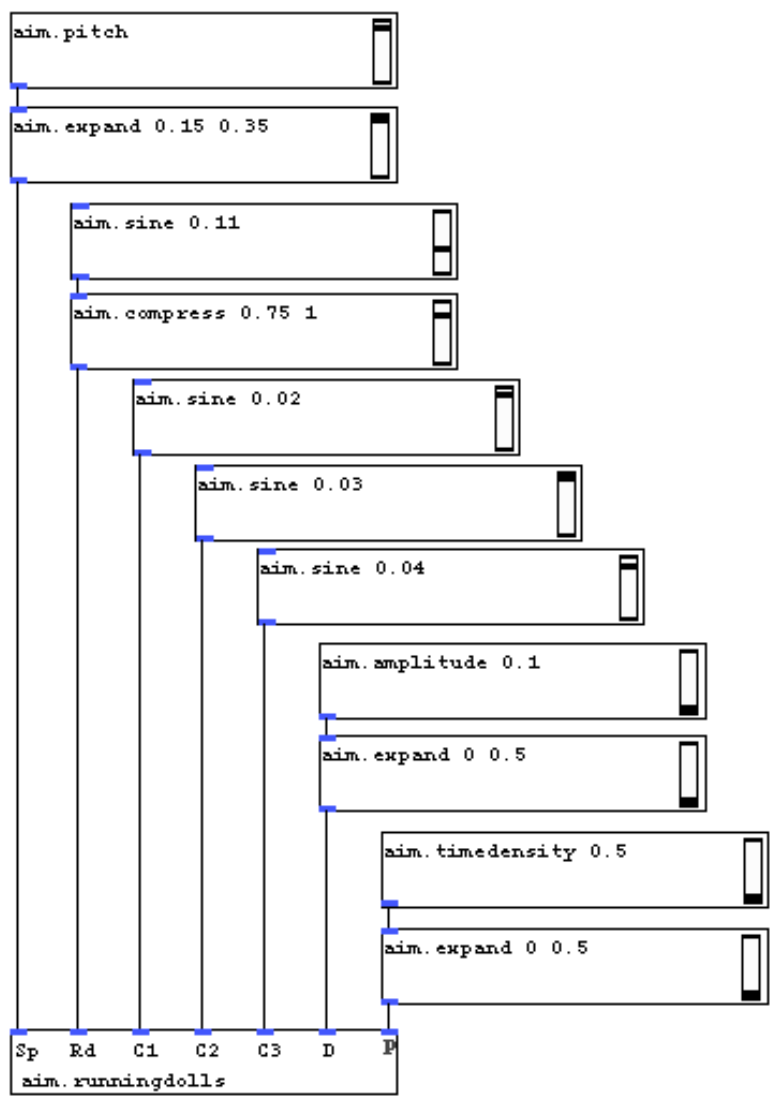

\subsection{Exemplos de saídas do Tutorial 10}
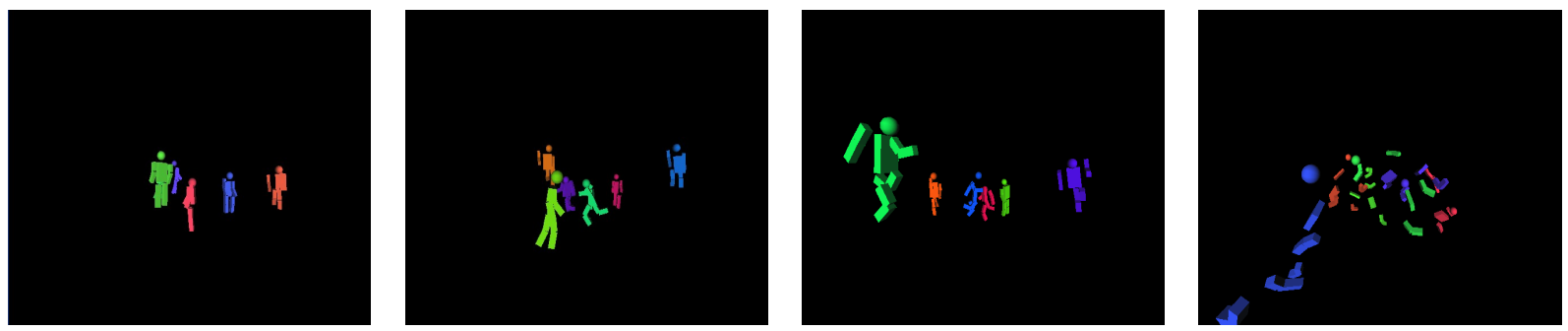

Ilustra outro objecto complexo de sintese de imagens, aim. runringdolls. Abra o objeto para obter maiores informações.

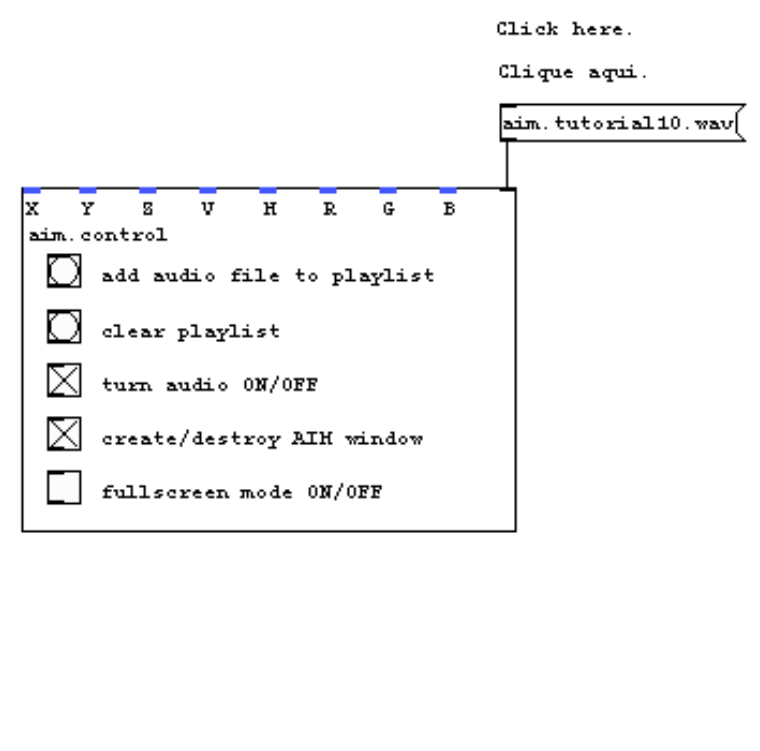




\section{Tutorial 11}

AUDIBLE_IMAGES_Tutorial_11

Illustrates the use of several AIH objects at once.

Ilustra o uso de váxios objetos AIH ao mesmo tempo.
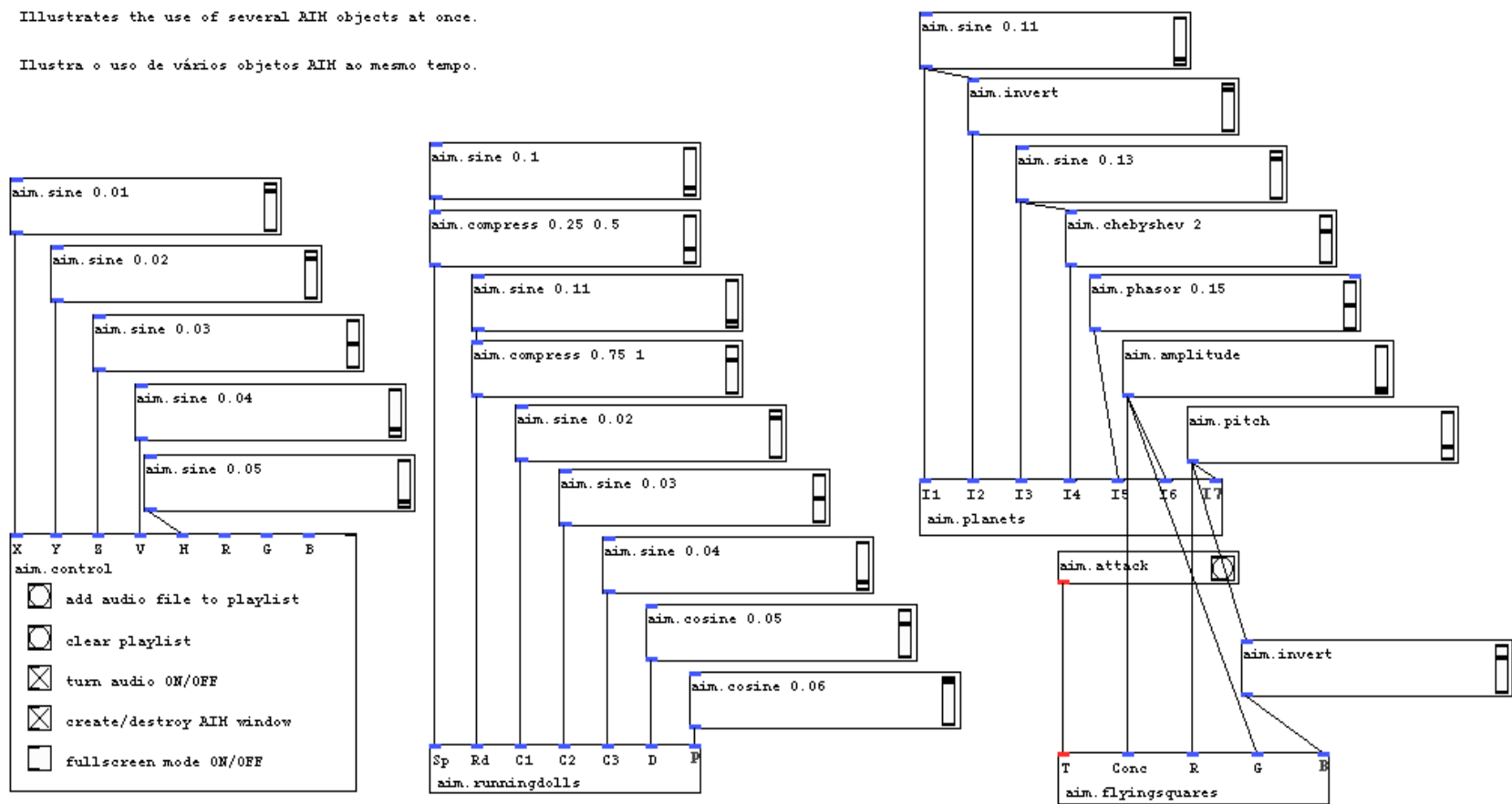

11.1 Exemplos de saídas do Tutorial 11
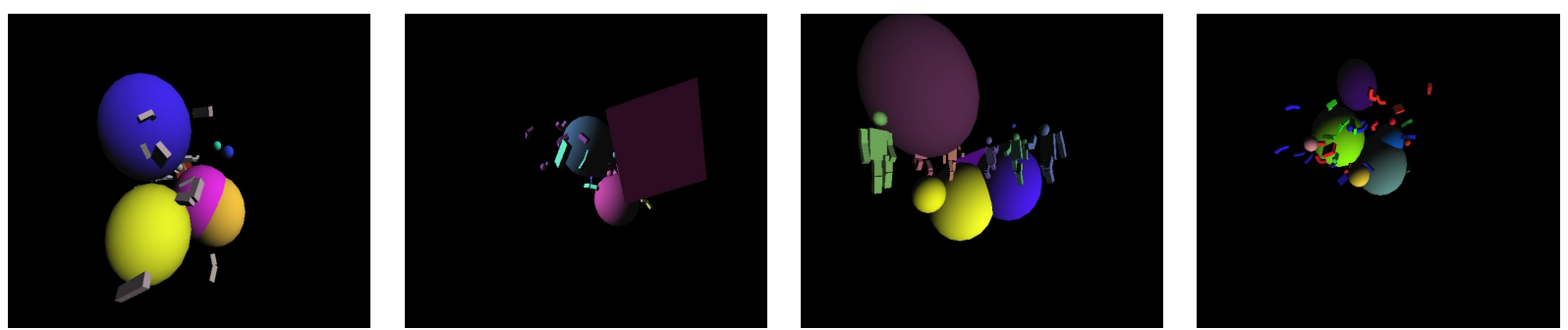


\section{Tutorial 12}

\section{AUDIBLE_IMAGES_Tutorial_12}

llustrates an image synthesis object that receives only bangs for controlling the movement of seagull-like Bexiex curves on the screen. Click on aim.bexierseagulls for details of its inlets.

Ilustra um objeto de sintese de imagens que recebe apenas bangs para controlar o movimento de gaivotas foumadas por curvas de Bexiex na tela. Clique en aim.bexierseagulls para saber detalkes de seus inlets.

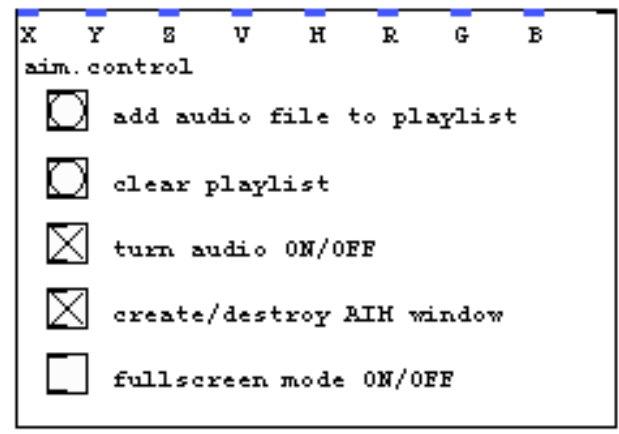

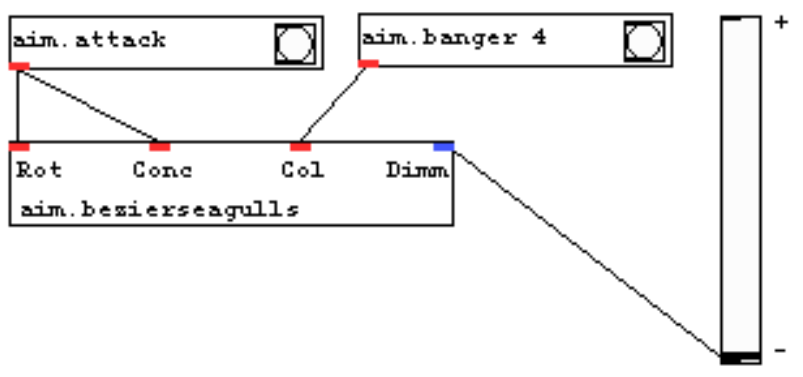

\subsection{Exemplos de saídas do Tutorial 12}
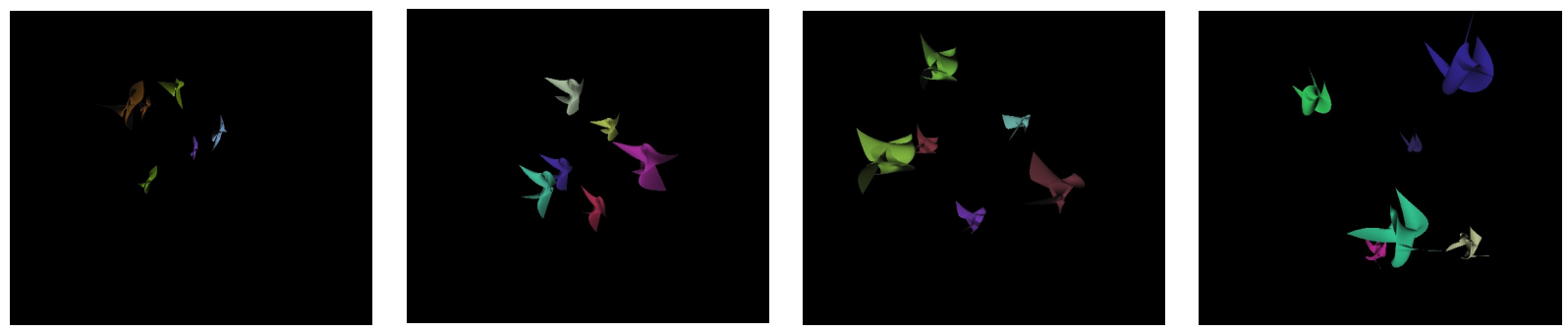


\section{Tutorial 13}
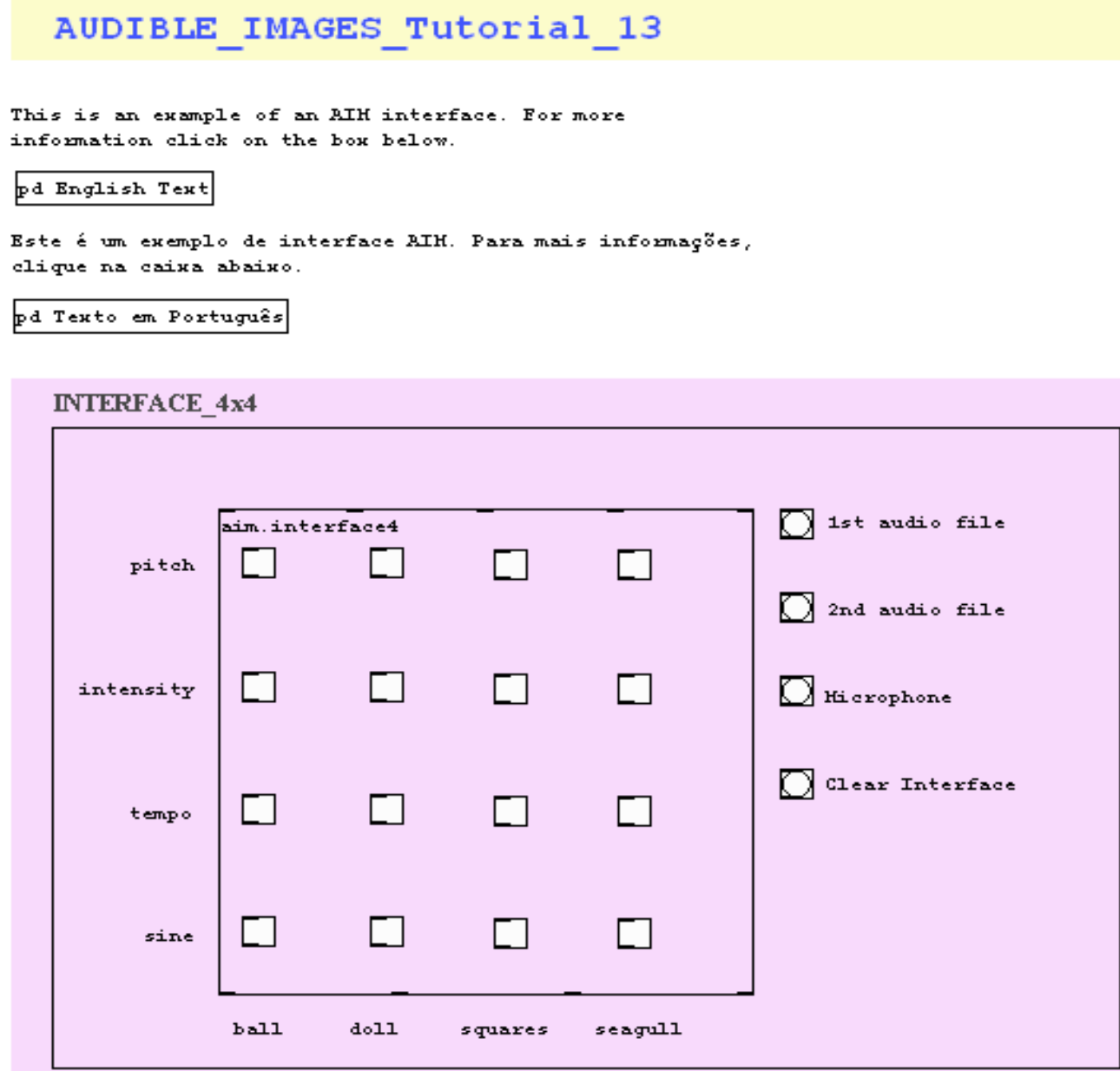

\subsection{Subpatch "Texto em português" do Tutorial 13}

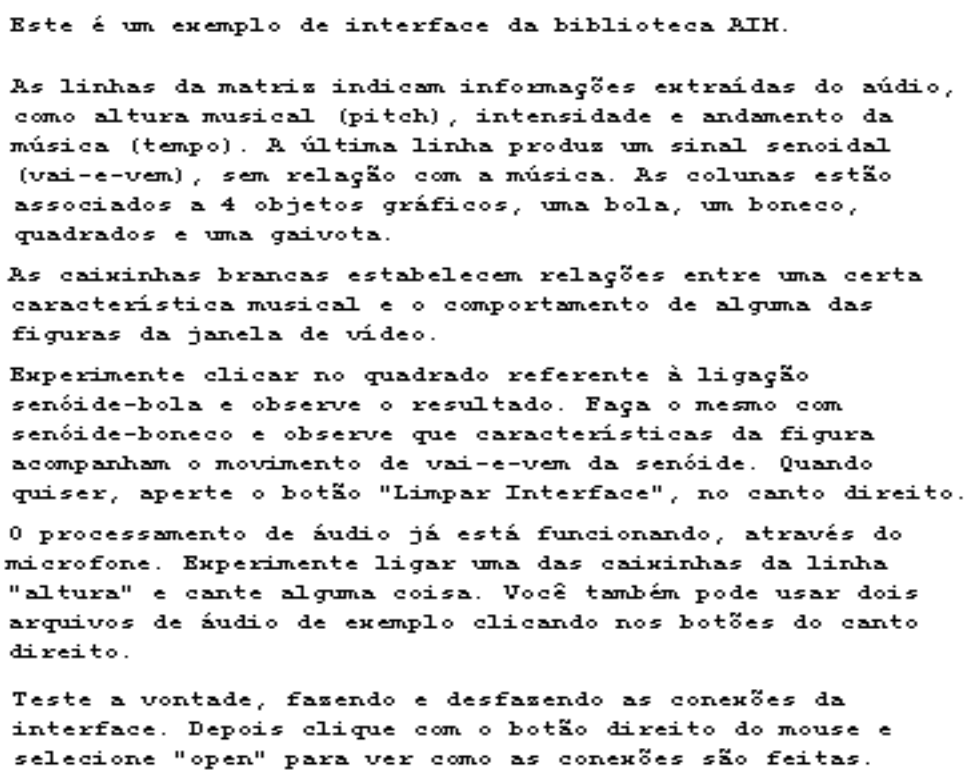




\title{
14. Tutorial 14
}

\author{
AUDIBLE_IMAGES_Tutorial_14 \\ Illustrates the construction of interfaces, using the \\ aim.interfaces object. Select random visual accompaniment \\ and see what happens. \\ Ilustra a construgão de interfaces, usando o objeto \\ aim.interfaces. Selecione a opģäo "random visual \\ accompaniment" e veja o que acontece.
}

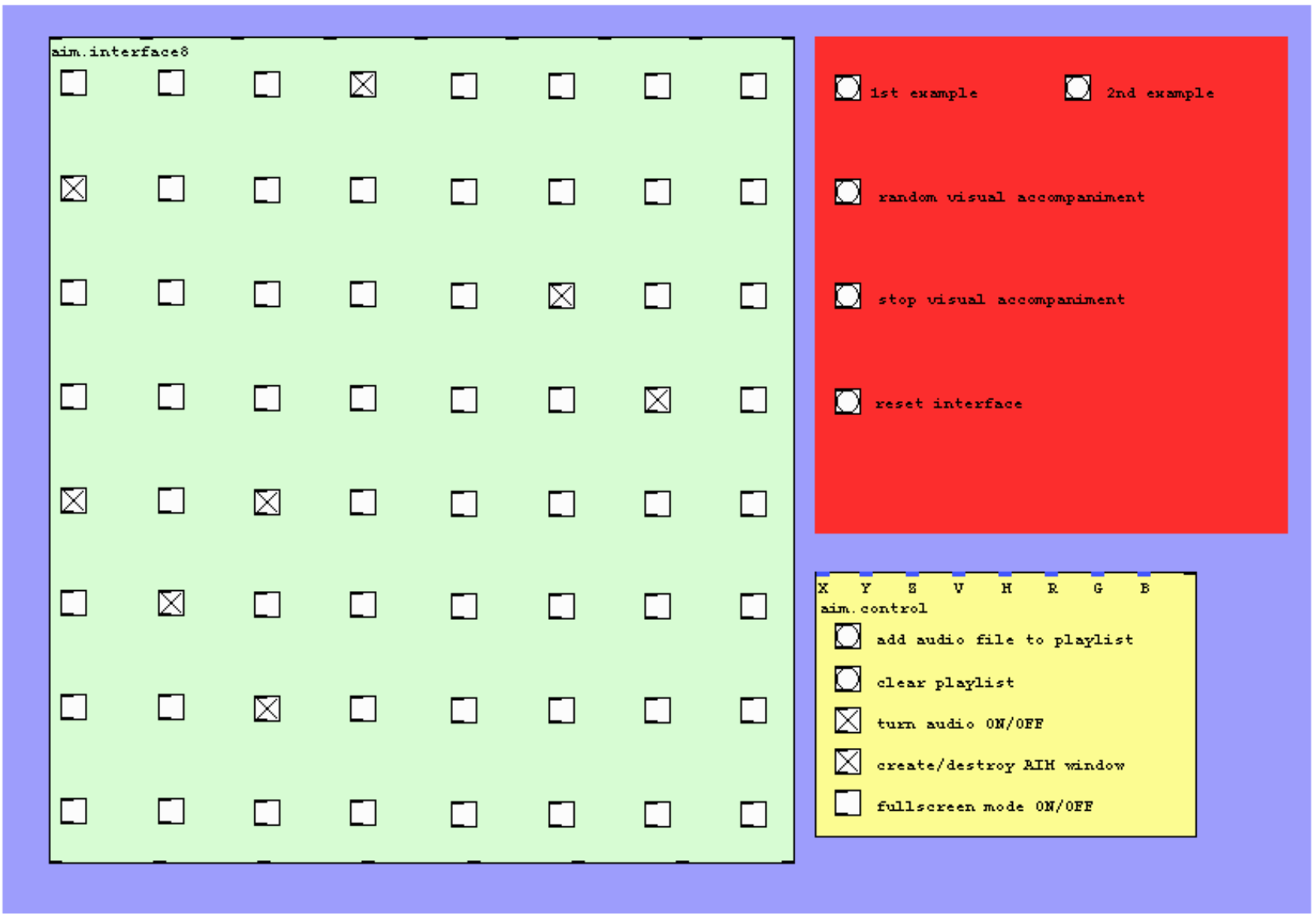

\section{Exemplos de saídas do Tutorial 14}
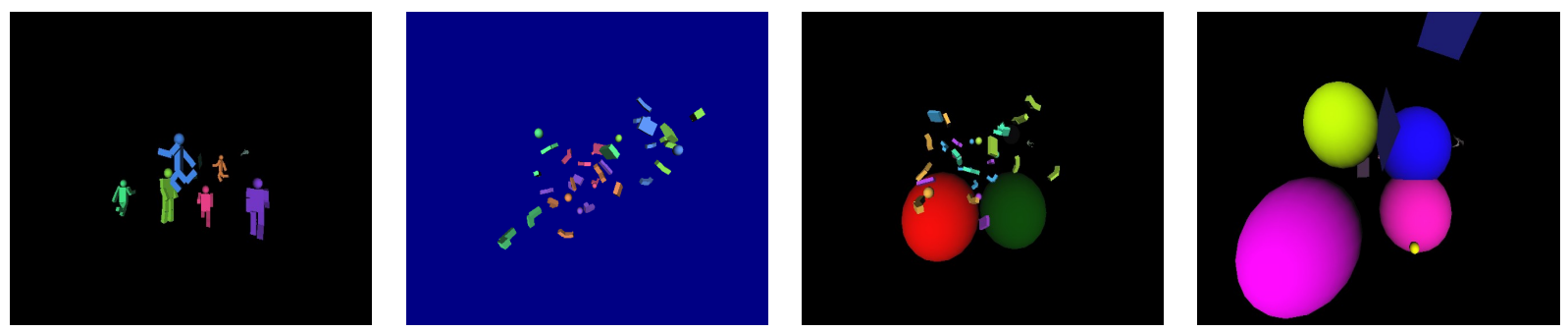